TAIANE FRACALOSSI ZOCATELLI

\title{
Cloração do pentóxido de tântalo com
} tetracloroetileno

Dissertação de Mestrado

Dissertação apresentada como requisito parcial para obtenção do grau de Mestre pelo Programa de Pósgraduação em Engenharia de Materiais e de Processos Químicos e Metalúrgicos do Departamento de Engenharia Química e de Materiais do Centro Técnico Científico da PUC-Rio.

Orientador: Prof. Rogério Navarro Correia de Siqueira

Rio de Janeiro 


\title{
Cloração do pentóxido de tântalo com tetracloroetileno
}

\begin{abstract}
Dissertação apresentada como requisito parcial para obtenção do grau de Mestre pelo Programa de Pósgraduação em Engenharia de Materiais e de Processos Químicos e Metalúrgicos do Departamento de Engenharia Química e de Materiais do Centro Técnico Científico da PUC-Rio. Aprovada pela Comissão Examinadora abaixo assinada.
\end{abstract}

Prof. Rogério Navarro Correia de Siqueira

Orientador e Presidente

Departamento de Engenharia Química e de Materiais - PUC Rio

Prof. Eduardo de Albuquerque Brocchi Departamento de Engenharia Química e de Materiais - PUC Rio

Prof. José Brant Campos Universidade Estadual do Rio de Janeiro - UERJ

Prof. Francisco José Moura

Departamento de Engenharia Química e de Materiais - PUC Rio

Prof. Márcio da Silveira Carvalho

Coordenador Setorial de Pós-Graduação do Centro Técnico Científico da PUC- Rio

Rio de Janeiro, 21 de Dezembro de 2016. 
Todos os direitos reservados. É proibida a reprodução total ou parcial do trabalho sem autorização da universidade, da autora e do orientador.

Taiane Fracalossi Zocatelli

Graduou-se em Engenharia de Produção na Universidade Vila Velha do Espírito Santo em 2013. Atuou como estagiária na Vale- Vitória, onde obteve experiências com processos logísticos e ferroviários. Ingressou no curso de mestrado em Engenharia de Materiais no ano de 2015. Realizou pesquisa na área de cloração com $\mathrm{C}_{2} \mathrm{Cl}_{4}$.

Ficha Catalográfica

Zocatelli, Taiane Fracalossi

Cloração do pentóxido de tântalo com tetracloroetileno / Taiane Fracalossi Zocatelli ; orientador: Rogério Navarro Correia de Siqueira. $-2016$.

81 f. : il. color. ; $30 \mathrm{~cm}$

Dissertação (mestrado)-Pontifícia Universidade Católica do Rio de Janeiro, Departamento de Engenharia Química e de Materiais, 2016.

Inclui bibliografia

1. Engenharia de Materiais - Teses. 2. Engenharia Química Teses. 3. Cloração. 4. C2Cl4. 5. Ta2O5. 6. Modelo do núcleo não reagido. 7. Modelo auto catalítico. I. Siqueira, Rogério Navarro Correia de. II. Pontifícia Universidade Católica do Rio de Janeiro. Departamento de Engenharia Química e de Materiais. III. Título. 


\section{Agradecimentos}

Primeiramente agradeço à Deus, que me guiou até aqui e por ter permitido concluir mais uma etapa da minha vida.

Ao meu marido, Bruno de Araújo Carriello Costa, pelo carinho e incentivo, por estar sempre ao meu lado e por ter me apoiado em tudo.

À minha mãe que sempre me incentivou a fazer o mestrado e a continuar com os estudos e nunca desistir de um sonho.

Ao professor e orientador, Rogério Navarro, por toda paciência e companheirismo nessa fase pesquisa, experimentos e escrita. Serei sempre grata pela oportunidade que me concedeu.

À minha amiga Rayane Covre, a qual me apresentou ao programa de mestrado e por toda a ajuda, incentivo e força desde o início.

Ao aluno de IC Eduardo Vasconcelos, o qual me ajudou muito para entendimento do processo de cloração e pela parceria com a linha de cloração.

Ao técnicoYuri pelas análises das amostras no laboratório de MEV/EDS.

À professora Sonia Letichevsky, pelas análises no laboratório de DRX.

Ao departamento de engenharia química e de materiais da PUC-Rio, pela oportunidade.

À CAPES, pelo apoio financeiro através da bolsa de mestrado.

Aos professores da banca, por terem aceitado o convite.

E a todos que, de alguma forma, contribuíram, e torceram, para a realização deste trabalho. 


\section{Resumo}

Zocatelli, Taiane Fracalossi; Siqueira, Rogério Navarro Correia de (orientador). Cloração do pentóxido de tântalo com tetracloroetileno. Rio de Janeiro, 2016. 81p. Dissertação de Mestrado - Departamento de Engenharia Química e de Materiais, Pontifícia Universidade Católica do Rio de Janeiro.

Processos de ustulação cloretante podem ser realizados de forma direta, utilizando $\circ \mathrm{Cl}_{2}$ como agente cloretante, ou através de agentes cloretantes alternativos. Neste contexto, compostos organoclorados são promissores, pois além de serem facilmente volatizados, já apresentam na mesma molécula o agente cloretante e redutor. O presente estudo teve como principal objetivo a avaliação quantitativa da cinética de cloração do pentóxido de tântalo com tetracloroetileno através dos modelos do núcleo não reagido (SC) e auto catalítico (AC). Tanto o material inicial, quanto o mesmo após o processo, bem como o produto sólido depositado na saída do reator foram caracterizados via DRX e MEV/EDS. Através de simulações termodinâmicas foi possível verificar a viabilidade de cloração de amostras puras de $\mathrm{Ta}_{2} \mathrm{O}_{5}$ com $\mathrm{C}_{2} \mathrm{Cl}_{4}$ diluído em atmosfera de $\mathrm{N}_{2}$ na faixa de temperatura entre 800 a $950^{\circ} \mathrm{C}$, sendo os principais cloretos gasosos formados, $\mathrm{TaOCl}_{3}$ e $\mathrm{TaCl}_{5}$. Verificou-se ainda a possível decomposição térmica do agente cloretante no caminho entre a entrada do reator e a amostra. Os resultados provenientes das caracterizações comprovaram as tendências apontadas pelas simulações termodinâmicas, comprovando a formação exclusiva de cloretos voláteis. No que diz respeito à modelagem cinética ambos os modelos permitiram o ajuste dos dados em nível quantitativo, sendo os valores de energia de ativação global iguais a $93,8 \mathrm{~kJ} / \mathrm{mol}$ (SC) e $32 \mathrm{~kJ} / \mathrm{mol}$ (AC). A comparação dos valores obtidos com dados da literatura sugere que o controle é de natureza química, sendo a decomposição do $\mathrm{C}_{2} \mathrm{Cl}_{4}$ na superfície das nanopartículas de $\mathrm{Ta}_{2} \mathrm{O}_{5}$, possivelmente, a etapa controladora.

\section{Palavras-chave}

Cloração; $\mathrm{C}_{2} \mathrm{Cl}_{4} ; \mathrm{Ta}_{2} \mathrm{O}_{5} ;$ Modelo do núcleo não reagido; Modelo auto catalítico. 


\section{Abstract}

Zocatelli, Taiane Fracalossi; Siqueira, Rogério Navarro Correia de (advisor). Tantalum Pentoxide Chlorination with Tetrachlorethylene. Rio de Janeiro, 2016. 81p. Dissertação de Mestrado - Departamento de Engenharia Química e de Materiais, Pontifícia Universidade Católica do Rio de Janeiro.

Chlorination roasting can be carried out directly, using $\mathrm{Cl}_{2}$ as a chlorinating agent, or through alternative reagents. In this context, organochlorine compounds are promising, since besides being easily volatilized, they already present in the same molecule the chlorinating and reducing agents. The present study had as main objective the quantitative evaluation of the chlorination kinetics of tantalum pentoxide with tetrachlorethylene through the shrinking core (SC) and auto catalytic (AC) models. The initial material, as well as post-processed materials, and also the solid product deposited at the reactor's exit were characterized through DRX and MEV/EDS. By means of thermodynamic simulations, it was possible to verify the viability of pure $\mathrm{Ta}_{2} \mathrm{O}_{5}$ samples chlorination with $\mathrm{C}_{2} \mathrm{Cl}_{4}$ diluted in $\mathrm{N}_{2}$ in the temperature range of interest $\left(800-950^{\circ} \mathrm{C}\right)$, thereby producing only gaseous chlorides, $\mathrm{TaOCl}_{3}$ and $\mathrm{TaCl}_{5}$. The possible $\mathrm{C}_{2} \mathrm{Cl}_{4}$ thermal decomposition in the path between the reactor inlet and sample was also identified. The characterization results were in accordance with the tendencies indicated by the thermodynamic simulations, proving the exclusive formation of volatile chlorides. With regard to the kinetic study, both tested models allowed quantitative adjustment of the conversion data, with overall activation energies equal to $93.8 \mathrm{~kJ} / \mathrm{mol}(\mathrm{SC})$ and $32 \mathrm{~kJ} / \mathrm{mol}(\mathrm{AC})$. The comparison of the values obtained with literature data suggests that the control is of chemical nature, the decomposition of $\mathrm{C}_{2} \mathrm{Cl}_{4}$ on the surface of the $\mathrm{Ta}_{2} \mathrm{O}_{5}$ nanoparticles being, possibly, the main control reaction step.

\section{Keywords}

Chlorination; $\mathrm{C}_{2} \mathrm{Cl}_{4}$; $\mathrm{Ta}_{2} \mathrm{O}_{5}$; Shrinking core model; Auto catalytic model. 


\section{Sumário}

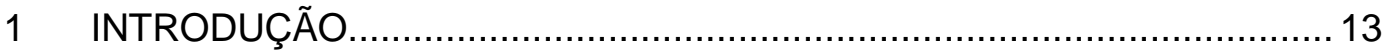

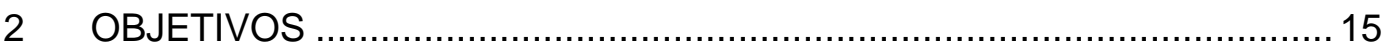

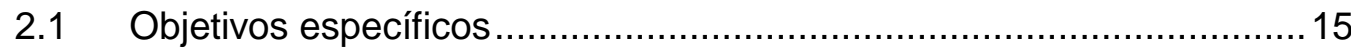

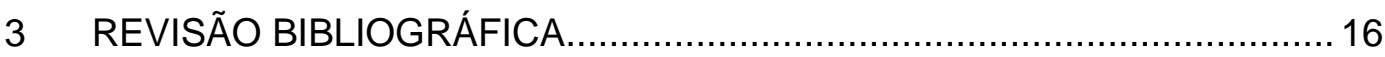

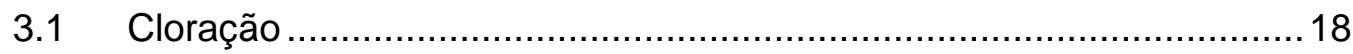

3.2 Cloração direta na presença de uma fonte de carbono .........................19

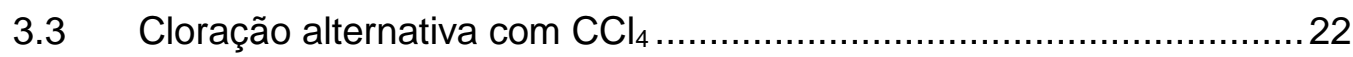

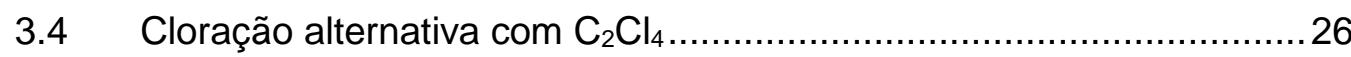

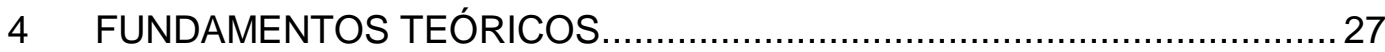

4.1 Aspectos termodinâmicos ................................................................27

4.1.1 Simulações da decomposição do $\mathrm{C}_{2} \mathrm{Cl}_{4}$ sem adição de oxigênio.....27

4.1.2 Simulações da decomposição do $\mathrm{C}_{2} \mathrm{Cl}_{4}$ com adição de oxigênio.....31

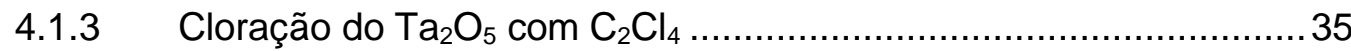

4.1.3.1 Diagramas de especiação variando a pressão parcial do $\mathrm{C}_{2} \mathrm{Cl}_{4} \ldots . .36$

4.1.3.2 Diagramas de especiação variando a pressão parcial do $\mathrm{C}_{2} \mathrm{Cl}_{4}$

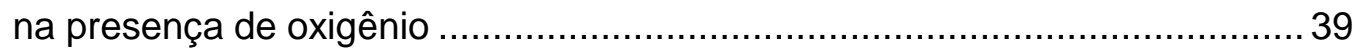

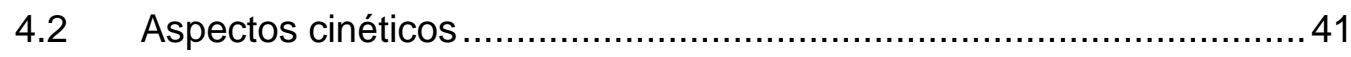

4.2.1 Reações gás-sólido................................................................... 41

4.2.2 Velocidade de reação................................................................... 42

4.2.3 Modelos matemáticos .................................................................. 44

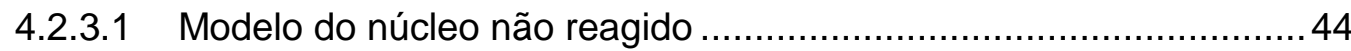

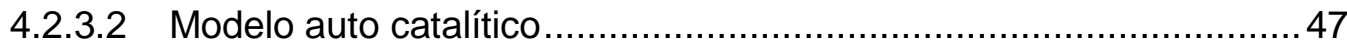

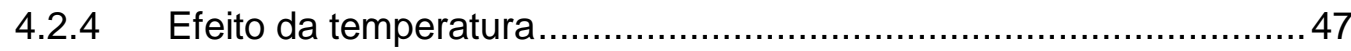

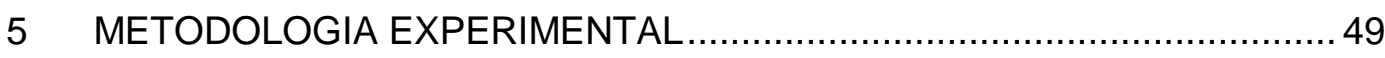

5.1 Descrição dos equipamentos e linha ……………………………...... 49

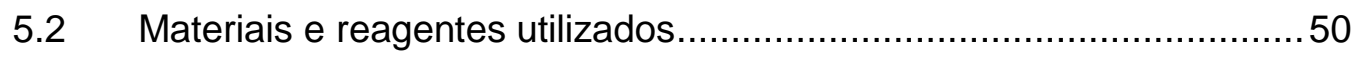

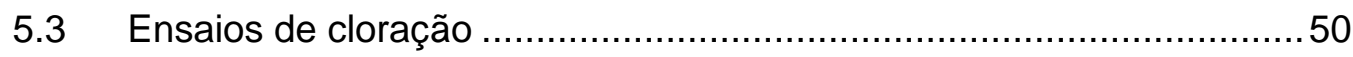


5.3.1 Perda de massa de tetracloroetileno ..........................................52

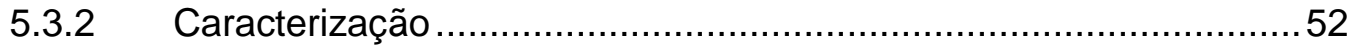

5.3.3 Avaliação do tântalo dissolvido .................................................. 53

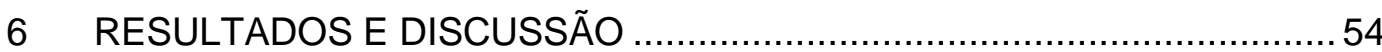

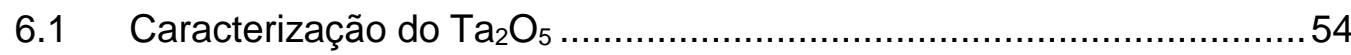

6.1.1 Caracterização antes da cloração ..................................................54

6.1.2 Caracterização pós-cloração.................................................... 56

6.1.3 Avaliação da concentração de tântalo nas soluções de $\mathrm{KOH}$...........62

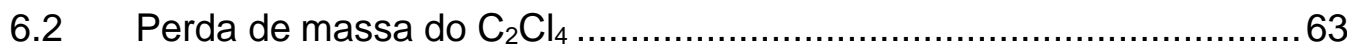

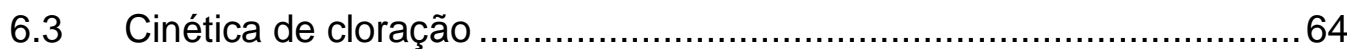

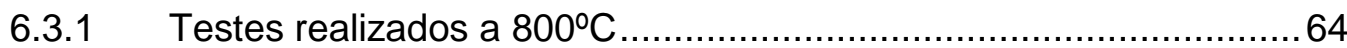

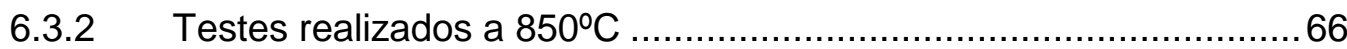

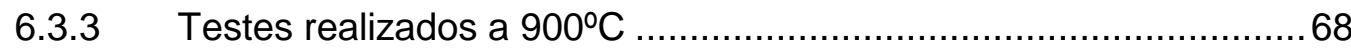

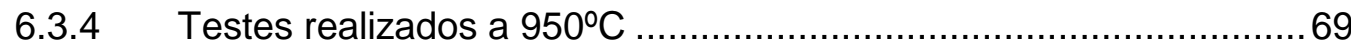

6.3.5 Energia de ativação global ....................................................... 71

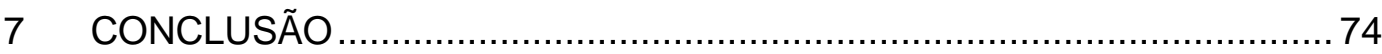

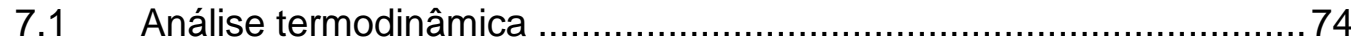

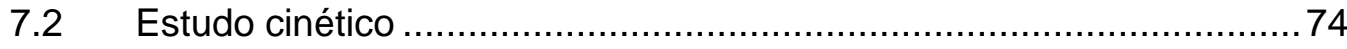

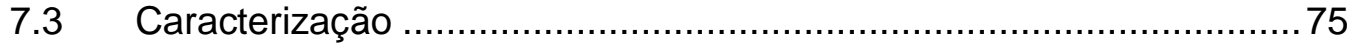

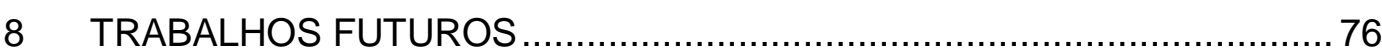

8.1 Investigação de mudança no mecanismo ….......................................76

8.2 Determinação da ordem da reação.................................................. 76

8.3 Caracterização do precipitado e filtrado .............................................76

8.4 Otimização da absorção e recuperação do tântalo ............................77

9 REFERÊNCIAS BIBLIOGRÁFICAS ..................................................... 78 


\section{Lista de figuras}

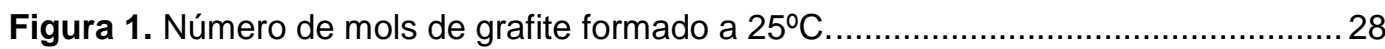

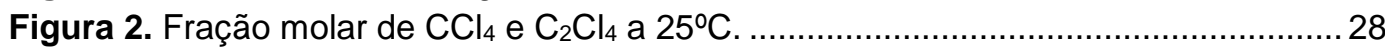

Figura 3. a) Número de mols de carbono produzido como função da temperatura

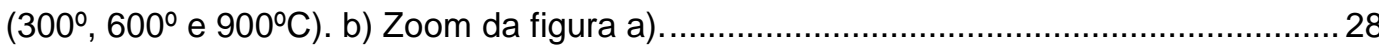

Figura 4. a) Fração molar de $\mathrm{CCl}_{4}$ formado entre as temperaturas de 600 a $900^{\circ} \mathrm{C}$.

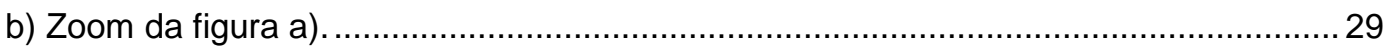

Figura 5. Energias de Gibbs reacionais para a decomposição do $\mathrm{C}_{2} \mathrm{Cl}_{4} \ldots \ldots \ldots \ldots \ldots \ldots \ldots . . . . . . . . . .30$

Figura 6. a) Fração molar de $\mathrm{Cl}_{2}$ nas temperaturas de 600 a $900^{\circ} \mathrm{C}$. b) Zoom da figura a).

Figura 7. a) Número de mols de grafite formado nas temperaturas entre $600 \mathrm{e}$

$900^{\circ} \mathrm{C}$. b) Zoom da figura a) 32

Figura 8. a) Fração molar de $\mathrm{CCl}_{4}$ nas temperaturas entre 600 e $900^{\circ} \mathrm{C}$. b) Zoom da figura a).

Figura 9. a) Fração molar de $\mathrm{Cl}_{2}$ nas temperaturas de 600 a $900^{\circ} \mathrm{C}$. b) Zoom da figura a).

Figura 10. a) Formação de $\mathrm{CO}$ e $\mathrm{CO}_{2}$ a partir da oxidação do grafite a $600^{\circ} \mathrm{C}$. b)

Zoom da figura a).

Figura 11. a) Formação de $\mathrm{CO}$ e $\mathrm{CO}_{2}$ a partir da oxidação do grafite a $700^{\circ} \mathrm{C}$. b)

Zoom da figura a).

Figura 12. a) Formação de $\mathrm{CO}$ e $\mathrm{CO}_{2}$ a partir da oxidação do grafite a $800^{\circ} \mathrm{C}$. b)

Zoom da figura a).

Figura 13. a) Formação de $\mathrm{CO}$ e $\mathrm{CO}_{2}$ a partir da oxidação do grafite a $900^{\circ} \mathrm{C}$. b)

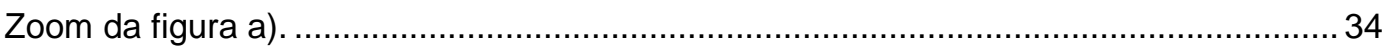

Figura 14. Energias de Gibbs reacionais para a decomposição sucessiva do $\mathrm{CCl}_{4}$........ 35

Figura 15. Energias de Gibbs reacionais para a decomposição sucessiva do

$\mathrm{C}_{2} \mathrm{Cl}_{4}$ 35

Figura 16. Energias de Gibbs reacionais para a formação de cloretos de tântalo a partir do $\mathrm{C}_{2} \mathrm{Cl}_{4}$ 36

Figura 17. a) Número de mols de grafite como função da concentração de $\mathrm{C}_{2} \mathrm{Cl}_{4} \mathrm{a}$ $600^{\circ} \mathrm{C}$. b) Frações molares de $\mathrm{CO}, \mathrm{CO}_{2}, \mathrm{TaOCl}_{3}$ e $\mathrm{TaCl}_{5}$ na fase gasosa como função da concentração de $\mathrm{C}_{2} \mathrm{Cl}_{4}$ a $600^{\circ} \mathrm{C}$.

Figura 18. a) Número de mols de grafite como função da concentração de $\mathrm{C}_{2} \mathrm{Cl}_{4}$ a $700^{\circ}$. b) Frações molares de $\mathrm{CO}, \mathrm{CO}_{2}, \mathrm{TaOCl}_{3}$ e $\mathrm{TaCl}_{5}$ na fase gasosa como função da concentração de $\mathrm{C}_{2} \mathrm{Cl}_{4}$ a $700^{\circ} \mathrm{C}$

Figura 19. a) Número de mols de grafite como função da concentração de $\mathrm{C}_{2} \mathrm{Cl}_{4}$ a $800^{\circ}$. b) Frações molares de $\mathrm{CO}, \mathrm{CO}_{2}, \mathrm{TaOCl}_{3}$ e $\mathrm{TaCl}_{5}$ na fase gasosa como função da concentração de $\mathrm{C}_{2} \mathrm{Cl}_{4}$ a $800^{\circ} \mathrm{C}$

Figura 20. a) Número de mols de grafite como função da concentração de $\mathrm{C}_{2} \mathrm{Cl}_{4}$ a $900^{\circ}$. b) Frações molares de $\mathrm{CO}, \mathrm{CO}_{2}, \mathrm{TaOCl}_{3}$ e $\mathrm{TaCl}_{5}$ na fase gasosa como função da concentração de $\mathrm{C}_{2} \mathrm{Cl}_{4}$ a $900^{\circ} \mathrm{C}$

Figura 21. a) Número de mols de grafite como função da concentração de $\mathrm{C}_{2} \mathrm{Cl}_{4}$, com adição de 0,26 mols de oxigênio diluído a $600^{\circ} \mathrm{C}$. b) Frações molares de $\mathrm{CO}$, $\mathrm{CO}_{2}, \mathrm{TaOCl}_{3}$ e TaCl $\mathrm{Ta}_{5}$ na fase gasosa como função da concentração de $\mathrm{C}_{2} \mathrm{Cl}_{4}$ a $600^{\circ} \mathrm{C}$.

Figura 22. a) Número de mols de grafite como função da concentração de $\mathrm{C}_{2} \mathrm{Cl}_{4}$, com adição de 0,26 mols de oxigênio diluído, a $700^{\circ} \mathrm{C}$. b) Frações molares de $\mathrm{CO}$, $\mathrm{CO}_{2}, \mathrm{TaOCl}_{3}$ e $\mathrm{TaCl}_{5}$ na fase gasosa como função da concentração de $\mathrm{C}_{2} \mathrm{Cl}_{4}$ a $700^{\circ} \mathrm{C}$ 
Figura 23. a) Número de mols de grafite como função da concentração de $\mathrm{C}_{2} \mathrm{Cl}_{4}$, com adição de 0,26 mols de oxigênio diluído, a $800^{\circ} \mathrm{C}$. b) Frações molares de $\mathrm{CO}$, $\mathrm{CO}_{2}, \mathrm{TaOCl}_{3}$ e $\mathrm{TaCl}_{5}$ na fase gasosa como função da concentração de $\mathrm{C}_{2} \mathrm{Cl}_{4}$ a $800^{\circ} \mathrm{C}$

Figura 24. a) Número de mols de grafite como função da concentração de $\mathrm{C}_{2} \mathrm{Cl}_{4}$, com adição de 0,26 mols de oxigênio diluído, a $900^{\circ} \mathrm{C}$. b) Frações molares de $\mathrm{CO}$, $\mathrm{CO}_{2}, \mathrm{TaOCl}_{3}$ e $\mathrm{TaCl}_{5}$ na fase gasosa como função da concentração de $\mathrm{C}_{2} \mathrm{Cl}_{4}$ a $900^{\circ} \mathrm{C}$

Figura 25. Número de mols de $\mathrm{Ta}_{2} \mathrm{O}_{5}$ no equilíbrio em diferentes temperaturas como função da concentração de $\mathrm{C}_{2} \mathrm{Cl}_{4}$.

Figura 26. Representação das conversões dos reagentes e produtos no caso de uma partícula que diminui de tamanho(32).

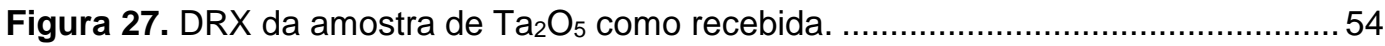

Figura 28. Espectro de EDS da amostra de $\mathrm{Ta}_{2} \mathrm{O}_{5}$ como recebida................................5 55

Figura 29. Imagens (MEV) da amostra de $\mathrm{Ta}_{2} \mathrm{O}_{5}$ como recebida..................................5 56

Figura 30. Mapa de EDS da amostra de $\mathrm{Ta}_{2} \mathrm{O}_{5}$ como recebida....................................56

Figura 31. DRX da amostra de $\mathrm{Ta}_{2} \mathrm{O}_{5}$ após a cloração com $\mathrm{C}_{2} \mathrm{Cl}_{4}$ a $800^{\circ} \mathrm{C}$....................5. 57

Figura 32. DR-X da amostra de $\mathrm{Ta}_{2} \mathrm{O}_{5}$ após a cloração com $\mathrm{C}_{2} \mathrm{Cl}_{4}$ a $950^{\circ} \mathrm{C}$....................57

Figura 33. Espectro de EDS da amostra de $\mathrm{Ta}_{2} \mathrm{O}_{5}$ após a cloração com $\mathrm{C}_{2} \mathrm{Cl}_{4}$ a

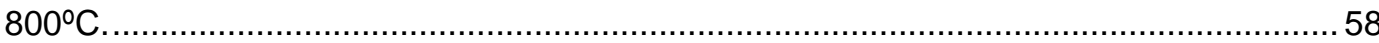

Figura 34. Imagens (MEV) da amostra de $\mathrm{Ta}_{2} \mathrm{O}_{5}$ após a cloração com $\mathrm{C}_{2} \mathrm{Cl}_{4}$ a $800^{\circ} \mathrm{C}$

Figura 35. Mapa de EDS da amostra de $\mathrm{Ta}_{2} \mathrm{O}_{5}$ após a cloração com $\mathrm{C}_{2} \mathrm{Cl}_{4}$ a $800^{\circ} \mathrm{C}$

Figura 36. Espectro de EDS da amostra de $\mathrm{Ta}_{2} \mathrm{O}_{5}$ após a cloração com $\mathrm{C}_{2} \mathrm{Cl}_{4}$ a $950^{\circ} \mathrm{C}$

Figura 37. Imagens (MEV) da amostra de $\mathrm{Ta}_{2} \mathrm{O}_{5}$ após a cloração com $\mathrm{C}_{2} \mathrm{Cl}_{4} \mathrm{a}$ $950^{\circ} \mathrm{C}$

Figura 38. Mapa de EDS da amostra de $\mathrm{Ta}_{2} \mathrm{O}_{5}$ após a cloração com $\mathrm{C}_{2} \mathrm{Cl}_{4}$ a $950^{\circ} \mathrm{C}$

Figura 39. Espectro de EDS amostra do precipitado coletado da parede do tubo após os experimentos de cloração.

Figura 40. Imagens (MEV) do precipitado coletado da parede do tubo após experimentos de cloração.

Figura 41. Mapa de EDS da amostra de precipitado coletado da parede do tubo após os experimentos de cloração.

Figura 42. Perda de massa de $\mathrm{C}_{2} \mathrm{Cl}_{4}$ em função do tempo (3 experimentos). .................63

Figura 43. Perda de massa média do vaso contendo $\mathrm{C}_{2} \mathrm{Cl}_{4}$ em função do tempo...........64

Figura 44. Conversão de $\mathrm{Ta}_{2} \mathrm{O}_{5}$ vs. tempo para três experimentos de cloração independentes realizados a $800^{\circ} \mathrm{C}$

Figura 45. Ajuste linearizado do modelo do núcleo não reagido com fator de forma igual a três.

Figura 46. Ajuste linearizado do modelo auto catalítico.

Figura 47. Conversão de $\mathrm{Ta}_{2} \mathrm{O}_{5}$ vs. tempo para três experimentos de cloração independentes realizados a $850^{\circ} \mathrm{C}$

Figura 48. Ajuste linearizado do modelo do núcleo não reagido com fator de forma igual a três.

Figura 49. Ajuste linearizado do modelo auto catalítico.

Figura 50. Conversão de $\mathrm{Ta}_{2} \mathrm{O}_{5}$ vs. tempo para três experimentos de cloração independentes realizados a $900^{\circ} \mathrm{C}$

Figura 51. Ajuste linearizado do modelo do núcleo não reagido com fator de forma igual a três.

Figura 52. Ajuste linearizado do modelo auto catalítico. 
Figura 53. Conversão de $\mathrm{Ta}_{2} \mathrm{O}_{5}$ vs. tempo para três experimentos de cloração independentes realizados a $950^{\circ} \mathrm{C}$.

Figura 54. Ajuste linearizado do modelo do núcleo não reagido com fator de forma

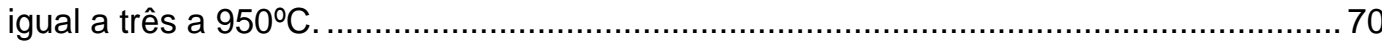

Figura 55. Ajuste linearizado do modelo auto catalítico a 950ํ….............................. 70

Figura 56. Ink vs. 1/T para os experimentos de cloração realizados entre $800 \mathrm{a}$ $950^{\circ} \mathrm{C}$ (modelo do núcleo não reagido com $\mathrm{f}=3$ ) .71

Figura 57. Ink vs. 1/T para os experimentos de cloração realizados entre 800 a $950^{\circ} \mathrm{C}$ (modelo auto catalítico). 


\section{Lista de tabelas}

Tabela 1. Composição global das escórias estaníferas estudadas ${ }^{(43)}$...........................2 21

Tabela 2. Número de mols de grafite (nc) formado a partir da decomposição do

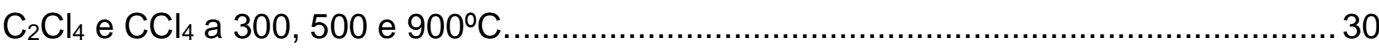

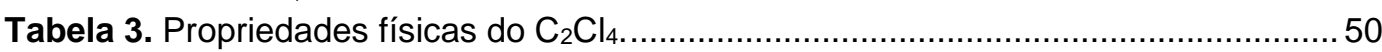

Tabela 4. Parâmetros de rede e tamanho médio de cristalito. .......................................5 54

Tabela 5. Resultado da análise de EDS da amostra de $\mathrm{Ta}_{2} \mathrm{O}_{5}$ como recebida. ...............55

Tabela 6. Parâmetros de rede e tamanhos médios de cristalito. .....................................57

Tabela 7. Parâmetros de rede e tamanhos médios de cristalito. ....................................58

Tabela 8. Resultado da análise de EDS da amostra de $\mathrm{Ta}_{2} \mathrm{O}_{5}$ após a cloração com

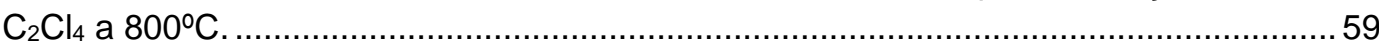

Tabela 9. Resultado da análise de EDS da amostra de $\mathrm{Ta}_{2} \mathrm{O}_{5}$ após a cloração com

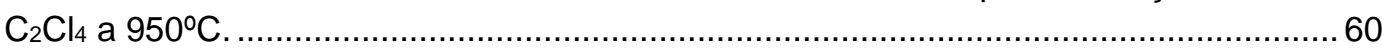

Tabela 10. Resultado da análise de EDS da amostra de precipitado coletado da

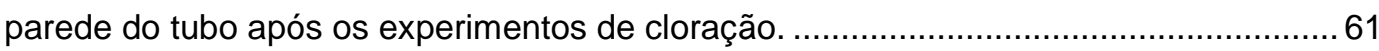

Tabela 11. Concentração de tântalo (ICP-AES) nas soluções de KOH............................. 63

Tabela 12. Energia de ativação global calculada para cada modelo cinético

considerado 


\section{1 \\ INTRODUÇÃO}

A utilização de metais como, por exemplo, o tântalo vem crescendo nos diversos segmentos da indústria, principalmente eletrônica e automotiva, devido ao seu alto poder de resistência à corrosão, resistência à temperatura, ductilidade e alto ponto de fusão, porém a principal utilização deste elemento é na fabricação de capacitores ${ }^{(1,2)}$.

A produção do tântalo era derivada como subproduto ou coproduto da mineração de cassiterita (mineral-minério do estanho), normalmente na forma de columbita-tantalita. Entretanto, as condições atrativas dos preços do $\mathrm{Ta}_{2} \mathrm{O}_{5}$, no final da década de 90, incentivaram sobremaneira a sobrevida de antigas minas, independente do estanho. No Brasil a principal produtora de concentrado e liga de tântalo é a Mineração Taboca S.A ${ }^{(3)}$.

O cloro vem se destacando na metalurgia extrativa de muitos metais refratários, como o titânio e o zircônio. Este processo de extração já é empregado industrialmente numa das fases da metalurgia extrativa do titânio para obtenção do metal e do $\mathrm{TiO}_{2}$ e do metal zircônio para a indústria química e nuclear ${ }^{(4)}$

O processo de ustulação cloretante realizado em reações com altas temperaturas, geralmente superiores a $600^{\circ} C^{(5)}$, tem por finalidade a separação de óxidos a partir da formação de cloretos, geralmente na fase gasosa, obtendo metais com alto valor econômico.

Dentre os reagentes cloretantes consagrados utilizados na indústria, encontra-se $\circ \mathrm{Cl}_{2}$ gasoso, que é o mais empregado. No entanto, a cloração direta muitas vezes não é termodinamicamente viável na faixa de temperatura típica de interesse $\left(600\right.$ a $\left.1200^{\circ} \mathrm{C}\right)$. De maneira a contornar tal problema, um agente redutor deve ser incorporado (fonte de carbono), elevando-se a força motriz do processo(6). Entretanto, o cloro consiste em uma molécula razoavelmente agressiva ao meio ambiente, o que justifica a busca por agentes alternativos, tais como $\mathrm{CCl}_{4}{ }^{(7)} \mathrm{e}_{2} \mathrm{Cl}_{4}{ }^{(8)}$.

No sentido de se buscar rotas mais sustentáveis, convém utilizar métodos alternativos com reagentes portadores de cloro ambientalmente corretos, tais

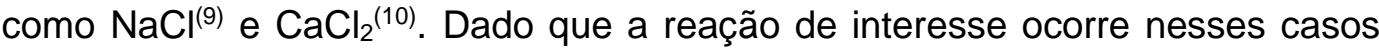
no estado sólido, temperaturas elevadas se fazem necessárias, contribuindo, 
desta forma, para a elevação do custo do processo. Neste contexto, agentes cloretantes gasosos devem ser preferidos, pois facilitam o contato com os óxidos a serem clorados na atmosfera reacional, promovendo assim a cinética das reações, e contribuindo, em última instância para uma possível redução na temperatura de processo. Adicionalmente, a presença de carbono na molécula consiste em um fator relevante, pois a formação de $\mathrm{CO} / \mathrm{CO}_{2}$ a partir da combinação do carbono ofertado e o oxigênio disponível na matéria-prima clorada, deve contribuir de forma expressiva para a viabilidade termodinâmica desejada.

Neste cenário, compostos organoclorados, tais como, o $\mathrm{CCl}_{4}{ }^{(7)}, \mathrm{C}_{2} \mathrm{Cl}_{4}{ }^{(8)} \mathrm{e}$ $\mathrm{COCl}_{2}{ }^{(11)}$ se destacam, fato este passível de ser compreendido pelos seguintes motivos:

a) substâncias facilmente levadas ao estado gasoso. São normalmente líquidos à temperatura ambiente.

b) o agente redutor e cloretante são simultaneamente ofertados - o carbono estimula tanto a força motriz quanto a cinética das reações de cloração envolvidas no processo.

Desta forma, o tântalo também pode ser extraído utilizando estes compostos, como no caso da reação do $\mathrm{Ta}_{2} \mathrm{O}_{5} \mathrm{com} \mathrm{CCl}_{4}{ }^{(12)}$ em temperaturas variando entre 425 e $580^{\circ} \mathrm{C}$ e na utilização do $\mathrm{C}_{2} \mathrm{Cl}_{4}$ para clorar, por exemplo, a alumina ${ }^{(8)}$, que é um óxido ainda mais estável que o $\mathrm{Ta}_{2} \mathrm{O}_{5}$, em temperaturas variando entre 660 e $770^{\circ} \mathrm{C}$. Assim como Jena et al. ${ }^{(11,12,13,14,15,16)}$ também realizaram diversos estudos sobre a cinética da cloração de óxidos de metais como $\mathrm{V}_{2} \mathrm{O}_{5}, \mathrm{ZrO}_{2}$, $\mathrm{Nb}_{2} \mathrm{O}_{5}$ e $\mathrm{Ta}_{2} \mathrm{O}_{5}$ por $\mathrm{CCl}_{4}$ em temperaturas entre 300 e $580^{\circ} \mathrm{C}$, e pressão parcial de $\mathrm{CCl}_{4}$ em nitrogênio. Tais estudos, além de comprovarem o potencial cloretante do $\mathrm{CCl}_{4}$ e do $\mathrm{C}_{2} \mathrm{Cl}_{4}$ em diferentes faixas de temperatura, também discutem diferentes tipos de controle (difusional ou químico), dependendo da temperatura e pressão parcial do agente cloretante.

Em conclusão disto, da mesma forma que o $\mathrm{CCl}_{4}, \circ \mathrm{C}_{2} \mathrm{Cl}_{4}$ foi estudado como um promissor agente, tendo apenas, até o presente estudo, o trabalho do Bertóti $^{(8)}$ como referência de que $0 \quad \mathrm{Al}_{2} \mathrm{O}_{3}$, mesmo tendo uma elevada estabilidade, é clorado em temperaturas consideradas elevadas para rotas pirometalúrgicas, em pressões parciais de $1,97 \times 10^{-5} \mathrm{~atm}$, formando cloretos voláteis. Este fator de escassez na literatura configura em mais um motivo para 0 presente estudo. 


\section{2}

\section{OBJETIVOS}

Neste contexto, o presente trabalho tem como principais objetivos a avaliação termodinâmica e o estudo quantitativo (energia de ativação) da cinética de cloração do $\mathrm{Ta}_{2} \mathrm{O}_{5}$ em altas temperaturas com $\mathrm{C}_{2} \mathrm{Cl}_{4}$ como agente cloretante em baixas pressões.

\section{1}

\section{Objetivos específicos}

- Caracterização do material antes e durante o processo e precipitado coletado na saída do reator tubular, através de difração de raio-X (DRX) fases presentes e tamanho médio de cristalito.

- Caracterização do material antes e durante o processo e precipitado coletado na saída do reator tubular, através de microscopia eletrônica de varredura (MEV/EDS) - análise química elementar, morfologia e tamanho de partícula.

- Análise química do tântalo na solução de $\mathrm{KOH}$ usada para o abate dos gases na saída do forno.

- Ensaios de cloração entre 800 e 950C para avaliar a energia de ativação global do processo utilizando-se os modelos do núcleo não reagido e auto catalítico. 


\section{3 \\ REVISÃO BIBLIOGRÁFICA}

O tântalo é um metal escuro azul grisáceo (cinzento), muito duro, denso, dúctil, resistente à corrosão por ácidos, com um alto ponto de fusão, elevada capacitância, além de ser um bom condutor de calor e eletricidade. À temperatura ambiente não reage com o ar, água, ou ácidos, exceto o fluorídrico ou sua mistura com o nítrico. Mediante aquecimento reage com a maioria dos elementos não metálicos formando ligas e ou fases intermetálicas, podendo ser oxidado mediante reações com bases fundidas ${ }^{(17)}$.

A principal utilização do tântalo metálico é para fabricação de capacitores, elementos estes com larga aplicação em circuitos eletrônicos. Capacitores de tântalo são formados pelo metal e pelo filme do pentóxido que é formado sobre o metal. Uma vez que a constante dielétrica do pentóxido de tântalo é elevada, uma área menor se faz necessária para atingir a mesma capacitância quando comparada a óxidos típicos, como por exemplo, o óxido de alumínio. Isto resulta em equipamentos menores e mais leves ${ }^{(18,19)}$.

O tântalo metálico também é utilizado em indústrias de equipamentos médicos, óptico, de raio-x, indústria cerâmica e como arame de metal para conexão de circuitos. A biocompatibilidade e dureza deste elemento faz com que não seja corroído por fluidos corporais e ao mesmo tempo não cause irritações no tecido vivo, não sendo, portanto, rejeitado pelo organismo ${ }^{(20)}$. Contudo, é a indústria eletrônica que consome a maior quantidade de tântalo.

Devido ao elevado ponto de fusão $\left(3020^{\circ} \mathrm{C}\right)$, o tântalo metálico é importante na produção de superligas refratárias com larga aplicação nas indústrias aeronáutica e de transportes para a fabricação de turbinas, produtos laminados e fios resistentes à corrosão(2). No que se refere aos aços especiais, a formação de carbeto do tântalo $(\mathrm{TaC})$ contribui para um aumento significativo na tenacidade, sendo benéfico para a confecção de ferramentas de corte, brocas para furadeiras e peças para máquinas trefiladoras ${ }^{(21)}$.

Por fim, filmes de pentóxido de tântalo $\left(\mathrm{Ta}_{2} \mathrm{O}_{5}\right)$ permitem elevar o índice de refração do vidro utilizado em lentes, podendo ser empregado como um material de revestimento antirreflexo em células solares, devido a sua elevada estabilidade química, elevado índice de refração e um coeficiente de absorção pouco expressivo. O filme também é usado em sensores químicos e biológicos. Halogenetos de tântalo têm sido utilizados na indústria petroquímica como 
catalisadores, de fato, foi evidenciado que cloreto de tântalo $\left(\mathrm{TaCl}_{5}\right)$ pode ser utilizado como um catalisador na síntese de compostos organometálicos contendo magnésio(22).

A necessidade de extração de tântalo apresentou um aumento significativo entre 1999 e 2001, devido principalmente à incorporação deste em dispositivos presentes em aparelhos eletrônicos portáteis, como celulares e laptops $^{(12)}$.

No entanto, o tântalo não ocorre em estado puro na natureza, mas sempre associado ao oxigênio e a outros elementos, principalmente o nióbio(1). Tal fato constitui um obstáculo tecnológico, dado que, em função da similaridade associada às propriedades físico-químicas desses elementos, a separação dos mesmos se mostra dificultada. Neste contexto, o minério é denominado tantalita se o conteúdo em pentóxido de tântalo for maior que o pentóxido de nióbio; ocorrendo o contrário, o termo columbita é empregado(2).

Quimicamente o tântalo ocorre disseminado em rochas graníticas ou em diques de pegmatitos associados ao granito ${ }^{(23)}$. Quantidades significativas deste elemento também são obtidas a partir de depósitos de rochas macias e aluviais por mineração artesanal, principalmente na África Central. O Brasil também possui reservas de columbita-tantalita, porém faltam recursos para a produção de tântalo(20). Os maiores produtores de tantalita são a Austrália e o Brasil, correspondendo juntos, a cerca de $64 \%$ das reservas mundiais, sendo que 0 Brasil concentra quase $50 \%$ das reservas no mundo, sendo a maior parte do minério exportada principalmente para os Países Baixos, China, Estados Unidos, Estônia, Hong Kong e Japão(3).

As reservas brasileiras de tântalo estão localizadas principalmente na Mina do Pitinga (Mineração Taboca), localizada no município de Presidente Figueiredo-AM, de propriedade do grupo peruano MINSUR S.A. As reservas lavráveis nesta mina são de cerca 175 Mt de minério (columbita-tantalita), com 35 mil toneladas de $\mathrm{Ta}_{2} \mathrm{O}_{5}$ contido e outros minerais portadores de $\mathrm{Li}$, $\mathrm{Zr}$, dentre outros. Também existem ocorrências relacionadas à Província Pegmatítica de Borborema situada na região nordeste, destacando-se os estados da Paraíba, Rio Grande do Norte e Ceará. Na Bahia, as ocorrências estão associadas a xistos e pegmatitos da Faixa de Dobramentos Araçuaí. No estado do Amazonas, podem ser citadas inúmeras ocorrências no Alto e Médio Rio Negro situadas nos municípios de Barcelos e São Gabriel da Cocheira. Existem também ocorrências nos estados de Roraima, Rondônia, Amapá, Minas Gerais e Goiás(3). 
No processo de extração do tântalo, incluindo a separação do nióbio e dos outros elementos presentes como impurezas (sílicio, ferro, manganês, etc.), o concentrado é geralmente tratado como uma mistura de ácidos fluorídrico e sulfúrico a elevadas temperaturas. Soluções de tântalo são produzidas através da filtragem da pasta diluída, seguida por uma extração por solvente, emprpegando-se metil-isobutil-cetona, ou através de resinas de troca iônica, usando uma amina diluída e querosene como extrator do tântalo adsorvido. Geralmente o tântalo contido nestas soluções é convertido em $\mathrm{K}_{2} \mathrm{TaF}_{7}$. Sais de potássio são adicionados e $0 \mathrm{~K}_{2} \mathrm{TaF}_{7}$ cristaliza. Normalmente o metal é produzido quase que exclusivamente pela redução do $\mathrm{K}_{2} \mathrm{TaF}_{7}$ pelo sódio em um sistema de sais fundidos ( $\mathrm{KCl}, \mathrm{NaCl}, \mathrm{KF}, \mathrm{NaF})$, de acordo com a Equação (1) ${ }^{(23)}$ :

$$
\mathrm{K}_{2} \mathrm{TaF}_{7}+5 \mathrm{Na}=2 \mathrm{KF}+5 \mathrm{NaF}+\mathrm{Ta}
$$

As elevadas temperaturas envolvidas na etapa de redução contribuem de forma expressiva para o custo global do processo. Adicionalmente, tanto a etapa de lixiviação quanto a etapa de redução estão associadas à produção de efluentes tóxicos, o que justifica a busca por processos mais sustentáveis.

Neste contexto, a cloração direta (reação com $\mathrm{Cl}_{2}$ ) na presença de uma fonte de carbono (agente redutor) se apresenta como uma solução possível, já implementada em âmbito industrial na extração de metais refratários tais como o $\mathrm{Ti}^{(24)}$ e $\circ \mathrm{Zr}^{(13)}$. Processos similares poderiam ser igualmente pensados para a extração de tântalo a partir de minerais oxidados.

\section{1 \\ Cloração}

Reações de cloração proporcionam um meio eficaz de extração de metais a partir de matérias-primas de natureza oxidada. $O$ processo de cloração está sendo usado com mais frequência no campo de extração de metais a partir da formação seletiva de cloretos, normalmente na fase gasosa. Além disso, a cloração tem sido empregada já em âmbito industrial para a extração de metais tanto de concentrados quanto rejeitos de origem mineral, bem como escórias.

A ustulação cloretante pode ser realizada de forma direta, ou seja, mediante a reação da matéria-prima de interesse com $\mathrm{Cl}_{2}$ gasoso, com ou sem a presença de um agente redutor, por exemplo, algum material com elevado teor de carbono (ex. coque verde do petróleo ou grafite) $)^{(13)}$, incorporado à 
alimentação do reator no sentido de se estimular a força motriz para a ocorrência das reações de interesse.

No sentido de se buscar rotas mais sustentáveis, convém utilizar processos alternativos com reagentes portadores de cloro ambientalmente mais corretos, como, por exemplo, o $\mathrm{CaCl}_{2}{ }^{(9)}$, já explorado visando a extração de lítio de amostras de espodumênio $\left(\mathrm{LiAl}\left(\mathrm{SiO}_{3}\right)_{2}\right)$ em atmosferas de $\mathrm{N}_{2}$. Observou-se que o mineral começa a reagir para temperaturas de $700^{\circ} \mathrm{C}$, sendo as condições ótimas para o processo a $900^{\circ} \mathrm{C}$ e $120 \mathrm{~min}$, alcançando-se uma conversão de magnitude igual $90,2 \%$. O fato das reações ocorrerem no estado sólido requer, naturalmente, temperaturas expressivas.

Com intuito de se reduzir a temperatura reacional, convém explorar agentes cloretantes que viabilizem um contato íntimo entre o óxido a ser clorado e o meio reacional, e permitam ao mesmo tempo, mediante a incorporação de um agente redutor, a magnificação da força motriz do processo. Como candidatos interessantes tem-se os compostos organoclorados, tais como o $\mathrm{C}_{2} \mathrm{Cl}_{4}$ e $\mathrm{CCl}_{4}$, pois são facilmente levados à forma gasosa, e ao mesmo tempo possuem carbono em sua constituição, que pode funcionar como agente redutor para as reações de interesse.

O tópico 3.2 resume algumas pesquisas recentes relacionadas à cloração com agentes organoclorados $\left(\mathrm{CCl}_{4} \mathrm{e} \mathrm{C}_{2} \mathrm{Cl}_{4}\right)$, apesar da literatura ainda ser escassa sobre este assunto, principalmente no que tange pesquisas relacionadas ao uso do $\mathrm{C}_{2} \mathrm{Cl}_{4}$.

\section{2}

\section{Cloração direta na presença de uma fonte de carbono}

Allain et $\mathrm{al}^{(11)}$ estudaram a cinética da cloração e carbocloração dos pentóxidos de nióbio e tântalo na faixa de temperatura entre $385^{\circ} \mathrm{C}$ e $1000^{\circ} \mathrm{C}$ em diferentes atmosferas: $\mathrm{Cl}_{2}-\mathrm{N}_{2}$ e $\mathrm{Cl}_{2}-\mathrm{CO}-\mathrm{N}_{2}$.

As energias de ativação globais para cloração em atmosfera contendo $\mathrm{Cl}_{2}$ e $\mathrm{N}_{2}$ foram de $246 \mathrm{~kJ} / \mathrm{mol}$ para $\mathrm{Ta}_{2} \mathrm{O}_{5}$ na faixa de temperatura entre $925^{\circ} \mathrm{C}$ e $1000^{\circ} \mathrm{C}$ e de $208 \mathrm{~kJ} / \mathrm{mol}$ para $\mathrm{Nb}_{2} \mathrm{O}_{5}$ na faixa de temperatura entre $700^{\circ} \mathrm{C}$ e $850^{\circ} \mathrm{C}$. Nos dois casos os resultados experimentais se ajustam à equação do modelo do núcleo não reagido com fator de forma igual a três (Eq. 2), sugerindo que a cinética é de controle químico.

$$
1-(1-x)^{\frac{1}{3}}=k t
$$


Onde " $x$ " é a fração do óxido reagida, a um tempo " $t$ " em minutos e " $k$ " é a constante cinética.

As ordens de reação globais foram determinadas para ambos os óxidos em atmosfera constituída por misturas de $\mathrm{Cl}_{2}$ e $\mathrm{N}_{2}$, a $1000^{\circ} \mathrm{C}$ para $\circ \mathrm{Ta}_{2} \mathrm{O}_{5}$ e $750^{\circ} \mathrm{C}$ para o $\mathrm{Nb}_{2} \mathrm{O}_{5}$. Em ambos os casos um valor igual a 0,82 foi encontrado. Já as ordens de reação globais da carbocloração dos dois óxidos, em atmosferas constituídas por misturas de $\mathrm{Cl}_{2}$ e $\mathrm{CO}$ (carbocloração), se mostraram iguais a dois. Para temperaturas inferiores a $600^{\circ} \mathrm{C}$, as energias de ativação globais em atmosferas contendo CO (carbocloração) apresentaram valores iguais a $74 \mathrm{~kJ} / \mathrm{mol}$ para a cloração do $\mathrm{Nb}_{2} \mathrm{O}_{5}$ e $110 \mathrm{~kJ} / \mathrm{mol}$ para a cloração do $\mathrm{Ta}_{2} \mathrm{O}_{5}$. Entre $850^{\circ} \mathrm{C}$ e $1000^{\circ} \mathrm{C}$, as energias de ativação globais apresentam valores iguais a $78 \mathrm{~kJ} / \mathrm{mol}$ para $\mathrm{Nb}_{2} \mathrm{O}_{5}$ e $68 \mathrm{~kJ} / \mathrm{mol}$ para $\mathrm{Ta}_{2} \mathrm{O}_{5}$.

Brocchi et al $^{(25)}$ desenvolveram uma apreciação termodinâmica da cloração de amostras de escória estanífera, por cloro gasoso em presença de carbono, na faixa de temperatura entre 600 e $900^{\circ} \mathrm{C}$ e, como rota alternativa, lixiviação em ácido clorídrico, tendo em vista a recuperação de nióbio e tântalo.

Os autores observaram que a reação de redução do $\mathrm{Nb}_{2} \mathrm{O}_{5}$ com carbono gerando $\mathrm{Nb}$ e $\mathrm{CO}$ apresenta uma constante de equilíbrio $(\mathrm{K})$ maior que a unidade somente para temperaturas acima de $1300^{\circ} \mathrm{C}$ enquanto que para $\mathrm{TiO}_{2} \mathrm{e}$ $\mathrm{ZrO}_{2}$ valores similares de $\mathrm{K}$ são alcançados em temperaturas ainda maiores, sugerindo que tal redução seria dificilmente realizável na prática. No que se refere ao emprego da cloração como rota alternativa de extração, os autores analisaram a energia livre padrão para a produção de $\mathrm{NbCl}_{5}$, na forma gasosa, através de reações do $\mathrm{Nb}_{2} \mathrm{O}_{5} \mathrm{com} \mathrm{Cl}_{2}, \mathrm{C}_{/} \mathrm{Cl}_{2}, \mathrm{CCl}_{4}, \mathrm{HCl}$ e $\mathrm{CaCl}_{2}$, e concluíram que apenas as reações de cloração na presença de carbono são caracterizadas como termodinamicamente favoráveis. O mesmo deve ocorrer no caso de reações envolvendo $\mathrm{Ta}_{2} \mathrm{O}_{5}, \mathrm{ZrO}_{2}$ e $\mathrm{TiO}_{2}$.

Através de diagramas de predominância, Brocchi et al ${ }^{(25)}$ observaram que para um sistema que trabalha com pressões de $\mathrm{Cl}_{2}$ elevadas e de $\mathrm{O}_{2}$ reduzidas, os principais produtos gasosos devem ser: $\mathrm{NbCl}_{5}, \mathrm{TaCl}_{5}, \mathrm{TiCl}_{4}$ e $\mathrm{ZrCl}_{4}$.

A Tabela 1 apresenta uma seleção de escórias de estanho com diferentes origens, devido ao local e/ou período de amostragem (identificados como A, B, C, D, E e F) e suas respectivas análises. 
Tabela 1. Composição global das escórias estaníferas estudadas ${ }^{(25)}$.

\begin{tabular}{c|ccccccccc}
\hline \multirow{2}{*}{ Amostra } & \multicolumn{7}{|c}{ Composição global em termos dos óxidos constituintes } \\
\cline { 2 - 11 } & $\mathrm{Nb}_{2} \mathrm{O}_{5}$ & $\mathrm{Ta}_{2} \mathrm{O}_{5}$ & $\mathrm{ZrO}_{2}$ & $\mathrm{TiO}_{2}$ & $\mathrm{Fe}_{2} \mathrm{O}_{3}$ & $\mathrm{SiO}_{2}$ & $\mathrm{CaO}$ & $\mathrm{MgO}$ & $\mathrm{Al}_{2} \mathrm{O}_{3}$ \\
\hline $\mathrm{A}$ & 3.3 & 4.1 & - & 4.0 & 32.6 & 17.5 & 13.0 & 10.2 & 6.6 \\
$\mathrm{~B}$ & 23.0 & 4.6 & 5.2 & 5.2 & 9.4 & 29.0 & 5.1 & - & 6.6 \\
$\mathrm{C}$ & 5.9 & 2.4 & 5.6 & 10.4 & 3.8 & 30.1 & 13.5 & - & - \\
$\mathrm{D}$ & 7.6 & 1.3 & 16.6 & 4.8 & 7.5 & 30.1 & 7.0 & 3.0 & 10.7 \\
$\mathrm{E}$ & 8.9 & 1.8 & 19.6 & 4.8 & 5.9 & 33.9 & 9.7 & - & 1.5 \\
$\mathrm{~F}$ & 7.4 & 1.4 & 19.2 & 6.2 & 6.2 & 27.0 & 9.6 & 2.7 & 7.4 \\
\hline
\end{tabular}

As amostras de escórias $A, B, C$ e $D$ foram submetidas a investigação experimental através de diferentes métodos químicos (carbocloração, lixiviação em ácido clorídrico e cloração por vapor de tetracloreto de carbono) visando estudar as possibilidades de recuperação dos metais refratários.

Os resultados sugerem que, na carbocloração $\left(\mathrm{Cl}_{2}+\right.$ grafite), no que se refere à cloração do $\mathrm{Nb}_{2} \mathrm{O}_{5}$, conversões superiores a $90 \%$ podem ser alcançadas após $90 \mathrm{~min}$ a $800^{\circ} \mathrm{C}$. Naturalmente, este tempo pode ser sensivelmente diminuído usando temperaturas de cloração mais elevadas. Já o $\mathrm{Ta}_{2} \mathrm{O}_{5}$, o $\mathrm{TiO}_{2} \mathrm{e}$ o $\mathrm{ZrO}_{2}$, conversões superiores a $80 \%$ podem ser alcançadas após este mesmo tempo, enquanto que $\circ \mathrm{Fe}_{2} \mathrm{O}_{3}$, já alcança conversões superiores a $90 \%$ em apenas $35 \mathrm{~min}$.

Através dos resultados experimentais também foi possível observar que os óxidos são transformados em cloretos em taxas diferentes. Por exemplo, para a escória $A$, enquanto o óxido de cálcio reage rapidamente, a reação de sílica é muito mais lenta. No caso do $\mathrm{TiO}_{2}$, sua cloração só ocorre algum tempo após o início da reação (quando a maior parte do ferro já foi removida). No caso da escória $B$, enquanto o estanho é rapidamente removido, a transformação de óxido de zircônio é a mais lenta, com nióbio, tântalo e titânio apresentando um comportamento semelhante, tal como $75 \%$ de remoção numa corrida a $700^{\circ} \mathrm{C}$ durante 20 min com uma amostra contendo $30 \%$ de carvão com $58,4 \%$ de carbono fixo.

Pode-se concluir que as escórias de estanho geradas por diferentes indústrias, em diferentes momentos, são caracterizadas pela presença de metais refratários, cuja composição pode variar significativamente, em particular, no que se refere aos teores de nióbio e zircônio. Verificou-se que estas amostras, sob certas condições experimentais, eram inertes ao agente de cloração aplicado tal 
como $\mathrm{HCl}$ e $\mathrm{Cl}_{2}$, sugerindo elevada estabilidade, que pode ser "rompida" mediante a incorporação de um agente redutor.

Em contrapartida, a cloração, na presença de um agente redutor, possibilita a recuperação de todos os metais de relevância tecnológica. Os resultados experimentais indicam que, para qualquer uma das escórias de estanho disponíveis, a cloração com o carbono como agente redutor durante 40 minutos realizada a $900^{\circ} \mathrm{C}$ permite a transformação da maior parte dos óxidos metálicos em cloretos.

Uma amostra da escória $\mathrm{A}$ foi submetida à lixiviação de $\mathrm{HCl}$ e observouse uma dissolução de $57 \%$ em massa da amostra, e concomitante solubilização de $93,5 \%$ da quantidade de ferro presente inicialmente, elevando-se os teores de nióbio e tântalo de 3,3\% e 4,1\% para 7,2\% e 8,4\%, respectivamente. Os resultados sugerem que $95,5 \%$ do nióbio e 93,9\% do tântalo permanecem insolúveis. Observou-se também um aumento significativo dos teores de titânio e silício em contraponto com uma diminuição das frações mássicas de óxidos de ferro e cálcio.

Micco et al(26) estudaram a cinética da cloração de duas amostras do $\mathrm{MoO}_{3}$ por termogravimetria entre 525 e $600^{\circ} \mathrm{C}$ e pressão parcial de $\mathrm{Cl}_{2}$ variando entre 0,0987 e 0,5428atm. A temperatura de partida para a reação de $\mathrm{MoO}_{3} \mathrm{com}$ $\mathrm{Cl}_{2}$ se mostrou próxima de $427^{\circ} \mathrm{C}$. Determinou-se uma energia de ativação média de $211 \mathrm{~kJ} / \mathrm{mol}$ e uma ordem global de reação igual à unidade. Nas duas amostras os resultados experimentais se ajustam à equação do modelo do núcleo não reagido, porém a amostra "I" com fator de forma igual a três e a amostra "II" igual a dois (Eq. 2), sugerindo que a cinética é de controle químico.

\section{3}

\section{Cloração alternativa com $\mathrm{CCl}_{4}$}

Jena et $\mathrm{al}^{(16)}$ estudaram a cinética de cloração do pentóxido de nióbio com vapor de $\mathrm{CCl}_{4}$ em mistura com $\mathrm{N}_{2}$ na faixa de temperatura entre $425^{\circ} \mathrm{C}$ e $580^{\circ} \mathrm{C}$ com pressões parciais de tetracloreto de carbono variando entre $0,10 \mathrm{e}$ 0,75 atm. A taxa reacional $\left(k_{1}\right)$ foi determinada para pressões parciais de $\mathrm{CCl}_{4}$ entre 0,4 e 0,75 atm, e, na faixa de temperatura entre 425 e $500^{\circ} \mathrm{C}$, verificou-se que a mesma obedece à seguinte equação:

$$
k_{1}=k_{1}^{\prime} \cdot p^{1,5} \operatorname{CCl}_{4}
$$

Onde k' ${ }_{1}$ é a constante cinética do processo. 
Fixando-se a pressão parcial de $\mathrm{CCl}_{4}$ em 0,6 atm, a energia de ativação global do processo apresentou um valor igual a $112 \mathrm{~kJ} / \mathrm{mol}$. Os dados experimentais puderam ser quantitativamente ajustados através do modelo auto catalítico.

Estudos também foram realizados na faixa de temperatura entre $520^{\circ} \mathrm{C}$ e $580^{\circ} \mathrm{C}$. Observou-se-que, dependendo da pressão parcial de $\mathrm{CCl}_{4}$ imposta, a ordem da reação muda, sendo igual a 0,5 entre 0,1 e 0,2 atm e 1,0 entre 0,4 e 0,6 atm (Eq. 4 e 5).

$$
\begin{aligned}
& k_{1}=k_{1}^{\prime} \cdot p_{C C l_{4}}^{0,5} \\
& k_{1}=k_{1}^{\prime} \cdot p_{C C l_{4}}
\end{aligned}
$$

$\mathrm{Na}$ referida faixa de temperatura a energia de ativação global do processo apresentou valores iguais a $115 \mathrm{~kJ} / \mathrm{mol}(0,1$ e $0,2 \mathrm{~atm})$ e $57 \mathrm{~kJ} / \mathrm{mol}(0,4$ e 0,6atm).

Os dados cinéticos nesta faixa de temperatura foram descritos através do modelo de Adsorção de Langmuir.

Carvalho(12) estudou a cinética de cloração do pentóxido de tântalo com tetracloreto de carbono em duas faixas de temperatura distintas, $425^{\circ} \mathrm{C}$ a $500^{\circ} \mathrm{C}$ e $520^{\circ} \mathrm{C}$ a $580^{\circ} \mathrm{C}$, variando-se a pressão parcial de $\mathrm{CCl}_{4}$ entre 0,1 e 0,74 atm.

Mediante uma avaliação cinética nos instantes iniciais do processo, verificou-se que a variação temporal da conversão podia ser descrita através da Eq. (6) - modelo da reação contínua, onde a velocidade do processo é proporcional à quantidade de óxido disponível.

$$
-\ln (1-\alpha)=k_{1} \cdot t
$$

Onde " $\alpha$ " representa a conversão em um dado instante e " $k_{1}$ " é a constante cinética do processo. Aplicando a equação acima, os autores encontraram energias de ativação globais iguais a $145 \mathrm{~kJ} / \mathrm{mol}\left(425\right.$ a $500^{\circ} \mathrm{C}$ ) e $71 \mathrm{~kJ} / \mathrm{mol}$ (520 a $\left.580^{\circ} \mathrm{C}\right)$.

A ordem global do processo também foi determinada, variando-se a pressão parcial de $\mathrm{CCl}_{4}$ entre 0,21 e 0,74 atm $\left(475^{\circ} \mathrm{C}\right)$, e entre 0,1 e 0,6 atm $\left(560^{\circ} \mathrm{C}\right)$. A $475^{\circ} \mathrm{C}$ a ordem global apresentou um valor igual a 1,5 , a $560^{\circ} \mathrm{C}$ igual a 0,9 conforme as Equações (7) e (8):

$$
\begin{aligned}
& k_{1}=k^{\prime}{ }_{1} \cdot p_{C C l_{4}}^{1,5} \\
& k_{1}=k_{1}^{\prime} \cdot p_{C C l_{4}}^{0,9}
\end{aligned}
$$


No que diz respeito à cinética em instantes posteriores, verificou-se que as conversões medidas atendem à Equação (9), característica de um processo com controle químico e onde o óxido clorado possui atividade catalítica (modelo auto-catalítico).

$$
\ln \left(\frac{\alpha}{(1-\alpha)}\right)=t k_{2}^{\prime} \cdot p_{C C l_{4}}^{n}
$$

Onde a é a fração do óxido reagida no tempo $t$ (min) e $k_{2}$ é a constante cinética do processo. Aplicando-se a equação de Arrhenius, os valores de energia de ativação global encontrados foram de $31 \mathrm{~kJ} / \mathrm{mol}$ entre 425 e $500^{\circ} \mathrm{C}$ e de $142 \mathrm{~kJ} / \mathrm{mol}$ entre 520 e $580^{\circ} \mathrm{C}$. A ordem global do processo foi determinada em temperaturas intermediárias em cada um dos mencionados intervalos, variando-se $\mathrm{p}\left(\mathrm{C}_{2} \mathrm{Cl}_{4}\right)$ entre 0,21 e 0,74 atm, sendo igual a zero a $475^{\circ} \mathrm{C}$ e 0,9 a $560^{\circ} \mathrm{C}$.

Bertóti et al $^{(7)}$ estudaram a cinética de cloração da alumina utilizando misturas de $\mathrm{CCl}_{4}$ e $\mathrm{N}_{2}$ ou He na faixa de temperatura entre 427 a $850^{\circ} \mathrm{C}$ para pressões parciais de $\mathrm{CCl}_{4}$ iguais ou inferiores a $1,97 \times 10^{-5} \mathrm{~atm}$.

O modelo do núcleo não reagido com fator de forma igual a dois permitiu um ajuste quantitativo dos dados experimentais (Eq. 10).

$$
1-(1-\alpha)^{\frac{1}{2}}=k . t \cdot p_{C C l_{4}}^{n}=\text { k.t. }
$$

Onde " $\alpha$ " representa a conversão $\mathrm{Al}_{2} \mathrm{O}_{3}$, " $\mathrm{k}$ " é a constante cinética, "t" o tempo e $\mathrm{n}$ a ordem global do processo. Através da aplicação da equação de Arrhenius, obteve-se uma energia de ativação aparente de $212 \mathrm{~kJ} / \mathrm{mol}$ na faixa de temperatura entre 427 e $450^{\circ} \mathrm{C}$.

Para pressões parciais de $\mathrm{CCl}_{4}$ iguais ou inferiores a $2.1 \times 10^{3} \mathrm{~Pa}$ $\left(2,07 \times 10^{-5} \mathrm{~atm}\right)$, a cinética reacional em instantes iniciais é descrita pelo modelo de Langmuir-Hinshelwood.

$$
\mathrm{R}_{\mathrm{o}}=\frac{\left(k^{\prime} \cdot \sqrt{P_{C C l 4}}\right)}{\left(1+K \cdot \sqrt{P_{C C l 4}}\right)}
$$

Onde $R_{0}$ é a taxa inicial da reação, $P_{C C l 4}$ é a pressão parcial do $\mathrm{CCl}_{4}, \mathrm{~K}$ é a constante de equilíbrio da reação de formação do cloreto $\mathrm{AlCl}_{3}$ e k' é a constante cinética do processo. Através da Eq. 11, obteve-se uma energia de ativação aparente de $212 \mathrm{~kJ} / \mathrm{mol}$ na faixa de temperatura entre 440 e $450^{\circ} \mathrm{C}$. De acordo com o valor determinado pelo modelo do núcleo não reagido na mesma faixa de temperatura. Convém comentar que ambos os modelos assumem um 
controle químico, sendo a etapa lenta, a dissociação do $\mathrm{CCl}_{4}$ na superfície do óxido no caso da Eq. (11) e a reação entre o $\mathrm{CCl}_{4}$ e o óxido no caso da Eq. (10).

Brocchi at al. ${ }^{(25)}$ realizaram, uma apreciação teórica e experimental da cloração de amostras de escória estanífera via vapor de tetracloreto de carbono, na faixa de temperatura entre 510 e $650^{\circ} \mathrm{C}$ e pressão parcial de $\mathrm{CCl}_{4}$ entre 0,2 atm e 0,6 atm, para recuperar os metais valiosos, particularmente o nióbio e o tântalo. As experiências foram realizadas com a escória $D$, conforme a Tabela 1 descrita no tópico 3.2 .

Os autores observaram que para $35 \%$ da escória reagida, os níveis de conversão dos óxidos de metais refratários se mostraram superiores a $80 \%$. É também interessante chamar a atenção para o fato de que, dentro da faixa de condições experimentais empregadas, a perda de peso máxima obtida para a escória se mostrou igual a de $38 \%$, com $\mathrm{P}_{\mathrm{CC} 14}=0,6$ atm, $\mathrm{T}=650^{\circ} \mathrm{C}$ e $\mathrm{t}=40 \mathrm{~min}$. Desta forma, concluiu-se que a reação das amostras de escórias testadas com $\mathrm{CCl}_{4}$ permite a transformação de parte significativa dos metais refratários ( $\mathrm{Ta}, \mathrm{Nb}$ e Zr) em cloretos voláteis. Em contrapartida, sob um ponto de vista prático, pode considerar-se que cerca de $60 \%$ da escória inicial se mostrou inerte ao processo, o que poderia ser explicado pela expressiva estabilidade dos óxidos de $\mathrm{Si}, \mathrm{Al}, \mathrm{Ca}$ e Mg presentes.

Finalmente, Pap et al (27) estudaram a cinética de cloração do $\mathrm{MO}_{3}$ com $\mathrm{CCl}_{4}$ gasoso por termogravimetria na faixa de temperatura entre 307 e $477^{\circ} \mathrm{C}$ com pressão parcial de $\mathrm{CCl}_{4}$ entre 0,0197 e 0,1184atm. Apenas $\circ \mathrm{MoO}_{3}$ foi detectado via DRX após a cloração, ou seja, comprovando-se a formação exclusiva de cloretos voláteis. Adicionalmente, devido à baixa porosidade da amostra, a taxa de reação é diferente nas paredes dos poros internos e na superfície externa das partículas.

Para descrever as curvas de conversão-tempo, os autores propuseram um modelo cinético envolvendo tanto as reações em uma zona próxima aos túneis dos poros quanto na superfície externa (modelo de cilindro de contração para partículas com baixa porosidade), cuja essência se encontra expressa nas equações (12) e (13):

Se $k_{2} t<1$ :

$$
\alpha=\frac{1-m}{m_{o}}=1-\left[(1-q)\left(1-k_{1} t\right)^{2}+q\left(1-k_{2} t\right)^{2}\right]
$$

Se $k_{2} t>=1$ :

$$
\alpha=\frac{1-m}{m_{o}}=1-\left[(1-q)\left(1-k_{1} t\right)^{2}\right]
$$


Onde $k_{2}$ e $k_{1}$ são constantes cinéticas, e $k_{1}$ está associado a reação na superfície e $k_{2}$ associado a difusão através do poro, $q=\frac{\Sigma z}{l}$, ou seja, a relação entre a espessura total controlada pela difusão através dos poros, sendo $l 0$ comprimento do poro, e t o tempo.

As curvas calculadas com este modelo se ajustam bem aos resultados experimentais. As energias de ativação de 110 e $53 \mathrm{~kJ} / \mathrm{mol}$ com ordens de reação de $n=0,75$ e $n=0,5$ foram obtidas nas faixas de temperatura $277-327^{\circ} \mathrm{C}$ e $327-427^{\circ} \mathrm{C}$, respectivamente. Como pode ser visto, a energia de ativação global na faixa de temperatura mais elevada é cerca de metade da determinada abaixo de $327^{\circ} \mathrm{C}$. Isto sugere que a baixas temperaturas o controle é de natureza química enquanto que acima de $327^{\circ} \mathrm{C}$ o controle é de natureza difusional.

\section{4 \\ Cloração alternativa com $\mathrm{C}_{2} \mathrm{Cl}_{4}$}

No presente tópico serão abordados os principais resultados decorrentes do único artigo encontrado até a presente data, que trata da cloração de óxidos com $\mathrm{C}_{2} \mathrm{Cl}_{4}$. Neste estudo, Bertóti et al. ${ }^{\left({ }^{(8)}\right.}$ estudaram a cinética da cloração da alumina com misturas de $\mathrm{C}_{2} \mathrm{Cl}_{4}$ e $\mathrm{N}_{2}$ para temperaturas iguais ou inferiores a $850^{\circ} \mathrm{C}$, e $\mathrm{P}_{(\mathrm{C} 2 \mathrm{C} 14)}=1,58 \times 10^{-5} \mathrm{~atm}$.

Inicialmente foram realizados testes com uma pressão parcial de $\mathrm{C}_{2} \mathrm{Cl}_{4}$ de $1,58 \times 10^{-5} \mathrm{~atm}$ na faixa de uma temperatura entre 650 e $750^{\circ} \mathrm{C}$. O modelo do núcleo não reagido com fator de forma igual a dois permitiu um ajuste quantitativo dos dados experimentais (Eq. 10). Através da aplicação da equação de Arrhenius, obteve-se uma energia de ativação global de $141 \mathrm{~kJ} / \mathrm{mol}$.

A energia de ativação global também foi avaliada na faixa de temperatura entre 700 e $777^{\circ} \mathrm{C}$, mantendo-se a pressão parcial de $\mathrm{C}_{2} \mathrm{Cl}_{4}$ fixa em $1,58 \times 10^{-5}$ atm. A taxa inicial $\left(R_{0}\right)$ foi nesse caso, modelada de acordo com a Eq. (11), derivada do modelo de-Langmuir-Hinshelwood para adsorção reativa.

A energia de ativação global determinada a partir do modelo acima entre 705 e $777^{\circ} \mathrm{C}$ apresentou um valor igual a $133 \mathrm{~kJ} / \mathrm{mol}$, e deve, de acordo com o referido modelo estar associada à decomposição do $\mathrm{C}_{2} \mathrm{Cl}_{4}$ na superfície das partículas de $\mathrm{Al}_{2} \mathrm{O}_{3}$. 


\section{4 \\ FUNDAMENTOS TEÓRICOS}

\section{1}

\section{Aspectos termodinâmicos}

A viabilidade de reações químicas pode ser explorada mediante uma abordagem estritamente termodinâmica. Tal análise se faz especialmente relevante principalmente, ao se explorar o potencial cloretante de um agente alternativo, ainda pouco conhecido, tal como, de especial interesse para a presente dissertação, o $\mathrm{C}_{2} \mathrm{Cl}_{4}$.

Desta forma, previamente aos experimentos de cloração, foram realizadas simulações fundamentadas na construção de diagramas de variação de energia de Gibbs, bem como diagramas de especiação através do software Thermocalc $^{(28)}$, de forma a avaliar a viabilidade dos processos reacionais, tanto no que se refere à formação de cloretos e oxicloretos voláteis, $\mathrm{CO}$ e $\mathrm{CO}_{2}$, quanto no que se refere à possível decomposição térmica do agente cloretante, produzindo-se grafite, que pode depositar sobre a amostra, interferindo em última instância, no comportamento cinético a ser medido. Como uma iniciativa para inibir a formação do grafite, tem-se admissão de $\mathrm{O}_{2}$ na atmosfera reacional. Desta forma, a cloração do $\mathrm{Ta}_{2} \mathrm{O}_{5}$ foi estudada tanto na ausência (tópico 4.1.1) quanto na presença (tópico 4.1.2) do referido agente oxidante.

\subsection{1}

\section{Simulações da decomposição do $\mathrm{C}_{2} \mathrm{Cl}_{4}$ sem adição de oxigênio}

Primeiramente foi analisada a formação de carbono na temperatura de $25^{\circ} \mathrm{C}$ a partir do $\mathrm{C}_{2} \mathrm{Cl}_{4}$ fixando-se a quantidade de nitrogênio em 10 mols. $\mathrm{A}$ Figura (1) apresenta o número de mols de carbono como função da razão molar

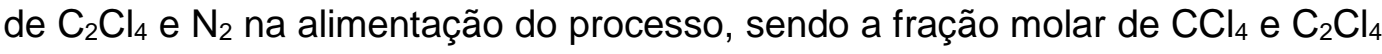
no equilíbrio apresentadas na Figura (2). Os dados sugerem que o agente cloretante em questão, de fato, pode sofrer decomposição térmica mesmo em temperaturas muito baixas, formando o grafite (C) e $\mathrm{CCl}_{4}$. 


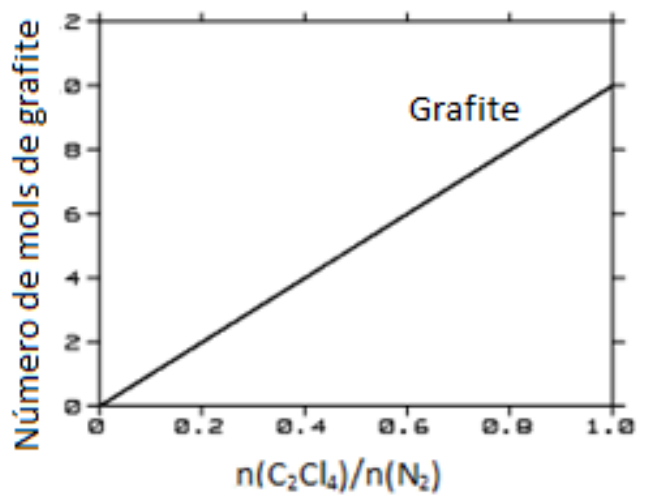

Figura 1. Número de mols de grafite formado a $25^{\circ} \mathrm{C}$.

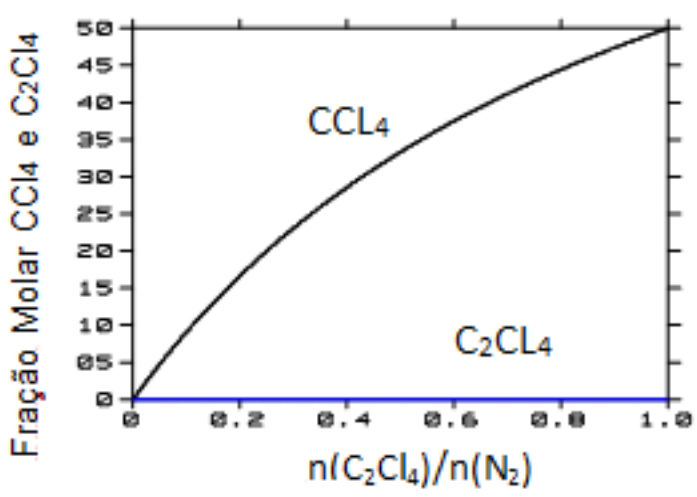

Figura 2. Fração molar de $\mathrm{CCl}_{4}$ e $\mathrm{C}_{2} \mathrm{Cl}_{4}$ a $25^{\circ} \mathrm{C}$.

De maneira a se explorar o efeito da temperatura sobre a referida decomposição térmica, simulações foram realizadas entre 300 e $900^{\circ} \mathrm{C}$ (Figuras 3 e 4).
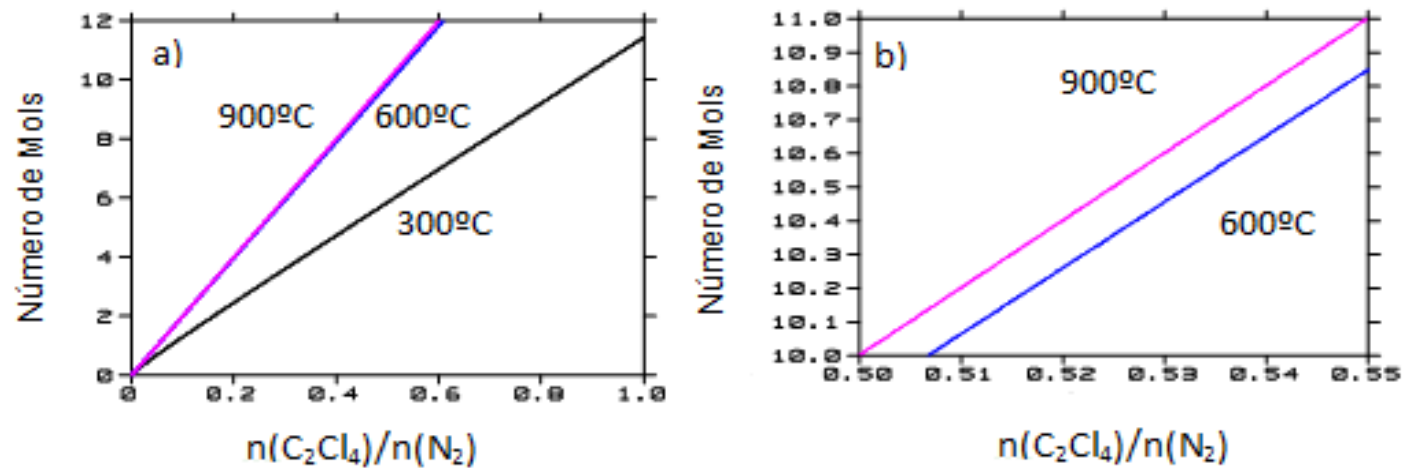

Figura 3. a) Número de mols de carbono produzido como função da temperatura $\left(300^{\circ}, 600^{\circ}\right.$ e $900^{\circ}$ C). b) Zoom da figura a).

Os dados contidos nas Figuras (3) e (4) sugerem que a quantidade de carbono (grafite) apresenta um significativo aumento entre 300 e $600^{\circ} \mathrm{C}$, porém, para temperaturas acima de $600^{\circ} \mathrm{C}$ a variação é mínima. De forma similar, a fração de $\mathrm{CCl}_{4}$ sofre uma progressiva redução, sendo esta bastante expressiva em temperaturas inferiores a $600^{\circ} \mathrm{C}$, tornando-se mínima acima. 

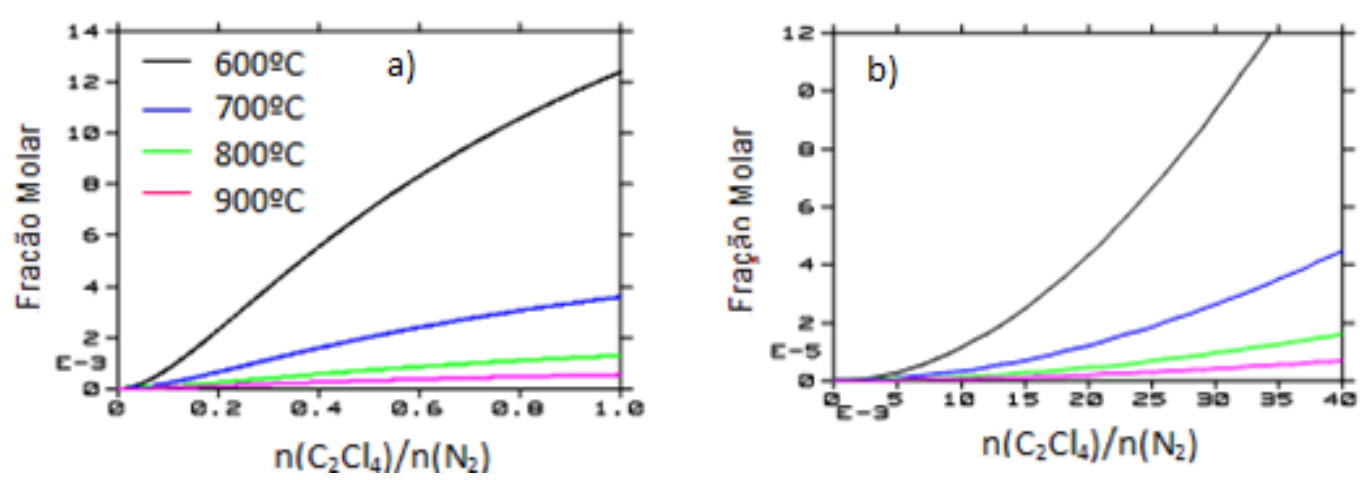

Figura 4. a) Fração molar de $\mathrm{CCl}_{4}$ formado entre as temperaturas de 600 a $900^{\circ} \mathrm{C}$. b) Zoom da figura a).

Os resultados sugerem a presença de duas reações, que ocorrem simultaneamente (Eq. 14 e 15), sendo a primeira associada à decomposição parcial do $\mathrm{C}_{2} \mathrm{Cl}_{4}$ inicialmente admitido em $\mathrm{CCl}_{4}$ e grafite e a segunda à decomposição do $\mathrm{CCl}_{4}$ formado produzindo grafite e $\mathrm{Cl}_{2}$. Tal fato se verifica em função das reduzidas frações de $\mathrm{CCl}_{4}$ presentes no equilíbrio para temperaturas acima de $800^{\circ} \mathrm{C}$.

$$
\begin{aligned}
& \mathrm{C}_{2} \mathrm{Cl}_{4}(\mathrm{~g}) \rightarrow \mathrm{CCl}_{4}(\mathrm{~g})+\mathrm{C} \\
& \mathrm{CCl}_{4}(\mathrm{~g}) \rightarrow 2 \mathrm{Cl}_{2}(\mathrm{~g})+\mathrm{C}
\end{aligned}
$$

Essas duas reações competem a partir de $400^{\circ} \mathrm{C}$, como pode ser observado a partir do diagrama $\Delta \mathrm{G}^{\circ}$ versus Temperatura apresentado na Figura (5). Acima de $800^{\circ} \mathrm{C}$ o comportamento reacional deve mudar, sendo a reação dominante a decomposição direta do $\mathrm{C}_{2} \mathrm{Cl}_{4}$ gerando $\mathrm{C}$ e $\mathrm{Cl}_{2}$ (Eq. 16).

$$
\mathrm{C}_{2} \mathrm{Cl}_{4}(\mathrm{~g})=2 \mathrm{Cl}_{2}(\mathrm{~g})+2 \mathrm{C}
$$




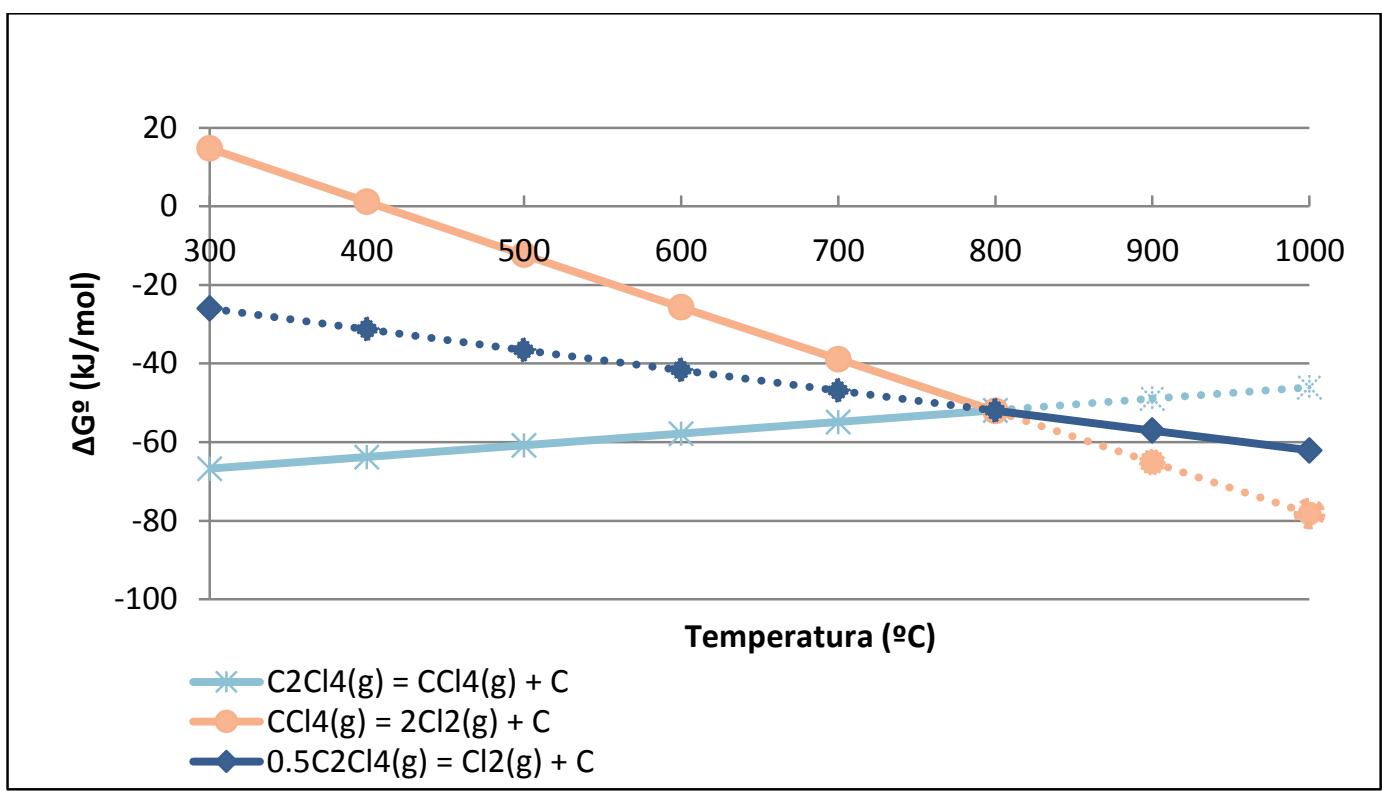

Figura 5. Energias de Gibbs reacionais para a decomposição do $\mathrm{C}_{2} \mathrm{Cl}_{4}$.

A Tabela 2 representa o número de mols de grafite formado nas temperaturas de $300^{\circ} \mathrm{C}, 500^{\circ} \mathrm{C}$ e $900^{\circ} \mathrm{C}$ para 10 mols de $\mathrm{C}_{2} \mathrm{Cl}_{4}$ e 10 mols de nitrogênio alimentados no processo.

Tabela 2. Número de mols de grafite (nc) formado a partir da decomposição do $\mathrm{C}_{2} \mathrm{Cl}_{4}$ e $\mathrm{CCl}_{4}$ a 300 , 500 e $900^{\circ} \mathrm{C}$.

\begin{tabular}{ll}
\hline Temperatura & nc (mols) \\
\hline $300^{\circ} \mathrm{C}$ & 11.4 \\
$500^{\circ} \mathrm{C}$ & 18.5 \\
$900^{\circ} \mathrm{C}$ & 20.0 \\
\hline
\end{tabular}

Observa-se que a $300^{\circ} \mathrm{C} 11,4$ mols de grafite - valor próximo aos 10 mols ofertados inicialmente de $\mathrm{C}_{2} \mathrm{Cl}_{4}$. Nessas condições, a reação (14) deve apresentar uma superior força motriz (Figura 5), ocorrendo em maior proporção em relação à reação (15). À medida que a temperatura aumenta, a força motriz da reação envolvendo o $\mathrm{CCl}_{4}$ apresenta uma apreciável elevação (Figura 5). Desta forma, espera-se que a contribuição desta para a quantidade de grafite total formado se torne progressivamente maior, o que pode ser comprovado pelos dados da Tabela 2. A $900^{\circ} \mathrm{C}$, todo $\mathrm{C}_{2} \mathrm{Cl}_{4}$ presente inicialmente se decompõe de acordo com a reação (16), resultando em uma quantidade de carbono em mols duas vezes maior que a quantidade de $\mathrm{C}_{2} \mathrm{Cl}_{4}$ presente no início. Este fato se encontra em concordância com o comportamento 
apresentado no gráfico da Figura (5), que sugere que a reação (16) deve ser a reação mais provável para temperaturas acima de $850^{\circ} \mathrm{C}$.

Os dados para a concentração $\mathrm{Cl}_{2}$ no equilíbrio estão em perfeito acordo com o comportamento reacional discutido acima, dado que é possível notar um aumento da concentração deste conforme a temperatura aumenta (Figura 5), o que pode ser explicado pela participação crescente da reação (15) no sistema reacional.
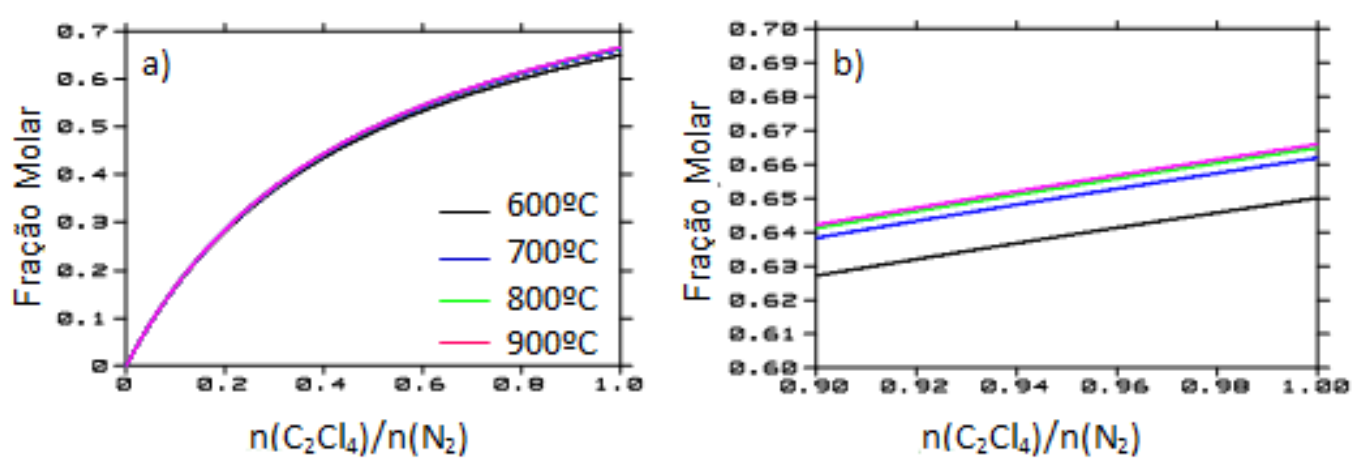

Figura 6. a) Fração molar de $\mathrm{Cl}_{2}$ nas temperaturas de 600 a $900^{\circ} \mathrm{C}$. b) Zoom da figura a).

Do exposto acima, é possível concluir que, acima de $800^{\circ} \mathrm{C} \circ \mathrm{C}_{2} \mathrm{Cl}_{4}$ é um precursor para a formação do $\mathrm{Cl}_{2}$, o agente cloretante que de fato deve ser considerado. Em temperaturas abaixo de $700^{\circ} \mathrm{C}$, tanto $\circ \mathrm{CCl}_{4}$ quanto $\circ \mathrm{Cl}_{2}$ são os agentes cloretantes, em proporção que irá depender da temperatura imposta, sendo a participação do $\mathrm{CCl}_{4}$ progressivamente maior à medida que a temperatura reacional se eleva.

\subsection{2}

Simulações da decomposição do $\mathrm{C}_{2} \mathrm{Cl}_{4}$ com adição de
oxigênio

Foram realizadas simulações da decomposição do $\mathrm{C}_{2} \mathrm{Cl}_{4}$ adicionando-se 0,26 mols de oxigênio para cada 10 mols de nitrogênio, com o intuito de se explorar a possibilidade de inibição da formação de grafite. Os gráficos contidos na Figura (7) apresentam a quantidade de grafite presente no equilíbrio na faixa de temperatura entre 600 e $900^{\circ} \mathrm{C}$, sendo as frações molares de $\mathrm{Cl}_{2}$ e $\mathrm{CCl}_{4}$ presentes no equilíbrio plotadas nas Figuras (8) e (9), respectivamente. 

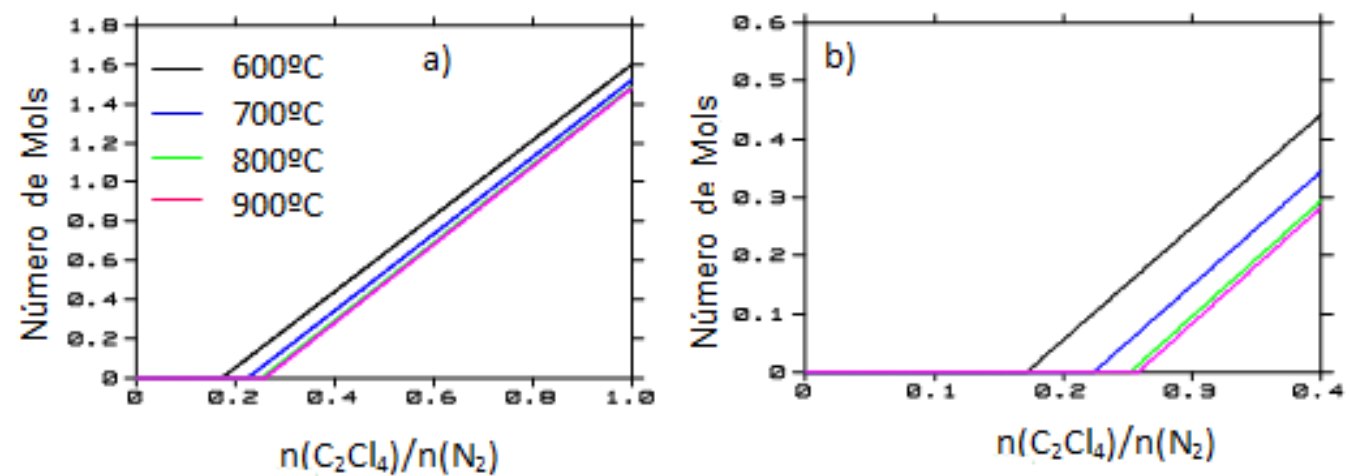

Figura 7. a) Número de mols de grafite formado nas temperaturas entre 600 e $900^{\circ} \mathrm{C}$. b) Zoom da figura a).
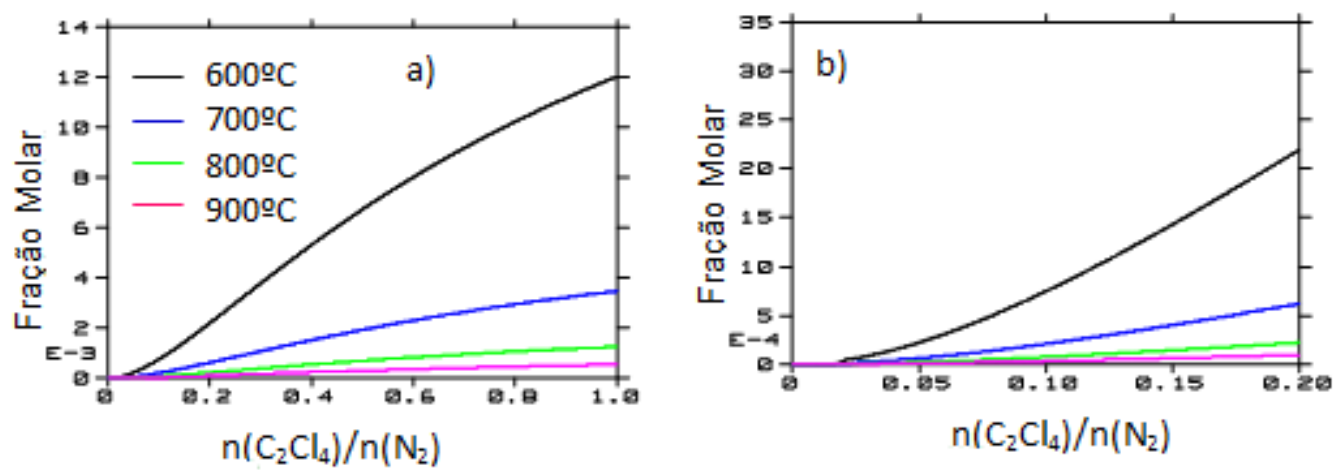

Figura 8. a) Fração molar de $\mathrm{CCl}_{4}$ nas temperaturas entre 600 e $900^{\circ} \mathrm{C}$. b) Zoom da figura a).
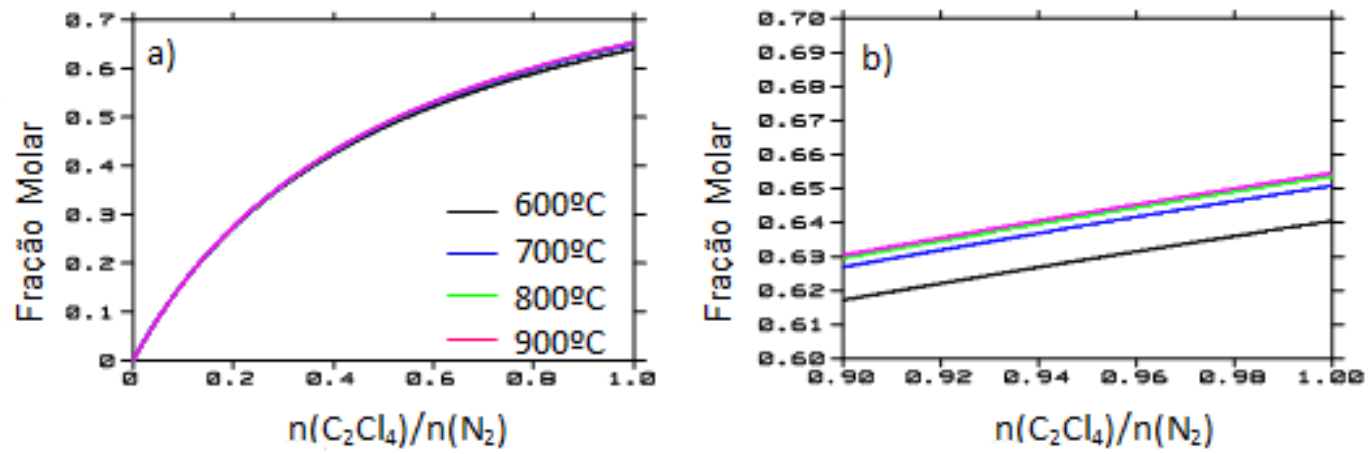

Figura 9. a) Fração molar de $\mathrm{Cl}_{2}$ nas temperaturas de 600 a $900^{\circ} \mathrm{C}$. b) Zoom da figura a).

Os gráficos indicam que a quantidade de grafite presente no equilíbrio é nula até que a razão entre 0 número de mols de $\mathrm{C}_{2} \mathrm{Cl}_{4}$ e $\mathrm{N}_{2}$ atinja um valor superior a 0,17 a $600^{\circ} \mathrm{C}$, e assim este limite se amplifica à medida que a temperatura se eleva, dado que a oxidação do grafite formado (Eq. 17) deve ser estimulada pela temperatura. Conforme mencionado no caso da simulação sem $\mathrm{O}_{2}$, o mesmo efeito é observado, onde a decomposição do $\mathrm{C}_{2} \mathrm{Cl}_{4}$ é estimulada pela temperatura, se tornando plena em temperaturas superiores a $800^{\circ} \mathrm{C}$ (Eq. 16). Pode-se verificar também que a fração molar de $\mathrm{CCl}_{4}$ é nula para condições 
diluídas em $\mathrm{C}_{2} \mathrm{Cl}_{4}$. Este fato pode ser explicado pela oxidação do $\mathrm{C}_{2} \mathrm{Cl}_{4}$ ou do $\mathrm{CCl}_{4}$ formado. De forma similar ao grafite, a concentração limite de $\mathrm{C}_{2} \mathrm{Cl}_{4}$ a partir da qual algum $\mathrm{CCl}_{4}$ residual se faz notável se eleva à medida que a temperatura aumenta. $\mathrm{A} 600^{\circ} \mathrm{C}$, por exemplo, a razão entre $\mathrm{C}_{2} \mathrm{Cl}_{4}$ e $\mathrm{N}_{2}$ mínima apresente um valor igual a 0,03 . Finalmente, no que se refere ao $\mathrm{Cl}_{2}$, um comportamento muito similar ao observado na ausência de oxigênio pode ser detectado. A oxidação do $\mathrm{C}_{2} \mathrm{Cl}_{4}$ e/ou $\mathrm{CCl}_{4}$ (Eq. 18 e 19) envolve, em ambos os casos, a formação de $\mathrm{Cl}_{2}$, da mesma forma que para as decomposições térmicas na ausência de $\mathrm{O}_{2}$. Como resultado formam-se $\mathrm{CO}$ e $\mathrm{CO}_{2}$ em proporção que dependerá da temperatura e quantidade de $\mathrm{C}_{2} \mathrm{Cl}_{4}$ inicial (Figuras 10 a 13).

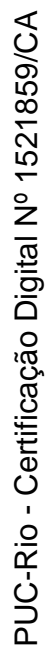
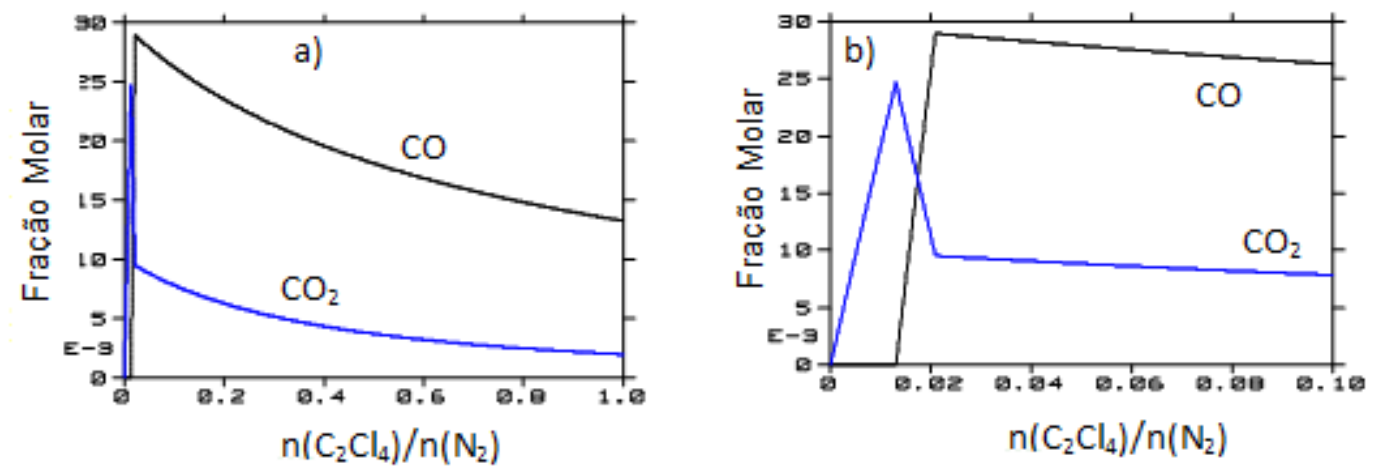

Figura 10. a) Formação de $\mathrm{CO}$ e $\mathrm{CO}_{2}$ a partir da oxidação do grafite a $600^{\circ} \mathrm{C}$. b) Zoom da figura a).
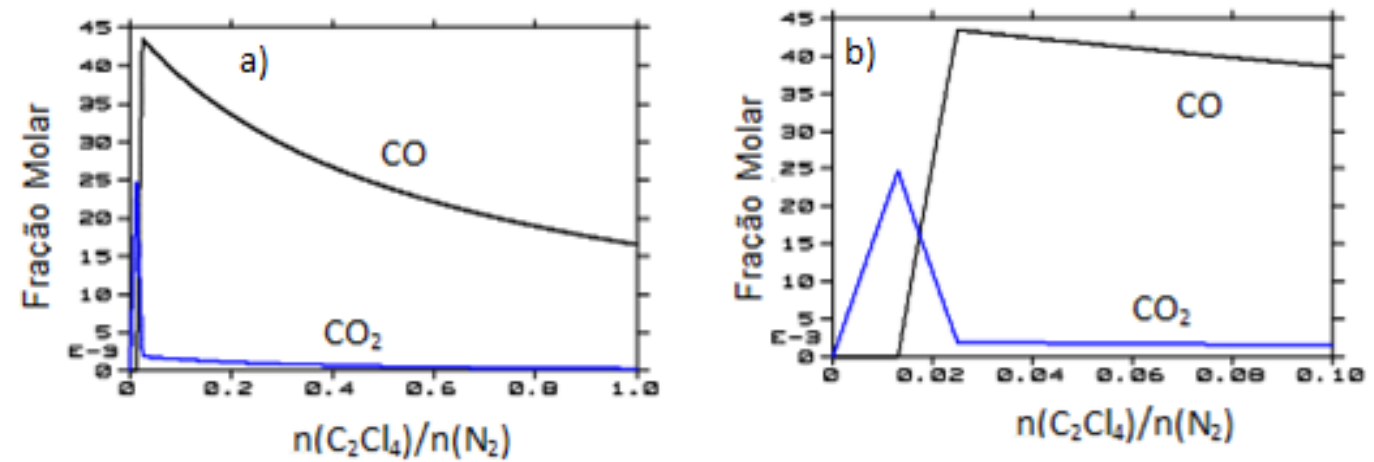

Figura 11. a) Formação de $\mathrm{CO}$ e $\mathrm{CO}_{2}$ a partir da oxidação do grafite a $700^{\circ} \mathrm{C}$. b) Zoom da figura a). 

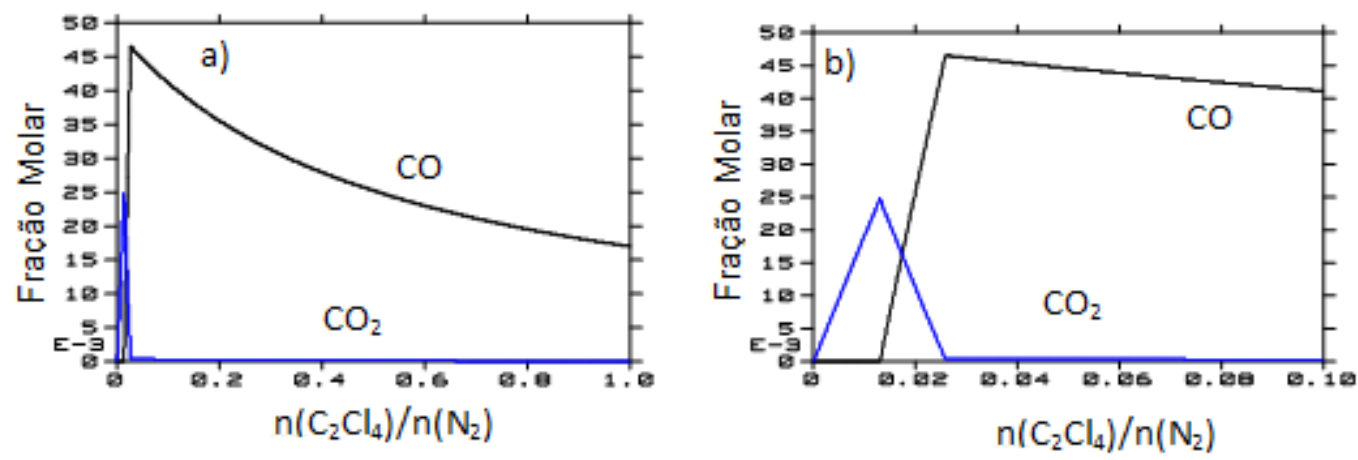

Figura 12. a) Formação de $\mathrm{CO}_{\text {e }} \mathrm{CO}_{2}$ a partir da oxidação do grafite a $800^{\circ} \mathrm{C}$. b) Zoom da figura a).
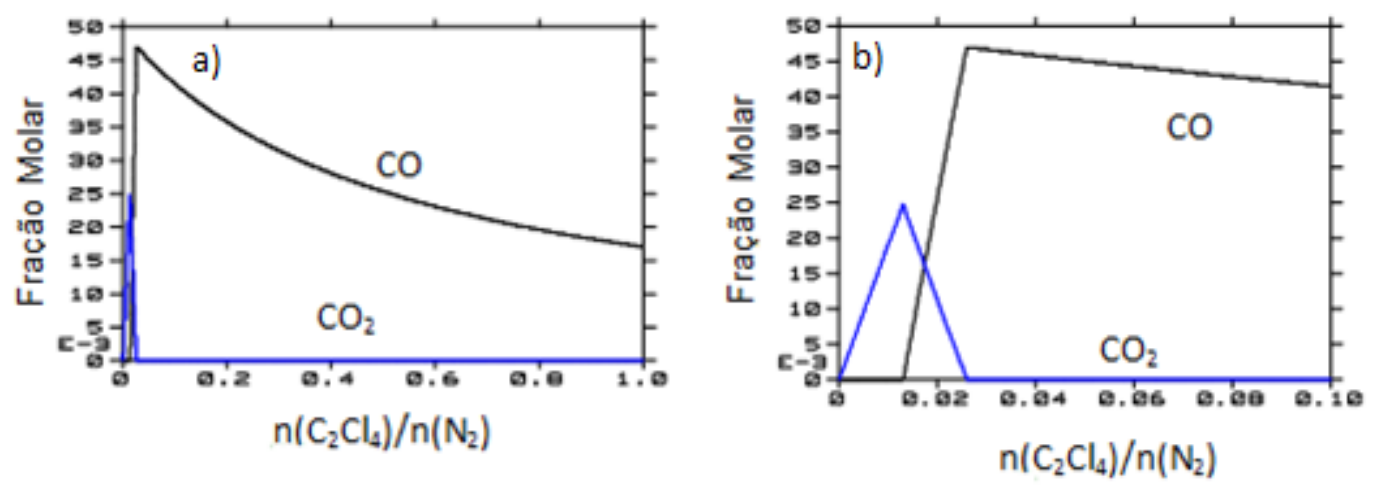

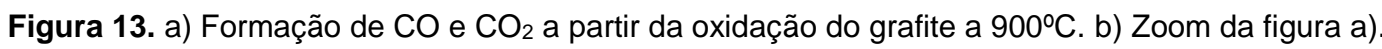

As frações molares de $\mathrm{CO}$ e $\mathrm{CO}_{2}$ são progressivamente maiores, para mesma quantidade de $\mathrm{C}_{2} \mathrm{Cl}_{4}$ inicial, conforme aumenta a temperatura, sugerindo que o potencial oxidante da atmosfera se torna progressivamente maior, fato este em concordância com o que foi comentado antes sobre a concentração limite de $\mathrm{C}_{2} \mathrm{Cl}_{4}$ para a formação de grafite e $\mathrm{CCl}_{4}$. Adicionalmente, de acordo com os diagramas de energia de Gibbs reacional como função da temperatura para as referidas reações (Eq. 18 e 19) a viabilidade de tais processos oxidativos deve se tornar superior em temperaturas mais elevadas, uma vez que a energia de Gibbs das reações apresenta uma progressiva redução à medida que a temperatura se torna mais elevada.

$$
\begin{aligned}
& \mathrm{O}_{2}+2 \mathrm{C}=2 \mathrm{CO} \text { ou } \mathrm{O}_{2}+\mathrm{C}=\mathrm{CO}_{2} \\
& \mathrm{O}_{2}+2 \mathrm{CCl}_{4}=4 \mathrm{Cl}_{2}+2 \mathrm{CO} \text { ou } \mathrm{O}_{2}+\mathrm{CCl}_{4}=2 \mathrm{Cl}_{2}+\mathrm{CO}_{2} \\
& \mathrm{O}_{2}+\mathrm{C}_{2} \mathrm{Cl}_{4}=2 \mathrm{Cl}_{2}+2 \mathrm{CO} \quad \text { ou } \quad \mathrm{O}_{2}+0.5 \mathrm{C}_{2} \mathrm{Cl}_{4}=\mathrm{Cl}_{2}+\mathrm{CO}_{2}
\end{aligned}
$$




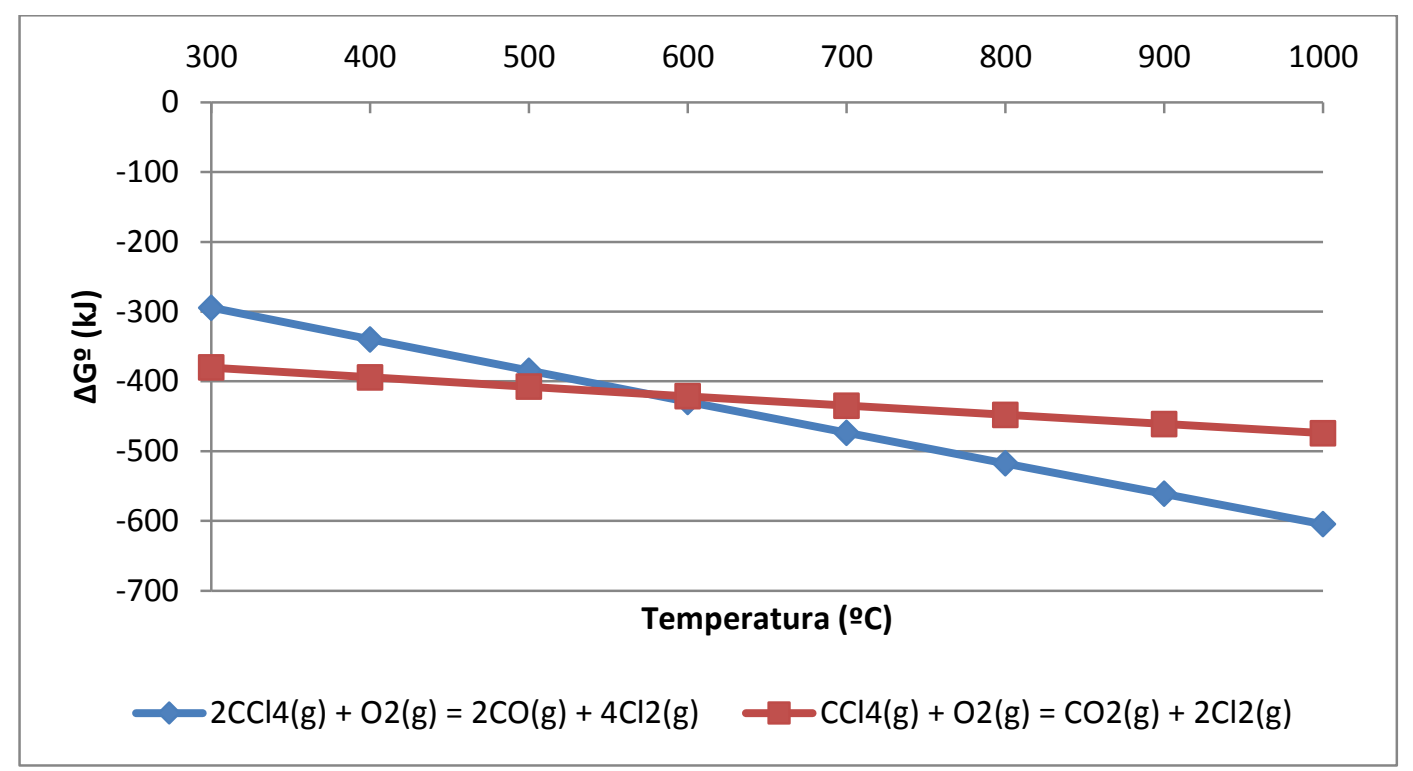

Figura 14. Energias de Gibbs reacionais para a decomposição sucessiva do $\mathrm{CCl}_{4}$.

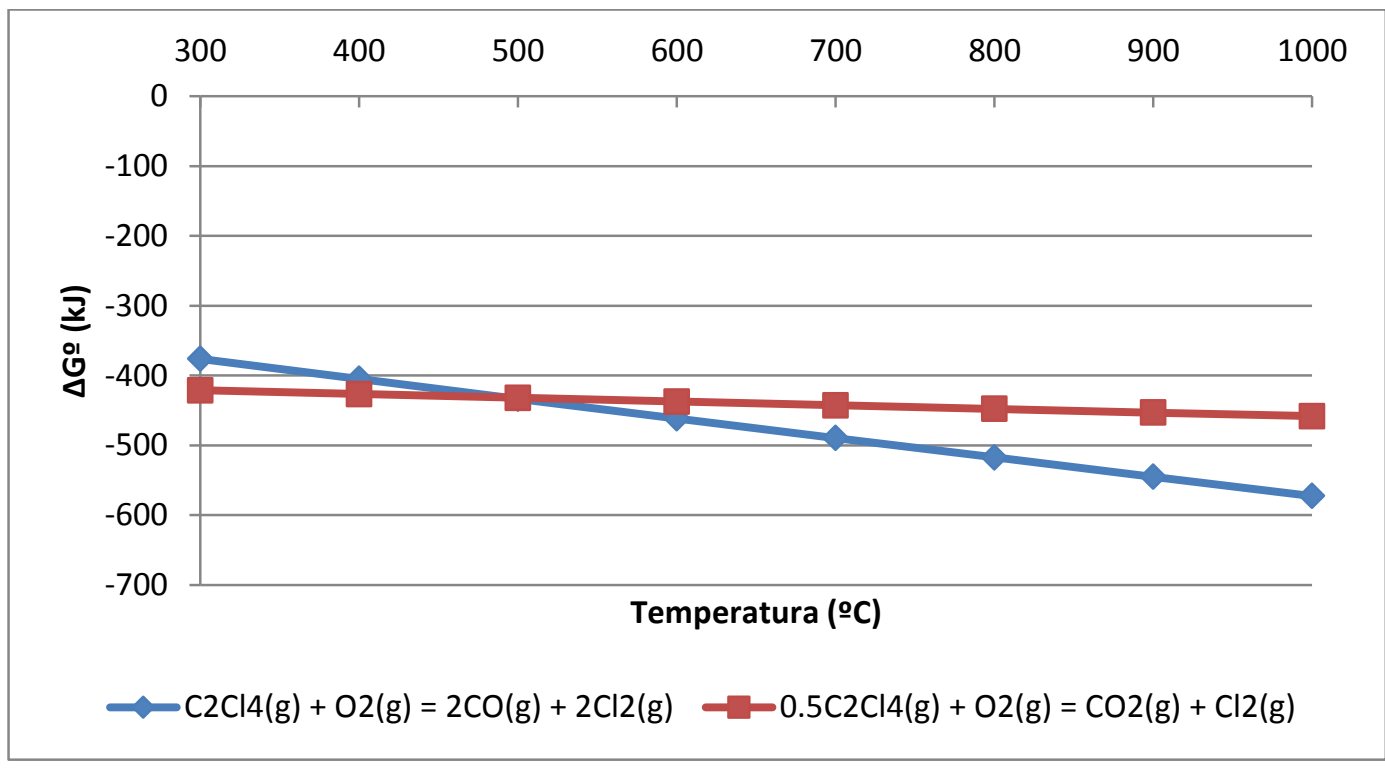

Figura 15. Energias de Gibbs reacionais para a decomposição sucessiva do $\mathrm{C}_{2} \mathrm{Cl}_{4}$.

\subsection{3}

\section{Cloração do $\mathrm{Ta}_{2} \mathrm{O}_{5} \mathrm{com} \mathrm{C}_{2} \mathrm{Cl}_{4}$}

Através do software $\mathrm{HSC}^{(29)}$, foi realizado um estudo preliminar com base em variação de energia de Gibbs das principais reações associadas à cloração do $\mathrm{Ta}_{2} \mathrm{O}_{5}$ com $\mathrm{C}_{2} \mathrm{Cl}_{4}$, formando-se cloretos voláteis (Equações 20 a 24).

$$
\begin{aligned}
& \mathrm{Ta}_{2} \mathrm{O}_{5}+2,5 \mathrm{C}_{2} \mathrm{Cl}_{4}(\mathrm{~g})=2 \mathrm{TaCl}_{5}(\mathrm{~g})+5 \mathrm{CO}(\mathrm{g}) \ldots \ldots \ldots \ldots \ldots \ldots \ldots \ldots \ldots \ldots \ldots \ldots \ldots \ldots \ldots \ldots \ldots \\
& \mathrm{Ta}_{2} \mathrm{O}_{5}+2,5 \mathrm{C}_{2} \mathrm{Cl}_{4}(\mathrm{~g})=2 \mathrm{TaOCl}_{3}(\mathrm{~g})+3 \mathrm{CO}(\mathrm{g})+2 \mathrm{Cl}_{2}(\mathrm{~g})+2 \mathrm{C}
\end{aligned}
$$




$$
\begin{aligned}
& \mathrm{Ta}_{2} \mathrm{O}_{5}+2,5 \mathrm{C}_{2} \mathrm{Cl}_{4}(\mathrm{~g})=2 \mathrm{TaCl}_{2}(\mathrm{~g})+5 \mathrm{CO}(\mathrm{g})+6 \mathrm{Cl}(\mathrm{g}) \ldots \\
& \mathrm{Ta}_{2} \mathrm{O}_{5}+2,5 \mathrm{C}_{2} \mathrm{Cl}_{4}(\mathrm{~g})=2 \mathrm{TaCl}_{3}(\mathrm{~g})+5 \mathrm{CO}(\mathrm{g})+2 \mathrm{Cl}_{2}(\mathrm{~g}) \\
& \mathrm{Ta}_{2} \mathrm{O}_{5}+2,5 \mathrm{C}_{2} \mathrm{Cl}_{4}(\mathrm{~g})=2 \mathrm{TaCl}_{4}(\mathrm{~g})+5 \mathrm{CO}(\mathrm{g})+\mathrm{Cl}_{2}(\mathrm{~g}) \ldots
\end{aligned}
$$

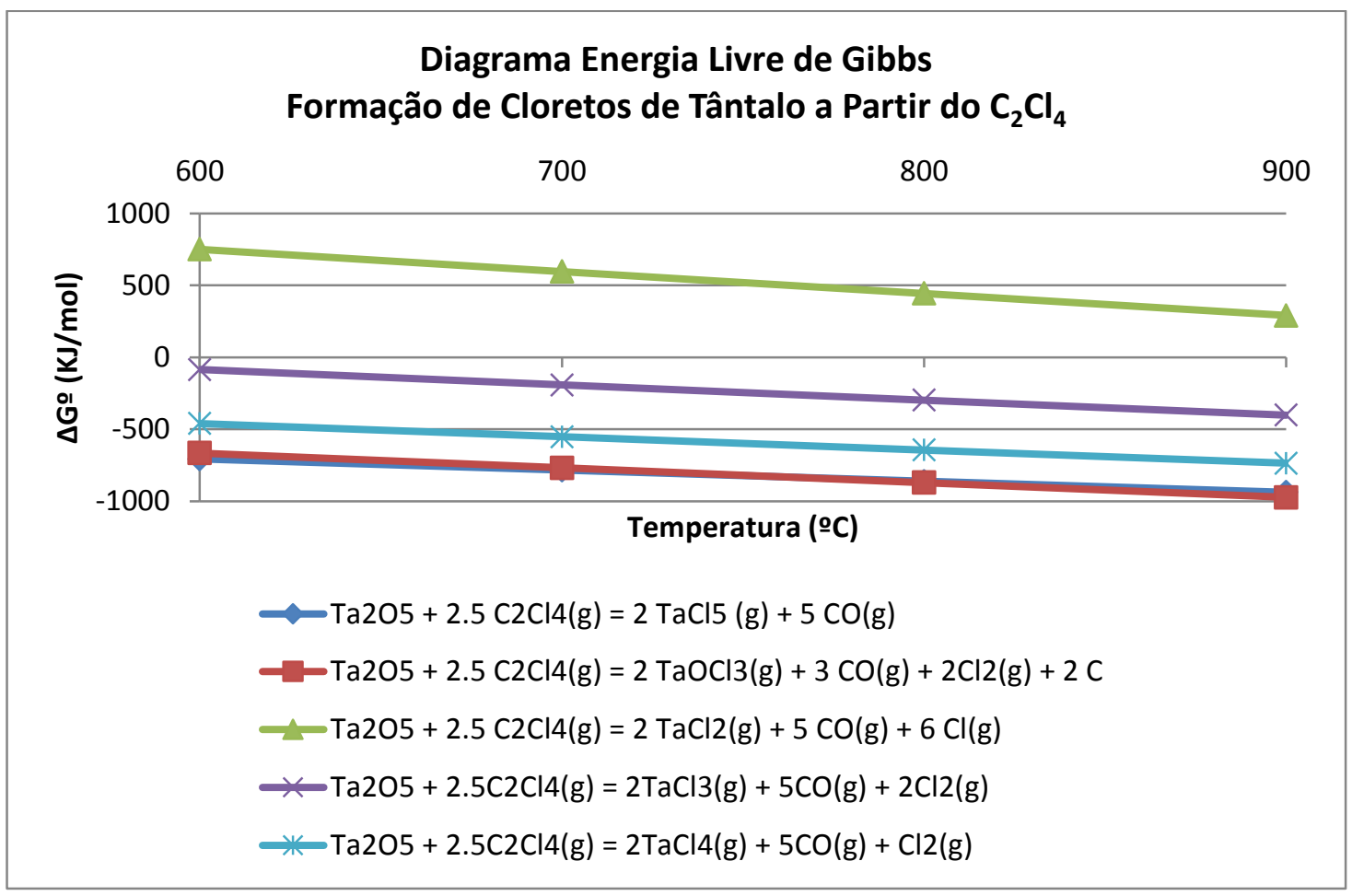

Figura 16. Energias de Gibbs reacionais para a formação de cloretos de tântalo a partir do $\mathrm{C}_{2} \mathrm{Cl}_{4}$.

Com exceção do $\operatorname{TaCl}_{2}(\mathrm{~g})$, em todos os casos é possível observar que as energias de Gibbs reacionais são negativas em toda a faixa de temperatura, sugerindo que a cloração do $\mathrm{Ta}_{2} \mathrm{O}_{5} \operatorname{com~} \mathrm{C}_{2} \mathrm{Cl}_{4}$ pode ser conduzida na prática de forma espontânea. Adicionalmente, verifica-se que o $\mathrm{TaCl}_{5}$ e $\mathrm{TaOCl}_{3}$ devem ser os cloretos formados com maior viabilidade, uma vez que apresentam energias de Gibbs reacionais mais negativas.

De maneira a se desenvolver um estudo quantitativo sobre as condições de equilíbrio para o processo de interesse, diagramas de especiação foram construídos, mediante o emprego do Software Thermocalc.

\subsubsection{1}

\section{Diagramas de especiação variando a pressão parcial do $\mathrm{C}_{2} \mathrm{Cl}_{4}$}

Através da construção de diagramas de especiação, foram analisadas a formação de grafite e, simultaneamente, o consumo do $\mathrm{Ta}_{2} \mathrm{O}_{5}$ nas temperaturas 
entre 600 e $900^{\circ} \mathrm{C}$ a partir da variação da pressão parcial do $\mathrm{C}_{2} \mathrm{Cl}_{4}$, além das frações molares dos principais produtos reacionais detectados: $\mathrm{CO}, \mathrm{CO}_{2}, \mathrm{TaCl}_{5} \mathrm{e}$ o $\mathrm{TaOCl}_{3}$.

No que diz respeito a formação de grafite, em temperturas de $600 \mathrm{e}$ $700^{\circ} \mathrm{C}$ a mesma deve ocorrer mesmo em atmosferas diluidas em paralelo à cloração do $\mathrm{Ta}_{2} \mathrm{O}_{5}$. A 800 e $900^{\circ} \mathrm{C}$, no entanto, os dados sugerem que é possível clorar sem a formação de grafite admitindo-se $\circ \mathrm{C}_{2} \mathrm{Cl}_{4}$ na forma diluida, quando a razão entre os números de mols de $\mathrm{C}_{2} \mathrm{Cl}_{4}$ e $\mathrm{N}_{2}$ é igual ou inferior a $0,05\left(800^{\circ} \mathrm{C}\right.$ ) e $0,5\left(900^{\circ} \mathrm{C}\right.$ ). Porém, se um reator de leito fixo for empregado (como no caso do presente trabalho) há possibilidade de decomposição do $\mathrm{C}_{2} \mathrm{Cl}_{4}$ no caminho entre a entrada do reator e a amostra. Tal processo poderia ser impedido elevando-se o contato entre o gás cloretante e o as partículas de óxido, por exemplo, em um reator de leito fluidizado.
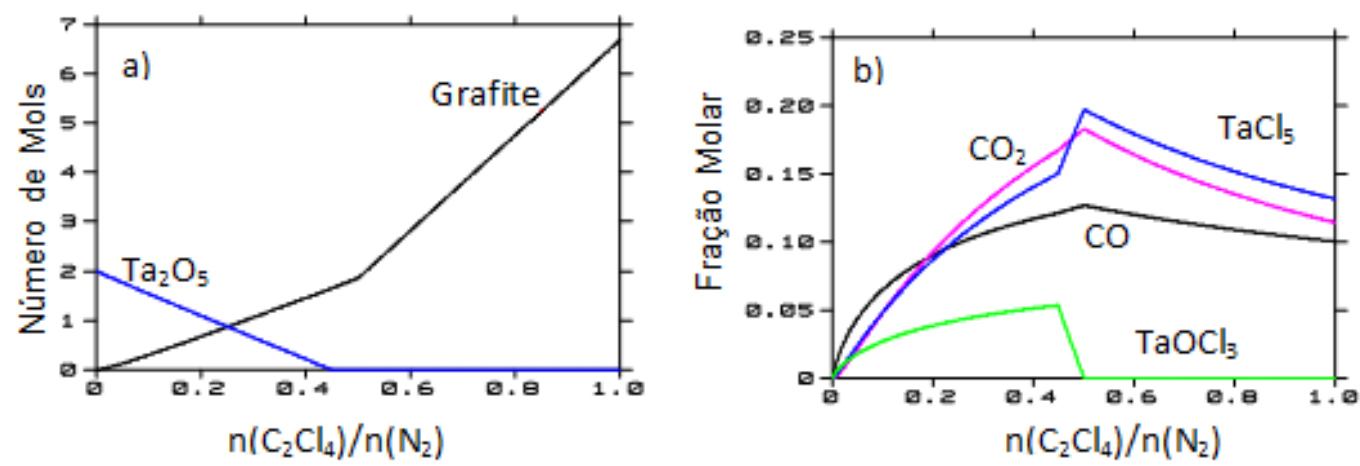

Figura 17. a) Número de mols de grafite como função da concentração de $\mathrm{C}_{2} \mathrm{Cl}_{4}$ a $600^{\circ} \mathrm{C}$. b) Frações molares de $\mathrm{CO}, \mathrm{CO}_{2}, \mathrm{TaOCl}_{3}$ e $\mathrm{TaCl}_{5}$ na fase gasosa como função da concentração de $\mathrm{C}_{2} \mathrm{Cl}_{4}$ a $600^{\circ} \mathrm{C}$
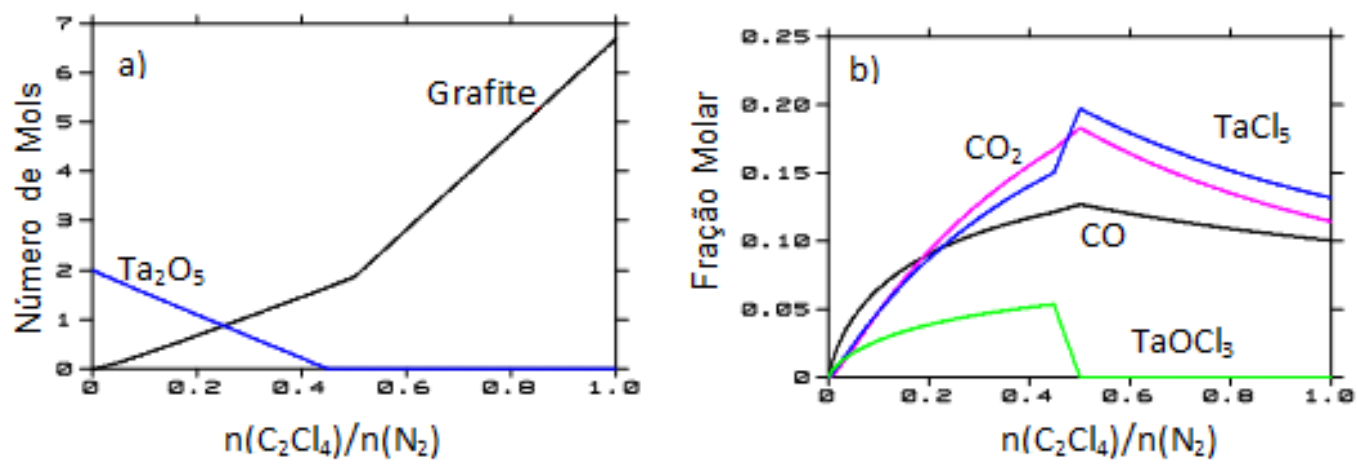

Figura 18. a) Número de mols de grafite como função da concentração de $\mathrm{C}_{2} \mathrm{Cl}_{4}$ a $700^{\circ}$. b) Frações molares de $\mathrm{CO}, \mathrm{CO}_{2}, \mathrm{TaOCl}_{3}$ e $\mathrm{TaCl}_{5}$ na fase gasosa como função da concentração de $\mathrm{C}_{2} \mathrm{Cl}_{4}$ a $700^{\circ} \mathrm{C}$ 

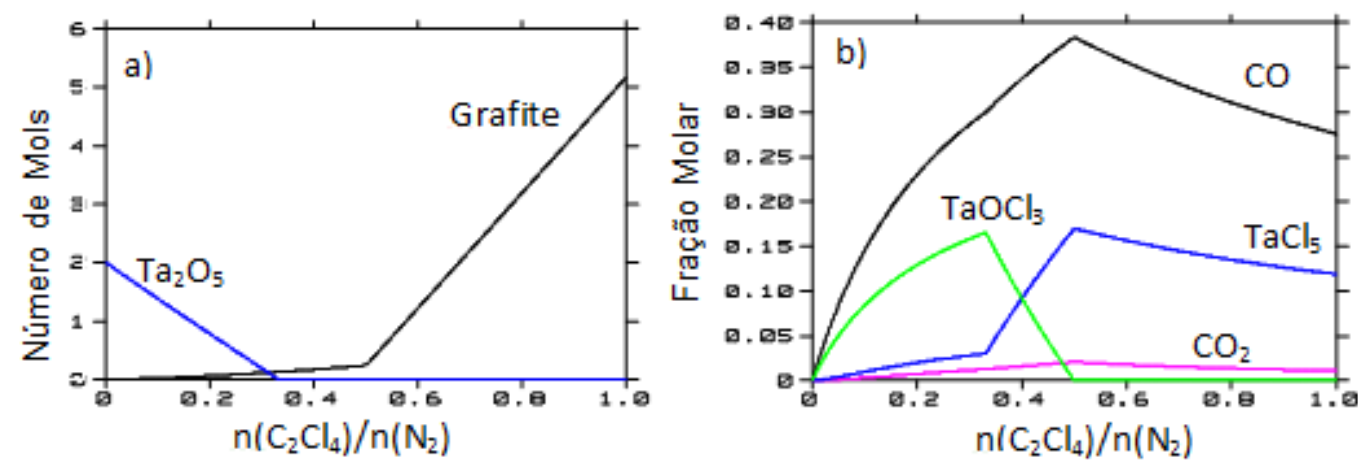

Figura 19. a) Número de mols de grafite como função da concentração de $\mathrm{C}_{2} \mathrm{Cl}_{4}$ a $800^{\circ}$. b) Frações molares de $\mathrm{CO}, \mathrm{CO}_{2}, \mathrm{TaOCl}_{3}$ e $\mathrm{TaCl}_{5}$ na fase gasosa como função da concentração de $\mathrm{C}_{2} \mathrm{Cl}_{4}$ a $800^{\circ} \mathrm{C}$
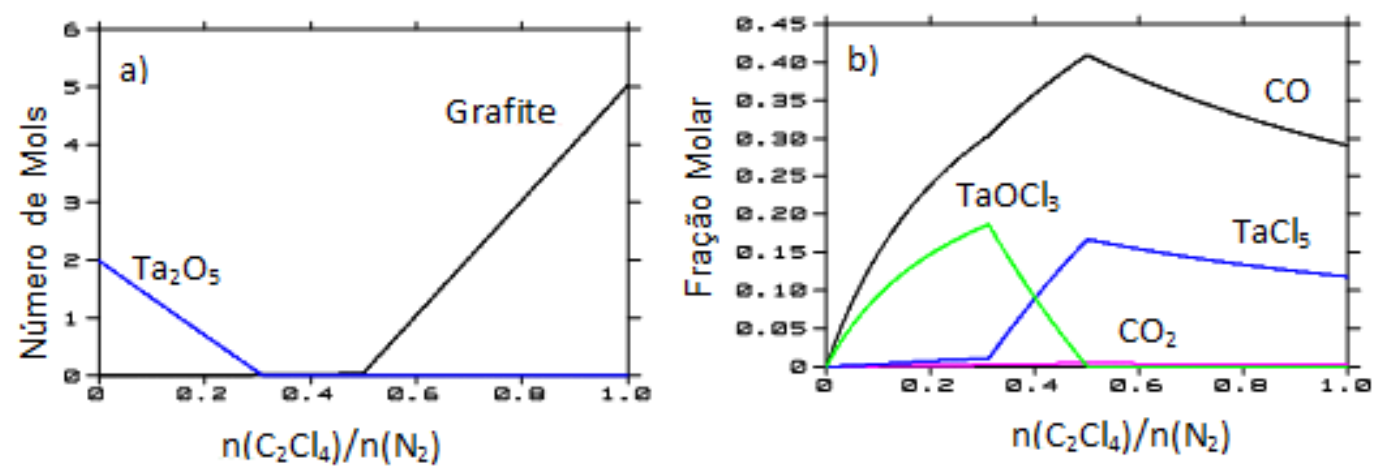

Figura 20. a) Número de mols de grafite como função da concentração de $\mathrm{C}_{2} \mathrm{Cl}_{4}$ a $900 \%$. b) Frações molares de $\mathrm{CO}, \mathrm{CO}_{2}, \mathrm{TaOCl}_{3}$ e $\mathrm{TaCl}_{5}$ na fase gasosa como função da concentração de $\mathrm{C}_{2} \mathrm{Cl}_{4}$ a $900^{\circ} \mathrm{C}$

Há a preferência para a formação de $\mathrm{CO}_{2}$ em temperaturas baixas (600 e $700^{\circ} \mathrm{C}$ ) e de $\mathrm{CO}$ em temperaturas mais elevadas (800 e $900^{\circ} \mathrm{C}$ ). Observa-se ainda, que em temperaturas baixas e atmosferas diluidas em $\mathrm{C}_{2} \mathrm{Cl}_{4}, \mathrm{TaCl}_{5} \mathrm{e}$ $\mathrm{TaOCl}_{3}$ se formam concomitantemente. No entanto, à medida que a atmosfera fica mais concentrada em $\mathrm{C}_{2} \mathrm{Cl}_{4}$, há um predomínio de $\mathrm{TaCl}_{5}$ na atmosfera reacional. Em temperaturas elevadas $0 \mathrm{TaCl}_{5}$ continua sendo 0 cloreto predominante em atmosferas concentradas no agente cloretante, porém em condições diluidas há preferência para a formação do $\mathrm{TaOCl}_{3}$. Esses resultados são consistentes com os dados contidos no diagrama da Figura (16), que já apontava para o fato dos cloretos $\mathrm{TaCl}_{5}$ e $\mathrm{TaOCl}_{3}$ serem os mais estáveis dentre todos os cloretos passíveis de serem formados. 


\subsubsection{2}

\section{Diagramas de especiação variando a pressão parcial do $\mathrm{C}_{2} \mathrm{Cl}_{4}$ na presença de oxigênio}

Foram realizadas simulações da cloração do $\mathrm{Ta}_{2} \mathrm{O}_{5}$ variando-se a pressão parcial do $\mathrm{C}_{2} \mathrm{Cl}_{4}$ adicionando-se 0,26 mols de oxigênio para cada 10 mols de nitrogênio, com o intuito de se explorar a possibilidade de inibição da formação de grafite. Os diagramas de especiação contidos nas Figuras (21) a (24) apresentam a quantidade de grafite e $\mathrm{Ta}_{2} \mathrm{O}_{5}$ presentes no equilíbrio na faixa de temperatura entre 600 e $900^{\circ} \mathrm{C}$, além das frações molares de $\mathrm{CO}, \mathrm{CO}_{2}, \mathrm{TaCl}_{5}$ e $\mathrm{TaOCl}_{3}$.

Observa-se um comportamento reacional muito similar ao detectado na ausência de $\mathrm{O}_{2}$ na atmosfera, com exceção da tendência de formação de grafite que deve ter início, na mesma temperatura, em pressões parciais de $\mathrm{C}_{2} \mathrm{Cl}_{4}$ maiores. Tal fato pode ser explicado tanto pela possível oxidação do grafite formado, quanto pela oxidação direta do $\mathrm{C}_{2} \mathrm{Cl}_{4}$ admitido, processos esses passíveis de ocorrer de forma simultânea.
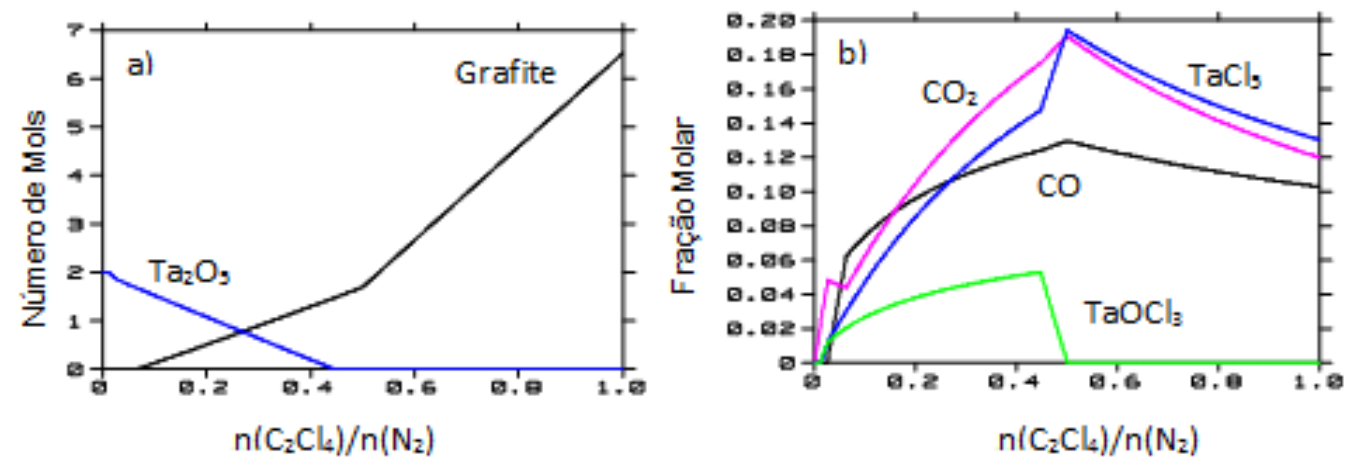

Figura 21. a) Número de mols de grafite como função da concentração de $\mathrm{C}_{2} \mathrm{Cl}_{4}$, com adição de 0,26 mols de oxigênio diluído a $600^{\circ} \mathrm{C}$. b) Frações molares de $\mathrm{CO}, \mathrm{CO}_{2}, \mathrm{TaOCl}_{3}$ e $\mathrm{TaCl}_{5}$ na fase gasosa como função da concentração de $\mathrm{C}_{2} \mathrm{Cl}_{4}$ a $600^{\circ} \mathrm{C}$.
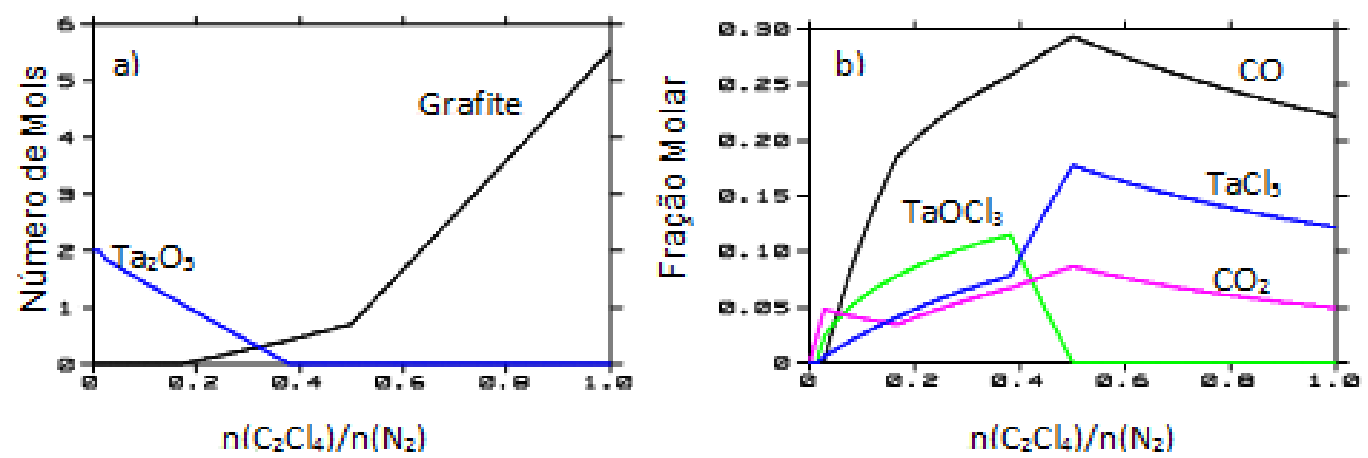

Figura 22. a) Número de mols de grafite como função da concentração de $\mathrm{C}_{2} \mathrm{Cl}_{4}$, com adição de 0,26 mols de oxigênio diluído, a $700^{\circ} \mathrm{C}$. b) Frações molares de $\mathrm{CO}, \mathrm{CO}_{2}, \mathrm{TaOCl}_{3}$ e $\mathrm{TaCl}_{5}$ na fase gasosa como função da concentração de $\mathrm{C}_{2} \mathrm{Cl}_{4}$ a $700^{\circ} \mathrm{C}$. 

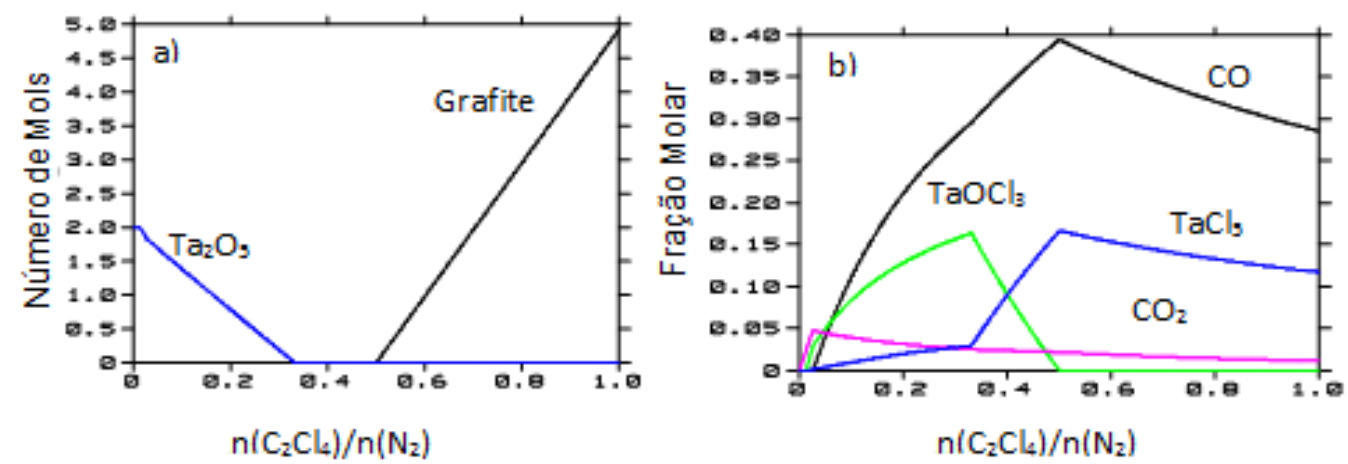

Figura 23. a) Número de mols de grafite como função da concentração de $\mathrm{C}_{2} \mathrm{Cl}_{4}$, com adição de 0,26 mols de oxigênio diluído, a $800^{\circ} \mathrm{C}$. b) Frações molares de $\mathrm{CO}, \mathrm{CO}_{2}, \mathrm{TaOCl}_{3}$ e $\mathrm{TaCl}_{5}$ na fase gasosa como função da concentração de $\mathrm{C}_{2} \mathrm{Cl}_{4}$ a $800^{\circ} \mathrm{C}$.
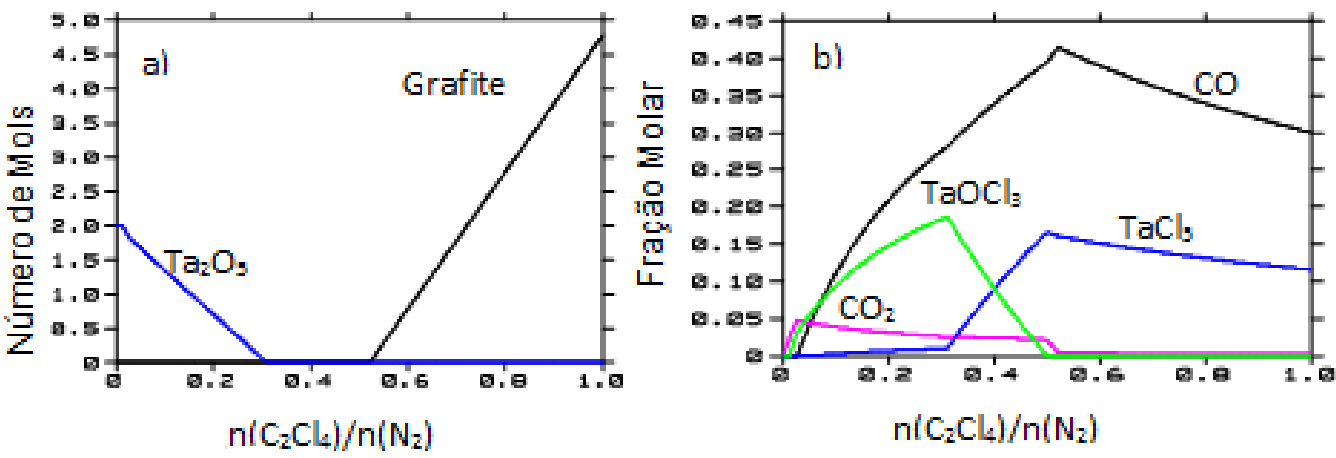

Figura 24. a) Número de mols de grafite como função da concentração de $\mathrm{C}_{2} \mathrm{Cl}_{4}$, com adição de 0,26 mols de oxigênio diluído, a $900^{\circ} \mathrm{C}$. b) Frações molares de $\mathrm{CO}, \mathrm{CO}_{2}, \mathrm{TaOCl}_{3}$ e $\mathrm{TaCl}_{5}$ na fase gasosa como função da concentração de $\mathrm{C}_{2} \mathrm{Cl}_{4}$ a $900^{\circ} \mathrm{C}$.

A partir do momento em que $0 \mathrm{Ta}_{2} \mathrm{O}_{5}$ é consumido por completo, observa-se a cloração do $\mathrm{TaOCl}_{3}$, produzindo-se $\mathrm{TaCl}_{5}$. O referido limite relacionado ao consumo de todo o pentóxido presente é função da temperatura (Figura 25). De fato, as reações de cloração de interesse (Eq. 20 e 21) devem apresentar uma maior força-motriz à medida que a temperatura do sistema se eleva, conforme indicam os dados presentes na Figura (16).

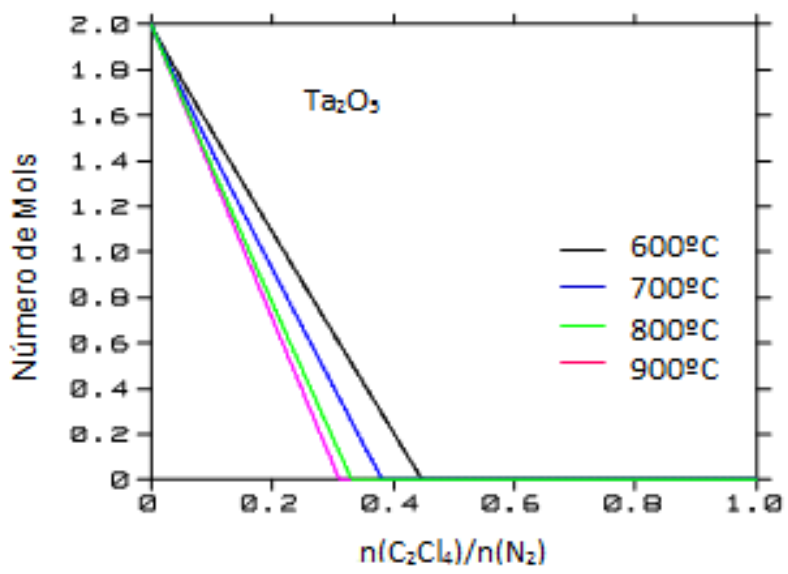

Figura 25. Número de mols de $\mathrm{Ta}_{2} \mathrm{O}_{5}$ no equilíbrio em diferentes temperaturas como função da concentração de $\mathrm{C}_{2} \mathrm{Cl}_{4}$. 
Desta forma, fica comprovado que experimentos realizados em um reator de leito fixo na presença de $\mathrm{O}_{2}$ diluído poderiam permitir o estudo da cloração excluindo-se a possibilidade de precipitação de grafite sobre a amostra de $\mathrm{Ta}_{2} \mathrm{O}_{5}$ a ser clorada, fato este capaz de interferir na cinética do processo reacional em estudo.

\section{2}

\section{Aspectos cinéticos}

A cinética de reações químicas busca caracterizar e analisar os fatores que envolvem a velocidade e o mecanismo com que uma reação química se processa.

Há dois sistemas na cinética que podem ser identificados: heterogêneo e homogêneo. No primeiro sistema, os reagentes formam duas ou mais fases e a reação esta limitada à interface. Já nos segundo sistema, as reações se processam de forma homogênea em todo o volume ocupado pela fase, seja ela, gasosa, líquida ou sólida(30,31).

No presente estudo, as reações de interesse são heterogêneas e ocorrem na interface entre uma fase sólida $\left(\mathrm{Ta}_{2} \mathrm{O}_{5}\right)$ e uma fase gasosa (mistura de $\mathrm{C}_{2} \mathrm{Cl}_{4}$ e $\mathrm{N}_{2}$ ). Por este motivo, será realizada uma apreciação dos principais fundamentos teóricos para o estudo cinético dessas reações e que darão suporte à avaliação dos dados experimentais obtidos no trabalho.

\subsection{1}

\section{Reações gás-sólido}

As reações do tipo gás-sólido são consideradas complexas, pois existem diversas variáveis envolvidas, sendo assim, é difícil determinar o seu verdadeiro mecanismo ${ }^{(32)}$. Efeitos físicos como a difusão e a transferência de calor, podem mascarar os resultados experimentais, fazendo com que as conclusões apresentadas sejam errôneas acerca do sistema em estudo. Entretanto, o conhecimento do efeito das variáveis que afetam a velocidade de reação é fundamental para que se avalie os resultados experimentais obtidos de forma correta.

As reações do tipo gás-sólido se caracterizam por envolver as etapas descritas a seguir(32): 
- Difusão dos reagentes (ou produtos) gasosos através da camada limite de gás, para a superfície do sólido (ou para a corrente gasosa).

- Difusão dos reagentes (ou produtos) gasosos através dos poros dos produtos sólidos ou do sólido parcialmente reagido.

- Adsorção dos reagentes gasosos na (ou dessorção dos produtos gasosos) superfície do sólido.

- Reação química entre os reagentes adsorvidos e o sólido.

Vale dizer que é importante estabelecer qual das etapas acima é a mais lenta, ou seja, a etapa controladora da cinética do processo. Neste contexto, três tipos de controle são descrito na literatura( ${ }^{(32)}$ :

- Controle difusional;

- Controle químico;

- Controle misto (difusional e químico).

Dependendo do tipo de controle, a natureza dos parâmetros operacionais relevantes pode variar de forma apreciável. Assim, por exemplo, em um sistema onde o controle é difusional, a porosidade é um dos parâmetros fundamentais. Entretanto, quando o controle é químico, a temperatura e a concentração são fatores que se destacam na cinética do processo.

O estudo cinético do ataque de uma partícula de reagente sólido por um gás tem por objetivo determinar sua velocidade de transformação, bem como parâmetros associados à lei cinética envolvida, energia de ativação e ordem globais do processo.

\subsection{2}

\section{Velocidade de reação}

Muitas variáveis podem influenciar a velocidade das reações químicas. Em sistemas homogêneos, ou seja, quando as reações ocorrem em uma única fase, há grande influência da temperatura, pressão e concentração; já em sistemas heterogêneos, ou seja, quando as reações estão presentes em pelo menos duas fases, a análise é mais complexa, pois os materiais podem se difundir de uma fase para outra, de tal maneira que a transferência de massa deve ser considerada. No primeiro caso, as concentrações dos reagentes e produtos são as mesmas em toda a extensão da fase, a menos que resistências 
difusionais se façam presentes; já no segundo caso, a reação esta limitada à área de contato entre as fases. Nos casos onde há valores intermediários de energia de ativação, estes são caracterizados por controle misto(33).

A taxa ou velocidade de reação $(r)$ é definida pelo consumo (ou geração) de reagente (ou produto) por unidade de área, volume ou massa, ao longo do tempo. Por exemplo, a velocidade de consumo (vi) de um reagente " $i$ " por unidade de volume pode ser representado pela equação ${ }^{(30)}$ :

$$
r=-v i=\frac{d n i}{(V \cdot d t)}
$$

Onde $V$ é o volume ocupado pela fase onde ocorre a reação e $d n i$ / $d t$ é a variação do número de mols de "i" com o tempo.

Como $n i / V$ é a concentração do reagente " $i$ ", e o volume do sistema reacional é assumido constante, obtém-se:

$$
r=-v i=\frac{d C i}{d t}=k \cdot[C i]^{n}
$$

Onde $n$ é a ordem de reação em relação ao reagente "i”, e $k$ a constante cinética ou velocidade específica de reação, calculada pela equação de Arhenius $^{(30)}$ (Equação 27).

$$
k=A \cdot \exp \left(\frac{-E}{R \cdot T}\right)
$$

Onde $A$ é o fator de frequência, definido pela teoria cinética dos gases, $T$ é a temperatura em kelvin, $R$ é a constante universal dos gases e $E$ é a energia de ativação necessária para que os reagentes alcancem estados intermediários instáveis (os chamados complexos ativados) formando, após a decomposição destes, os produtos finais. Usualmente, valores "altos" da energia de ativação, ou seja, $E>40 \mathrm{~kJ} / \mathrm{mol}$ indicam um controle químico para a reação, por outro lado, valores baixos de energia de ativação, ou seja, $E<30 \mathrm{~kJ} / \mathrm{mol}$ indicam um controle difusional(30).

Essa energia pode assumir valores aparentes ou intrínsecos. A determinação da energia de ativação intrínseca se deve às situações onde não há influência das variáveis físicas (efeitos de fenômenos de transporte) nas 
medições da velocidade global da reação, ou seja, onde os efeitos difusionais podem ser desprezados, por exemplo, em experimentos em que a cinética do processo se limita aos instantes iniciais, ou mediante estudos termogravimétricos. Por outro lado, se os efeitos de transporte influenciam ou são responsáveis pela velocidade global da reação, obtém-se uma energia de ativação aparente ${ }^{(30)}$, também denominada energia de ativação global.

\subsection{3}

\section{Modelos matemáticos}

Dentre os modelos das reações gás-sólido apresentados na literatura, optou-se pelo Modelo do Núcleo Não Reagido(35) e pelo Modelo Auto Catalítico ${ }^{(36)}$ para a avaliação cinética do presente estudo dado que, com base na avaliação termodinâmica prévia do sistema (tópico 4.1) espera-se somente a formação de cloretos e oxicloretos voláteis $\left(\mathrm{TaCl}_{5}, \mathrm{TaOCl}_{3}\right)$, resultando na redução progressiva do volume do óxido não reagido. Como há evidências de que o $\mathrm{Ta}_{2} \mathrm{O}_{5}$ pode apresentar atividade catalítica ${ }^{(36,37,38)}$, isso serviu de motivação para os testes com o modelo auto catalítico.

\subsubsection{1 \\ Modelo do núcleo não reagido}

O Modelo do Núcleo Não Reagido (Shrinking Core Model) ${ }^{(35)}$ supõe que a reação ocorre primeiro na superfície externa da partícula e se move em direção ao centro do sólido, deixando atrás de si uma camada de material totalmente convertido e sólido/líquido inerte (camada de cinza) em torno de um núcleo não reagido, ou produtos gasosos que difundem até o seio do meio reacional. Wen (1968) e Isihda et al. (1971), concluíram que este modelo constitui a melhor e mais simples representação para a maioria dos sistemas de reação gássolido ${ }^{(30)}$.

O presente trabalho, foca em reações com temperaturas variando de 800 a $950^{\circ} \mathrm{C}$ e a pressão parcial do gás reagente $\mathrm{C}_{2} \mathrm{Cl}_{4}$ a 0,0239 atm. Dentro destas condições, o sistema é do tipo gás-sólido, sendo $\mathrm{TaCl}_{5}$ e $\mathrm{TaOCl}_{3}$ os principais produtos. Uma vez que os produtos estão em estado gasoso e nenhuma cinza é formada na superfície das partículas sólidas durante a reação, a partícula $\mathrm{Ta}_{2} \mathrm{O}_{5}$ diminui à medida que a reação ocorre, até ela desaparecer por completo(35). 
O fenômeno da difusão bem como a reação na superfície sólido nãoporoso são estipulados como estágios que ocorrem na seguinte sucessão, sendo estes ilustrados pelo desenho na Figura (27).

Passo 1. Difusão do reagente gasoso $\mathrm{C}_{2} \mathrm{Cl}_{4}$, a partir da corrente de fluxo gasoso através da camada limite para a superfície da partícula sólida $\mathrm{Ta}_{2} \mathrm{O}_{5}$, através da camada limite.

Passo 2. Reação do reagente gasoso $\mathrm{C}_{2} \mathrm{Cl}_{4}$ com a partícula sólida $\mathrm{Ta}_{2} \mathrm{O}_{5}$ na superfície sólida.

Passo 3. Difusão dos produtos reacionais $\left(\mathrm{TaCl}_{5}, \mathrm{TaOCl}_{3}\right.$, $\mathrm{CO}$ e $\left.\mathrm{CO}_{2}\right)$, a partir da superfície do sólido através da camada limite de volta para a corrente gasosa.

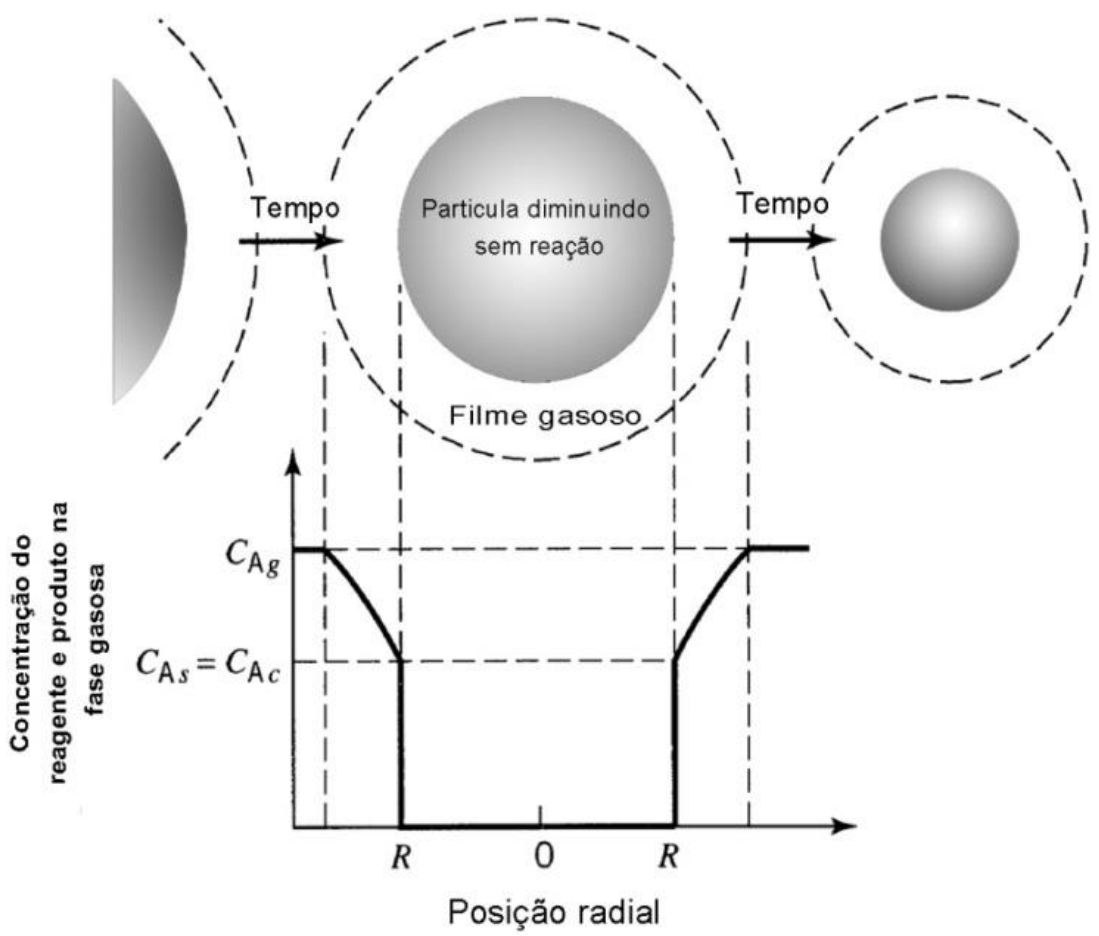

Figura 26. Representação das conversões dos reagentes e produtos no caso de uma partícula que diminui de tamanho(30).

Supondo que a reação é irreversível e que a partícula de $\mathrm{Ta}_{2} \mathrm{O}_{5}$ tem geometria esférica, a velocidade da reação pode ser calculada como segue ${ }^{(35)}$ :

$$
-\frac{1}{4 \pi r^{2}} \cdot \frac{d N_{T a_{2} O_{5}}}{d t}=k_{S} p_{C_{2} C l_{4}}^{n}
$$

Onde $\mathrm{N}_{\mathrm{Ta}_{2} \mathrm{O}_{5}}$ é o número de mols de $\mathrm{Ta}_{2} \mathrm{O}_{5}, k_{s}$ é a constante de velocidade para a reação de superfície e $p_{C_{2} C l_{4}}$ é a pressão parcial do agente cloretante, e $n$ a ordem global do processo. 
Dada a inexistência de cloretos condensados, a redução do número de mols de $\mathrm{Ta}_{2} \mathrm{O}_{5}$ presente na partícula pode ser correlacionada diretamente com a redução do seu tamanho (raio $-r$ ).

$$
\begin{aligned}
& -d N_{T a_{2} O_{5}}=-d\left(\rho_{T a_{2} O_{5}} V\right)=-\rho_{T a_{2} O_{5}} d V=-\rho_{T a_{2} O_{5}} d\left(\frac{4}{3} \pi r^{3}\right) \\
& =-4 \pi \rho_{T a_{2} O_{5}} r^{2} d r
\end{aligned}
$$

Onde $\rho_{\mathrm{Ta}_{2} \mathrm{O}_{5}}$ é a densidade do $\mathrm{Ta}_{2} \mathrm{O}_{5}$ e $\mathrm{V}$ o volume da partícula esférica. Substituindo a equação (29) na (28), tem-se a taxa em termos do raio do núcleo não reagido ${ }^{(35)}$ :

$$
-\rho_{T a_{2} O_{5}} \frac{d r}{d t}=k_{S} p_{C_{2} C l_{4}}^{n}
$$

Após a integração da equação (30), temos:

$$
\begin{aligned}
& -\rho_{T a_{2} O_{5}} \cdot \int_{r o}^{r} d r=k_{S} p_{C_{2} C l_{4}} \int_{0}^{t} d t . \\
& \mathrm{t}=\frac{\rho_{T a_{2} O_{5}}}{k_{s} p_{C_{2} C l_{4}}} \cdot\left(r_{0}-r\right) \ldots \ldots \ldots \ldots \ldots \ldots \ldots \ldots \ldots
\end{aligned}
$$

Onde $r_{0}$ representa o raio inicial da partícula e t o tempo. O tempo necessário para o completo desaparecimento da partícula $(\tau)$ pode ser calculado quando $r=0$.

$$
\tau=\frac{\rho_{T a_{2} O_{5}} r_{0}}{k_{s} p_{C_{2} C l_{4}}}
$$

A conversão de $\mathrm{Ta}_{2} \mathrm{O}_{5}$ em um instante qualquer pode ser correlacionada com o raio da esfera no mesmo instante ${ }^{(35)}$.

$$
1-X_{T a_{2} O_{5}}=\frac{\text { Vnão reagiu }}{\text { Vtotal }}=\frac{4 / 3 \pi r^{3}}{4 / 3 \pi r_{0}{ }^{3}}=\left(\frac{r}{r_{0}}\right)^{3}
$$

Combinando-se as equações (32), (33) e (34), pode-se obter a seguinte correlação entre o tempo de reação, raio da partícula e conversão de $\mathrm{Ta}_{2} \mathrm{O}_{5}$.

$$
\frac{t}{\tau}=1-\frac{r}{r_{0}}=1-\left(1-X_{T a_{2} O_{5}}\right)^{1 / 3}
$$


Conclui-se, portanto, que a equação final para o ajuste dos dados de conversão experimentais segundo o modelo do núcleo não reagido pode ser expressa por:

$$
1-\left(1-X_{T a_{2} O_{5}}\right)^{\frac{1}{3}}=k t
$$

Onde, $X_{\mathrm{Ta}_{2} \mathrm{O}_{5}}$ é a conversão do $\mathrm{Ta}_{2} \mathrm{O}_{5}, k=\frac{k s \cdot p_{C_{2} C l_{4}}{ }^{n}}{\left(r_{0} \cdot \rho_{T a_{2} O_{5}}\right)}$ e to tempo.

A Equação (36) pode ser generalizada considerando-se partículas com geometrias diversas (Eq. 37). Onde $f$ representa uma constante associada diretamente com a geometria das partículas, sendo igual a um para placas, dois para cilindros e três, partículas esféricas ${ }^{(35)}$.

$$
1-(1-X)^{1 / f}=k t
$$

\subsubsection{2}

\section{Modelo auto catalítico}

Dados da literatura recente indicam a possibilidade do $\mathrm{Ta}_{2} \mathrm{O}_{5}$ atuar como catalisador, por exemplo, na produção de $\mathrm{H}_{2}$ a partir da água ${ }^{(36,37,38)}$.

No intuito de se testar a possível ação auto catalítica do $\mathrm{Ta}_{2} \mathrm{O}_{5}$ no que se refere à cloração deste com $\mathrm{C}_{2} \mathrm{Cl}_{4}$, optou-se pelo emprego do modelo representado pela Equação (38), cujo desempenho foi comparado com o modelo do núcleo não reagido.

$$
\ln \left(\frac{\alpha}{(1-\alpha)}\right)=k \cdot t+c
$$

Onde a é a conversão do $\mathrm{Ta}_{2} \mathrm{O}_{5}$ e $k$ a constante cinética da reação e $c$ um parâmetro constante ajustável.

\subsection{4}

\section{Efeito da temperatura}

O estudo do efeito da temperatura é usualmente avaliado através da Equação de Arrhenius (Equação 27). Extraindo-se o logaritmo neperiano de ambos os lados da Equação (27), tem-se:

$$
\ln k=\ln \mathrm{A}-\left(\frac{E}{R}\right) \cdot\left(\frac{1}{T}\right)
$$


Para a obtenção do valor de $E$, faz-se um gráfico $\ln k$ versus $1 / T$ (Eq. 40). A partir da inclinação (coeficiente angular) da curva calcula-se a energia de ativação global do processo.

$$
E=-R \frac{d \ln k}{d t}
$$

Energias de ativação consideradas baixas (abaixo de $30 \mathrm{~kJ} / \mathrm{mol}$ ) sugerem um controle difusional, da mesma forma que valores "elevados" (acima de $40 \mathrm{~kJ} / \mathrm{mol}$ ) sugerem um controle químico ${ }^{(30)}$. Além disso, a sinterização das partículas cristalinas presentes também deve ser considerara, principalmente se a cloração for desenvolvida em temperaturas elevadas $\left(T>600^{\circ} \mathrm{C}\right)$. $\mathrm{O}$ aumento do tamanho de partícula tende a reduzir a área de contato com a fase gasosa, podendo ser motivo para restrições difusionais. Desta forma, no estudo cinético de reações gás-sólido, é recomendável que se realize uma apreciação tanto no início quanto no final do processo, que, por motivos de tempo, não foram contempladas na metodologia experimental adotada, porém sugeridas na sessão sobre trabalhos futuros (tópico 8). No entanto, a natureza dos modelos cinéticos utilizados tem como premissa um controle químico, ou seja, assume a inexistência de efeitos difusionais mensuráveis nas condições experimentais investigadas. 


\section{5 \\ METODOLOGIA EXPERIMENTAL}

\section{1 \\ Descrição dos equipamentos e linha}

Foi utilizada uma balança analítica digital, com precisão de $0,1 \mathrm{mg}$, para a medição da massa das amostras inicias e para o acompanhamento da perda de peso durante a realização de cada experimento.

Para introduzir as amostras no forno, foi utilizada uma barquete de alumina, a qual é posicionada no centro de um forno tubular de quartzo.

O reator consiste num tubo de quartzo inserido em um forno com controle digital de temperatura. O tubo do reator é aberto nas extremidades para entrada e saída dos gases, sendo o mesmo acoplado a um sistema de neutralização de gases, constituído por dois kitasatos dispostos em série, cada um contendo uma solução aquosa $0,5 \mathrm{M}$ de $\mathrm{KOH}$.

A linha de nitrogênio é composta por um cilindro de nitrogênio comercial com aproximadamente 99,6\% de pureza, gás este utilizado tanto para o arraste do $\mathrm{C}_{2} \mathrm{Cl}_{4}$ para o interior da câmara reacional, quanto para a remoção do mesmo durante a purga.

Utilizou-se um banho de água destilada (ultratermostatizado) que tem a função de aquecer o vaso portador do $\mathrm{C}_{2} \mathrm{Cl}_{4}$. Assim é possível estabilizar a temperatura do $\mathrm{C}_{2} \mathrm{Cl}_{4}$ com elevada precisão, dado que esta, da mesma forma que a vazão de $\mathrm{N}_{2}$ empregada, estabelece a pressão parcial de $\mathrm{C}_{2} \mathrm{Cl}_{4}$ na entrada do reator. A temperatura interna do reservatório é monitorada de forma digital e permite um controle de -10 a $100^{\circ} \mathrm{C}$ com variação da ordem de $1^{\circ}$.

$\mathrm{O}$ arraste do $\mathrm{C}_{2} \mathrm{Cl}_{4}$ vaporizado para o interior do forno tubular de quartzo, pré-aquecido na temperatura de interesse, é feito através do fluxo de nitrogênio, sendo este borbulhado no vaso que contem $\mathrm{C}_{2} \mathrm{Cl}_{4}$ líquido. 


\section{2 \\ Materiais e reagentes utilizados}

O pentóxido de tântalo com pureza de $99,5 \%$ foi a matéria-prima utilizada nos experimentos do presente trabalho, tendo sido adquirido junto à empresa ALDRICH Chemistry.

O tetracloroetileno utilizado foi comprado junto à empresa VETEC QUÍMICA FINA LTDA. As principais propriedades físicas do $\mathrm{C}_{2} \mathrm{Cl}_{4}$, de acordo com as informações contidas no rótulo do produto, são apresentadas na tabela abaixo:

Tabela 3. Propriedades físicas do $\mathrm{C}_{2} \mathrm{Cl}_{4}$.

\begin{tabular}{ll}
\hline Descrição & Valor \\
\hline CAS & $127-18-4$ \\
Peso Molecular $(\mathrm{g} / \mathrm{mol})$ & 165,83 \\
Ponto de fusão $\left({ }^{\circ} \mathrm{C}\right)$ & $-22,3$ \\
Ponto de ebulição $\left({ }^{\circ} \mathrm{C}\right)$ & 121,4 \\
Densidade $(\mathrm{Kg} / \mathrm{L})$ & 1,62 \\
Pressão de vapor $\left(\mathrm{mmHg}\right.$, a $\left.25^{\circ} \mathrm{C}\right)$ & 18,9 \\
Solubilidade $\left(\mathrm{Mg} / \mathrm{L}\right.$, a $\left.25^{\circ} \mathrm{C}\right)$ & 150 \\
Densidade relativa do vapor a $25^{\circ} \mathrm{C}$ e 1 atm & 1,12 \\
\hline
\end{tabular}

O hidróxido de potássio utilizado na confecção das soluções aquosas para a absorção dos cloretos produzidos apresenta pureza grau analítico (>96\%) e foi adquirido junto à empresa VETEC QUÍMICA Fina LTDA.

O nitrogênio gasoso utilizado para o arraste do tetracloroetileno apresenta natureza comercial, pureza superior a $99 \%$, e foi adquirido junto à empresa LINDE.

\section{3}

\section{Ensaios de cloração}

Como mencionado anteriormente, a pesagem das amostras foi realizada por uma balança analítica digital e a barquete de alumina foi utilizada como um porta-amostra no interior do reator, sendo inerte nas condições de temperatura e pressão dos ensaios. Foi escolhido o peso inicial de aproximadamente $0,3 \mathrm{~g}$ de pentóxido de tântalo. 
Inicialmente é realizada a pesagem da barquete vazia e, depois de anotado o seu peso, a balança novamente é zerada e então é pesada a barquete contendo o pentóxido de tântalo com a massa desejada, no presente caso, $0,3 \mathrm{~g}$.

Inicialmente o banho ultratermostatizado no qual se encontra o recipiente contendo $\mathrm{C}_{2} \mathrm{Cl}_{4}$ líquido e o forno devem ser aquecidos na temperatura desejada para a realização dos ensaios. O controle da temperatura do banho é importante, pois a partir dela, juntamente com a vazão de nitrogênio, gás inerte responsável pelo arraste do $\mathrm{C}_{2} \mathrm{Cl}_{4}$ para $\mathrm{o}$ interior da câmara reacional, determina-se a pressão parcial deste na atmosfera reacional.

Após a estabilização das temperaturas desejadas (25ํㅡ - temperatura do banho e $800^{\circ}$ a $950^{\circ} \mathrm{C}$ - temperatura do forno), a barquete de alumina contendo $0,3 \mathrm{~g}$ de $\mathrm{Ta}_{2} \mathrm{O}_{5}$ é inserida dentro do forno. O sistema primeiramente é purgado apenas com $\mathrm{N}_{2}(0,00615 \mathrm{~L} / \mathrm{s})$ por 20 minutos para garantir que a massa de óxido devido atinja um valor constante, dando-se então início ao ensaio de cloração. Durante o ensaio, o nitrogênio é borbulhado no vaso de $\mathrm{C}_{2} \mathrm{Cl}_{4}$, sendo a mistura arrastada para o interior do forno com uma vazão total de $6,62 \mathrm{~mL} / \mathrm{s}$. As medições de perda de massa foram realizadas em intervalos de 5 minutos, onde o material remanescente na barquete é pesado sequencialmente, para um tempo total de ensaio de quarenta minutos.

A conversão de $\mathrm{Ta}_{2} \mathrm{O}_{5}$ pode ser calculada pela massa antes e após a cloração, de acordo com a Eq (40), onde $m$ representa a massa de óxido em um instante qualquer, e $m_{0}$ a massa incial da amostra, determinada após o arraste com $\mathrm{N}_{2}$. No presente caso, a referida equação pode ser utilizada, pois se pressupõe, com base nos cálculos termodinâmicos realizados para o sistema reacional de interesse, espera-se haver formação apenas de cloretos voláteis $\left(\mathrm{TaOCl}_{3}\right.$ e/ou $\left.\mathrm{TaCl}_{5}\right)$, ou seja, sem acúmulo de massa sobre a barquete devido a produtos reacionais condensados. Assim, toda variação da massa pode ser diretamente relacionada com a cloração do óxido de interesse.

$$
X=100 .\left(\frac{m_{0}-m}{m_{o}}\right)
$$

Os dados cinéticos obtidos foram em seguida ajustados de acordo com o modelo do núcleo não reagido (Eq.37) e modelo auto catalítico (Eq. 38). Ao todo foram realizadas três medidas em cada tempo reacional, calculando-se a média. Tais valores médios foram em seguida ajustados de acordo com os modelos mencionados. 


\subsection{1}

\section{Perda de massa de tetracloroetileno}

Conforme sugerido pela avaliação da termodinâmica da decomposição térmica do $\mathrm{C}_{2} \mathrm{Cl}_{4}$ (Tópico 4.1.1), o controle da pressão parcial deste é fundamental no intuito de se reduzir a chance de formação de grafite, que poderia depositar sobre a amostra e interferir na análise cinética a ser executada. Desta forma a volatilização do $\mathrm{C}_{2} \mathrm{Cl}_{4}$ líquido foi investigada, através da variação da massa do vaso como função do tempo. A temperatura do banho foi fixada em $25^{\circ} \mathrm{C}$, sendo a massa total do vaso (vidro e $\mathrm{C}_{2} \mathrm{Cl}_{4}$ ) aferida em intervalos de 5 minutos, para um intervalo de tempo total de 40 minutos. Ao todo, três medidas independentes foram realizadas. Os ensaios foram conduzidos para fixando-se a vazão de arraste de $\mathrm{N}_{2}$ em $0,00615 \mathrm{~L} / \mathrm{s}$, sendo a pressão parcial de $\mathrm{C}_{2} \mathrm{Cl}_{4}$ calculada através da equação (42), que assume como premissa que $\mathrm{N}_{2}$ e $\mathrm{C}_{2} \mathrm{Cl}_{4}$ formam uma mistura de gases ideais.

$$
\mathrm{P}_{\mathrm{C}_{2} \mathrm{Cl}_{4}}=\frac{\mathrm{k}_{\mathrm{m}} \mathrm{RT}}{\dot{\mathrm{v}}_{\mathrm{t}} \mathrm{M}_{\mathrm{C}_{2} \mathrm{Cl}}}
$$

Onde, $\dot{v}_{t}, k_{m}$, e $M_{C_{2} C l_{4}}$, representam, respectivamente, a vazão total da mistura $\left(\mathrm{N}_{2}+\mathrm{C}_{2} \mathrm{Cl}_{4}\right)$, a taxa de perda de massa $(\mathrm{g} / \mathrm{min})$ e a massa molecular do $\mathrm{C}_{2} \mathrm{Cl}_{4}$.

\subsection{2 \\ Caracterização}

As amostras dos óxidos passaram por procedimentos de caracterização, antes e após o processo de cloração, sendo esta realizada via difração de RaiosX (DRX) e Microscopia Eletrônica de Varredura (MEV).

Os experimentos de DRX foram conduzidos em um difratômetro Bruker, com tubo de $\mathrm{Cu}(40 \mathrm{kV})$, monocromador de Si e detector de área modelo Lynxeye visando à determinação do tamanho médio de cristalito, bem como as frações mássicas das fases presentes. Para a quantificação das fases foi utilizado o software TOPAS-pro versão 4.2, que utiliza o método de Rietveld com parâmetros fundamentais.

As análises de MEV foram realizadas em um equipamento Jeol JSM $6510 \mathrm{LV}$, que trabalha com tensão máxima de aceleração de $30 \mathrm{kV}$, elétrons 
retroespalhados, e possui detector de Raios-X característico (EDS) Thermoscientific Noran 7 (estado sólido).

Foram analisadas amostras do $\mathrm{Ta}_{2} \mathrm{O}_{5}$ no início e final do processo, e também amostras do sólido depositado na saída do forno com o objetivo de se analisar de forma preliminar a morfologia das partículas, bem como sua composição química elementar.

\subsection{3}

\section{Avaliação do tântalo dissolvido}

Determinação da concentração de tântalo dissolvido nas soluções de $\mathrm{KOH}$ após a execução de todos os testes foi levada a efeito via espectrometria de emissão atômica (ICPAES). A identificação do tântalo nas soluções serviria de mais um indício à formação de cloretos voláteis $\left(\mathrm{TaCl}_{5}, \mathrm{TaOCl}_{3}\right)$ durante 0 processo. 


\section{6 \\ RESULTADOS E DISCUSSÃO}

\section{1}

\section{Caracterização do $\mathrm{Ta}_{2} \mathrm{O}_{5}$}

Visando uma adequada apreciação do processo de cloração de interesse para o presente trabalho, amostras de $\mathrm{Ta}_{2} \mathrm{O}_{5}$ tanto antes (avaliação da pureza), quanto após o processo de cloração (possível presença de grafite e ou cloretos condensados) foram caracterizadas via DRX e MEV.

\subsection{1}

\section{Caracterização antes da cloração}

Através da análise do difratograma característico da amostra de $\mathrm{Ta}_{2} \mathrm{O}_{5}$ antes da cloração (Figura 27), foi possível identificar, após análise de Rietveld, a existência exclusiva de $\mathrm{Ta}_{2} \mathrm{O}_{5}$ em duas formas alotrópicas, Tantite 011 e Tantite 120.

Mediante o cálculo do tamanho médio de cristalito (Tabela 4), espera-se a presença de partículas nanoestruturadas, o que também pode ser evidenciado a partir do expressivo "alargamento" dos picos presentes no difratograma característico da amostra. A qualidade do ajuste do referido difratograma pode ser atestada, tanto pela reduzida diferença entre o sinal calculado e o experimental (curva cinza na parte inferior da figura), quanto pela proximidade entre os parâmetros de rede ajustados e os valores da literatura para as duas estruturas cristalinas consideradas.

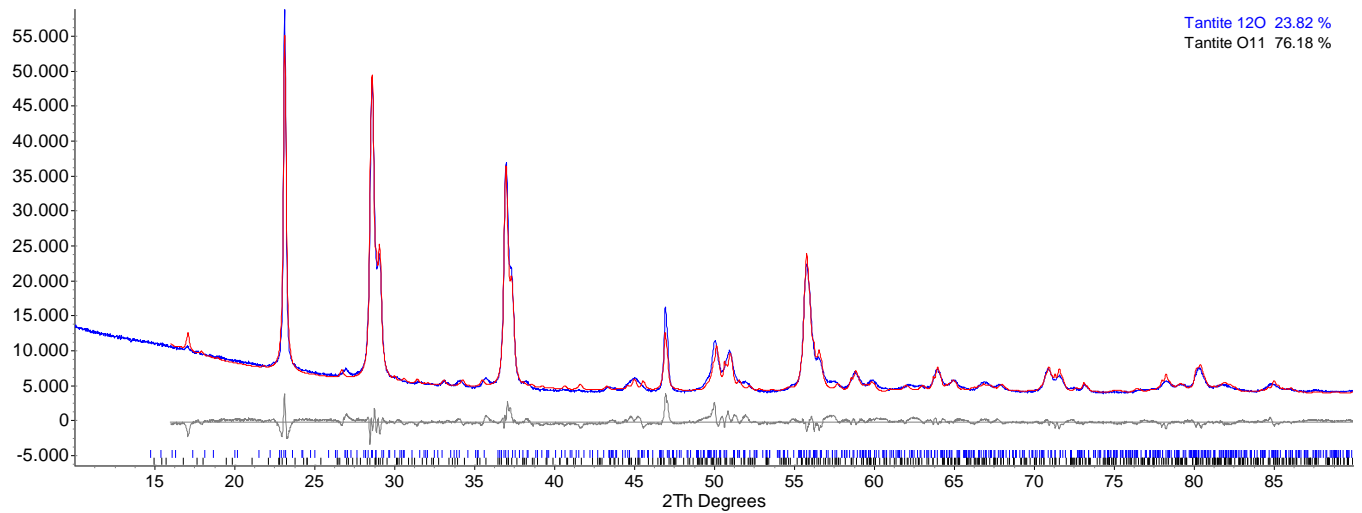

Figura 27. $\mathrm{DRX}$ da amostra de $\mathrm{Ta}_{2} \mathrm{O}_{5}$ como recebida.

Tabela 4. Parâmetros de rede e tamanho médio de cristalito. 


\begin{tabular}{lll}
\hline Estrutura & Tantite 011 & Tantite 120 \\
\hline Tamanho médio de cristalito & $51.6 \mathrm{~nm}$ & $83 \mathrm{~nm}$ \\
\hline Parâmetros de rede ajustados & & \\
a $(\AA)$ & 6.207 & 44.0504 \\
b $(\AA)$ & 40.227 & 3.8947 \\
c $(\AA)$ & 3.893 & 6.2483 \\
\hline Parâmetros de rede (ICSD) & & \\
a $(\AA)$ & 6.198 & 43.997 \\
b $(\AA)$ & 40.29 & 3.894 \\
c $(\AA)$ & 3.888 & 6.209 \\
\hline
\end{tabular}

Os dados de MEV/EDS para o material inicial (Figuras 28 a 30) sugerem a presença de um material constituído exclusivamente de tântalo e oxigênio. Adicionalmente, os teores de $\mathrm{O}$ e Ta determinados via EDS estão consistentes com os valores teóricos esperados para os referidos elementos $(\mathrm{O}-28,57 \%$ e Ta $-71,43 \%$ ) e o material fosse constituído exclusivamente por cristais de $\mathrm{Ta}_{2} \mathrm{O}_{5}$.

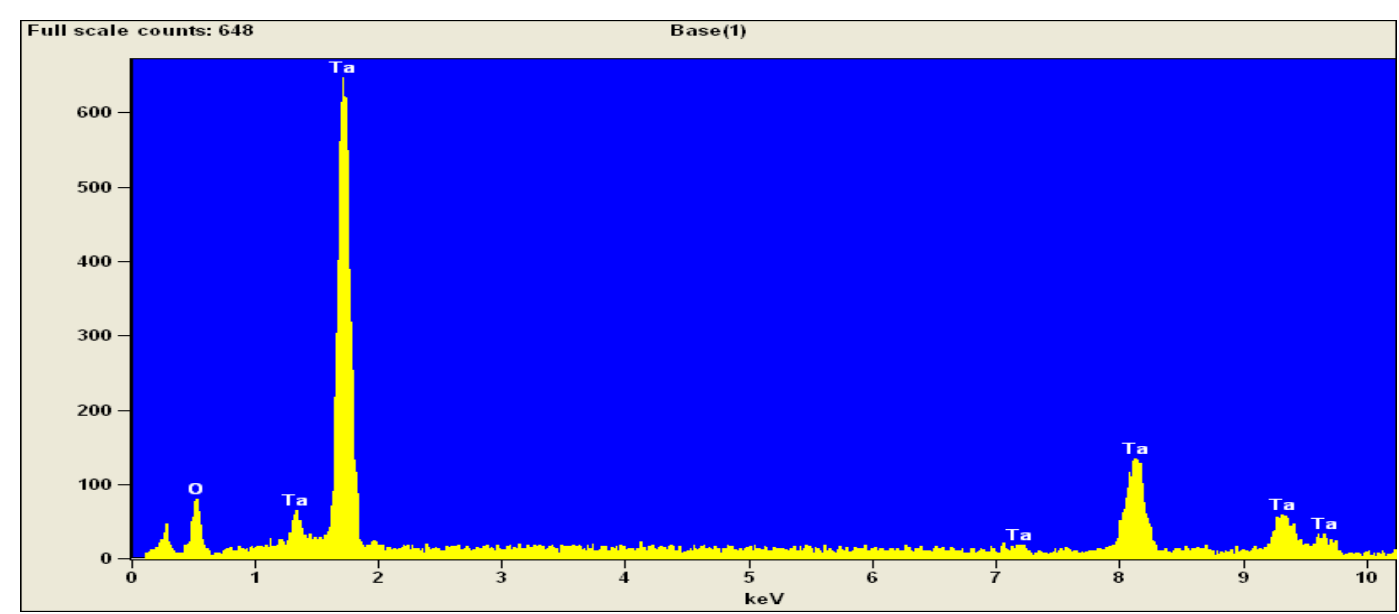

Figura 28. Espectro de EDS da amostra de $\mathrm{Ta}_{2} \mathrm{O}_{5}$ como recebida.

Tabela 5. Resultado da análise de EDS da amostra de $\mathrm{Ta}_{2} \mathrm{O}_{5}$ como recebida.

\begin{tabular}{ccccc}
$\begin{array}{c}\text { Element } \\
\text { Line }\end{array}$ & Weight \% & $\begin{array}{c}\text { Weight \% } \\
\text { Error }\end{array}$ & Atom \% & $\begin{array}{c}\text { Atom \% } \\
\text { Error }\end{array}$ \\
\hline O K & 16.22 & $+/-0.85$ & 68.65 & $+/-3.61$ \\
Ta L & 83.78 & $+/-3.99$ & 31.35 & $+/-1.49$ \\
Total & 100.00 & & 100.00 & \\
\hline
\end{tabular}



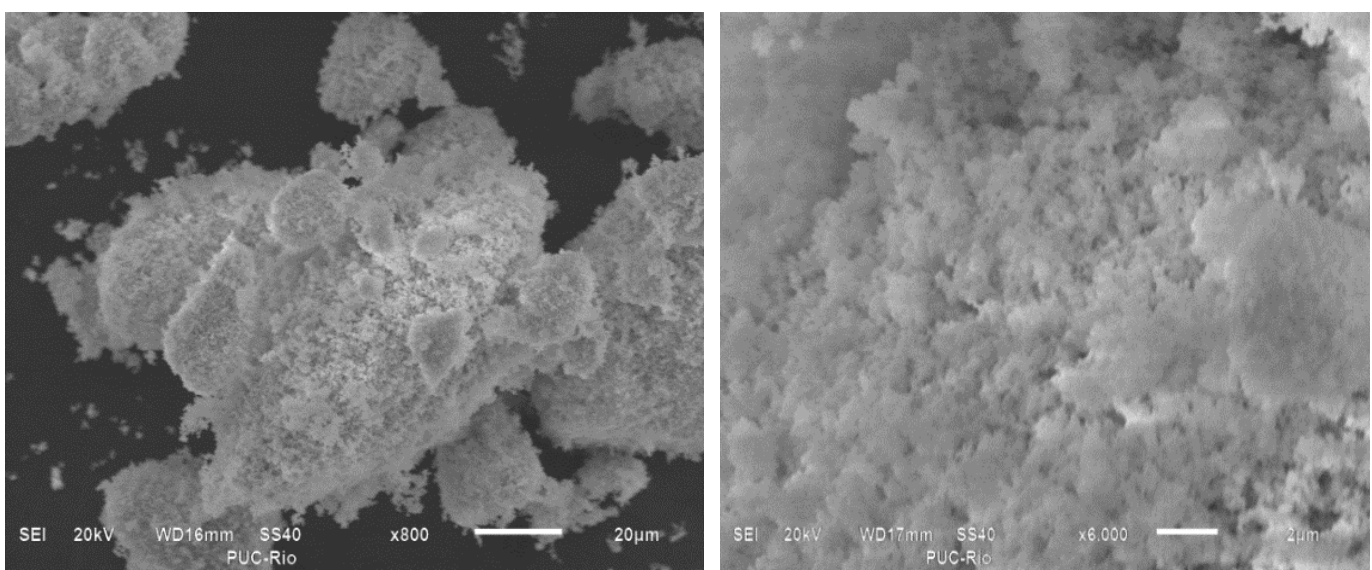

Figura 29. Imagens (MEV) da amostra de $\mathrm{Ta}_{2} \mathrm{O}_{5}$ como recebida.

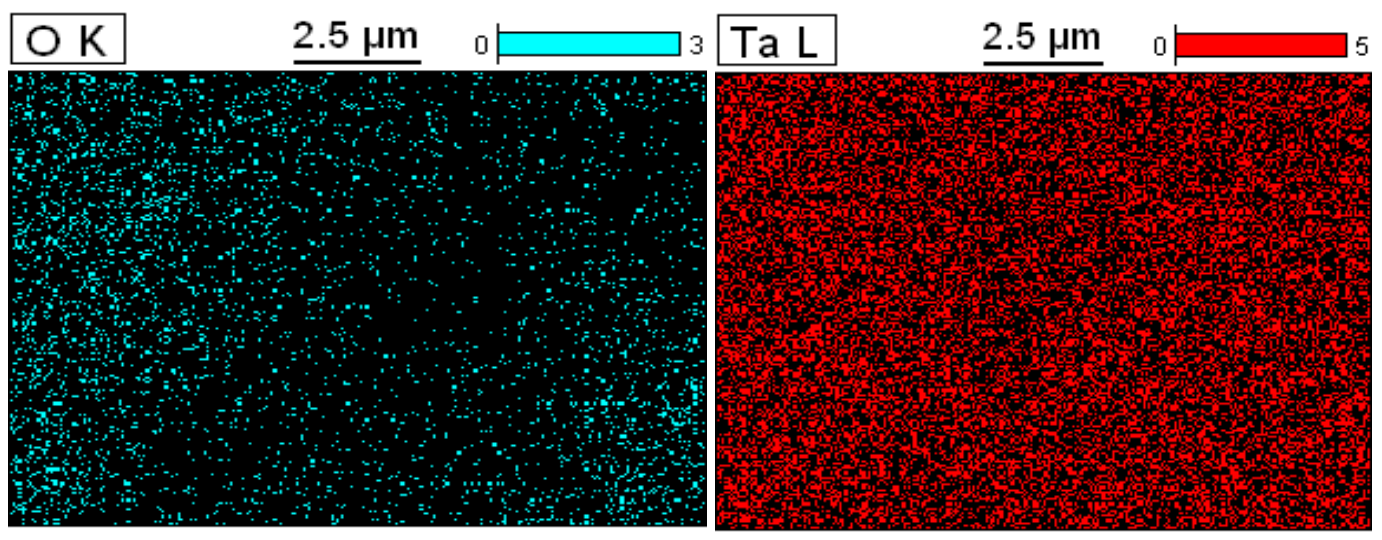

Figura 30. Mapa de EDS da amostra de $\mathrm{Ta}_{2} \mathrm{O}_{5}$ como recebida.

\section{1 .2}

\section{Caracterização pós-cloração}

A análise do material após a cloração realizada a $850^{\circ} \mathrm{C}$ e $950^{\circ} \mathrm{C}$ via $\mathrm{DRX}$ (Figuras 31 e 32) evidenciou uma natureza muito similar ao material antes do processo, comprovando a ausência de deposição de grafite sobre a amostra, bem como a formação de cloretos condensados. Em ambas as amostras, as mesmas fases identificadas inicialmente (Tantite 011 e Tantite 120) se encontram presentes. Quanto ao tamanho médio de cristalito, observa-se que há um progressivo aumento com a temperatura, sugerindo um crescimento dos cristais (sinterização). Tal fato também pode ser deduzido a partir do "estreitamento" dos picos presentes. Em ambos os casos, a qualidade do ajuste pode ser atestada tanto pela proximidade dos parâmetros de rede teóricos e determinados após o ajuste (Tabela 6), quanto pela reduzida diferença entre o sinal calculado e o sinal experimental. 


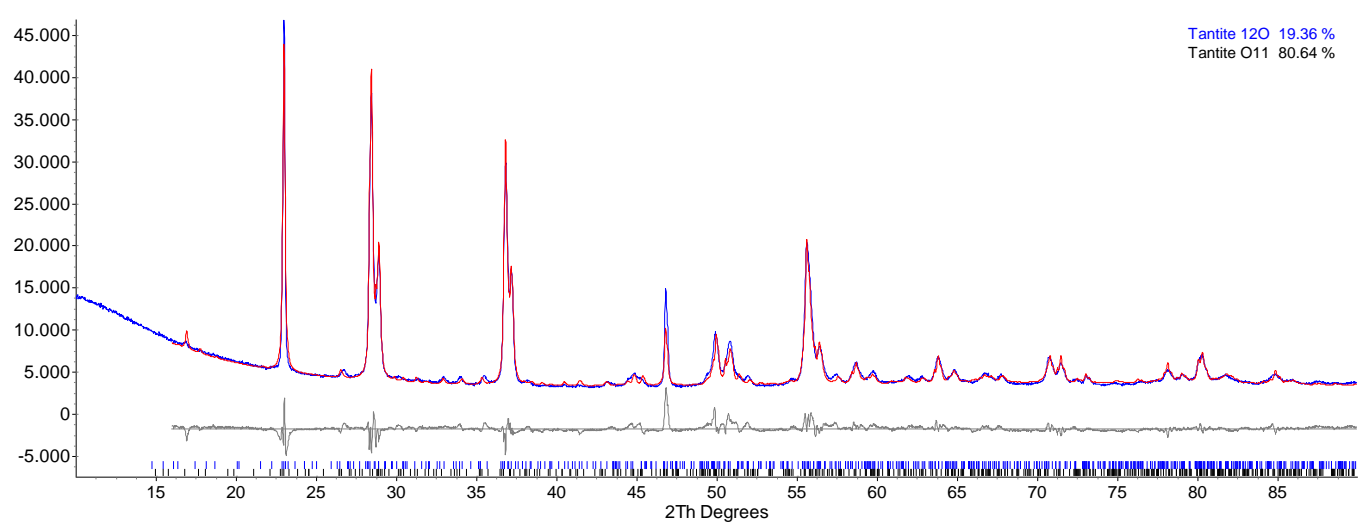

Figura 31. DRX da amostra de $\mathrm{Ta}_{2} \mathrm{O}_{5}$ após a cloração com $\mathrm{C}_{2} \mathrm{Cl}_{4}$ a $800^{\circ} \mathrm{C}$.

Tabela 6. Parâmetros de rede e tamanhos médios de cristalito.

\begin{tabular}{lll}
\hline Tamanho médio de cristalito & $72.5 \mathrm{~nm}$ & $124.9 \mathrm{~nm}$ \\
\hline Nome da Fase & Tantite 011 & Tantite 120 \\
\hline
\end{tabular}

\section{Parâmetros de rede ajustados}

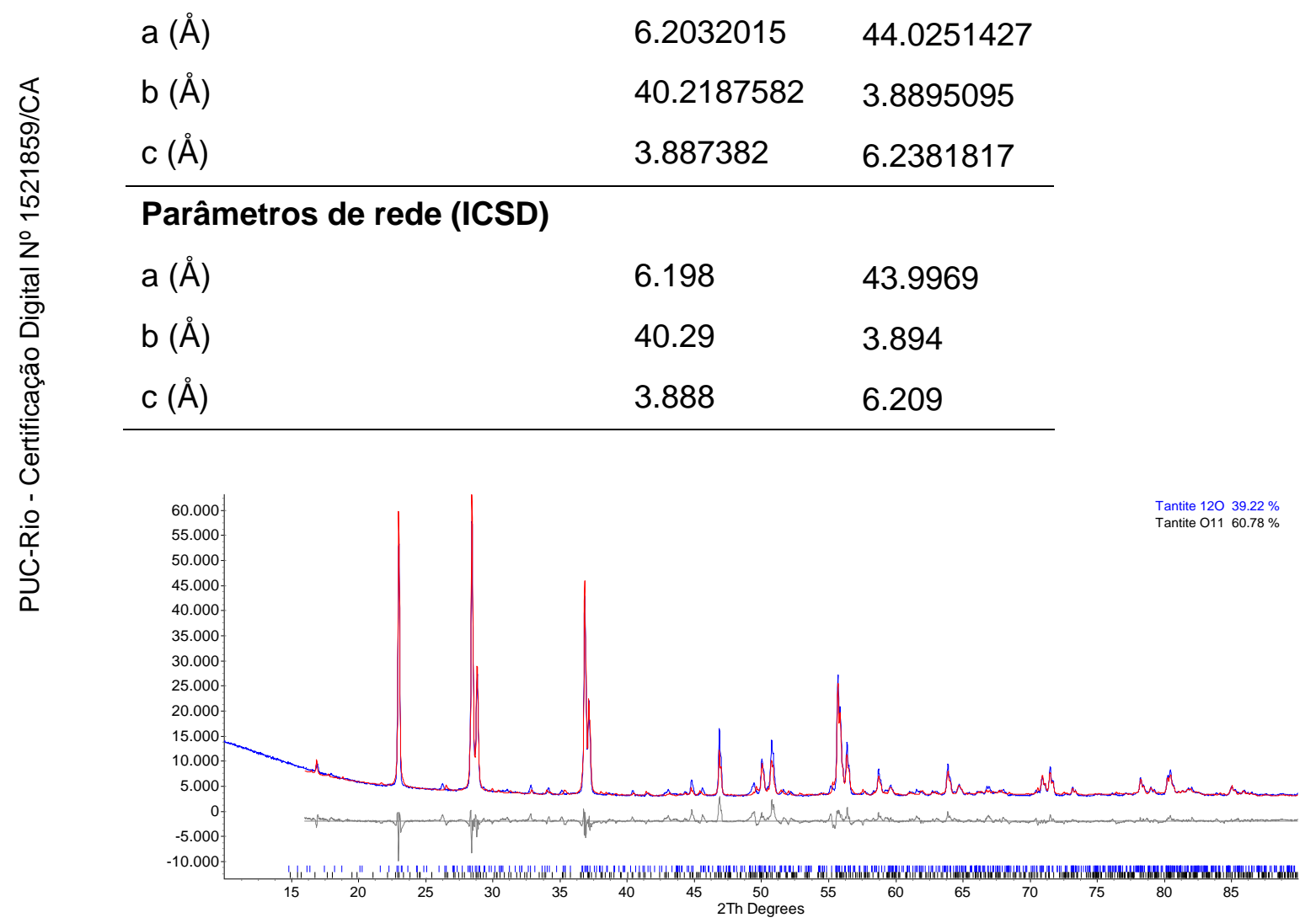

Figura 32. DR-X da amostra de $\mathrm{Ta}_{2} \mathrm{O}_{5}$ após a cloração com $\mathrm{C}_{2} \mathrm{Cl}_{4}$ a $950^{\circ} \mathrm{C}$. 
Tabela 7. Parâmetros de rede e tamanhos médios de cristalito.

\begin{tabular}{lll}
\hline Tamanho médio de cristalito & $144.1 \mathrm{~nm}$ & $146.5 \mathrm{~nm}$ \\
\hline Nome da Fase & Tantite 011 & Tantite 120 \\
\hline Parâmetros de rede ajustados & & \\
a $(\AA)$ & 43.8394716 & 6.2098081 \\
b $(\AA)$ & 3.8832995 & 40.1366602 \\
c $(\AA)$ & 6.2162182 & 3.8813454 \\
\hline Parâmetros de rede (ICSD) & & \\
a $(\AA)$ & 43.9969 & 6.198 \\
b $(\AA)$ & 3.894 & 40.29 \\
c $(\AA)$ & 6.209 & 3.888 \\
\hline
\end{tabular}

Os dados de MEV/EDS para os materiais após a cloração (Figuras 33 a 41) sugerem que as amostras se mostraram constituídas exclusivamente por tântalo e oxigênio, comprovando que não houve deposição de grafite, ou mesmo à presença de cloretos condensados (ausência $\mathrm{Cl}$ ). Adicionalmente, as imagens de MEV sugerem um possível aumento no tamanho dos cristais, em concordância com os efeitos já comentados associados à análise via $\mathrm{DRX}$.

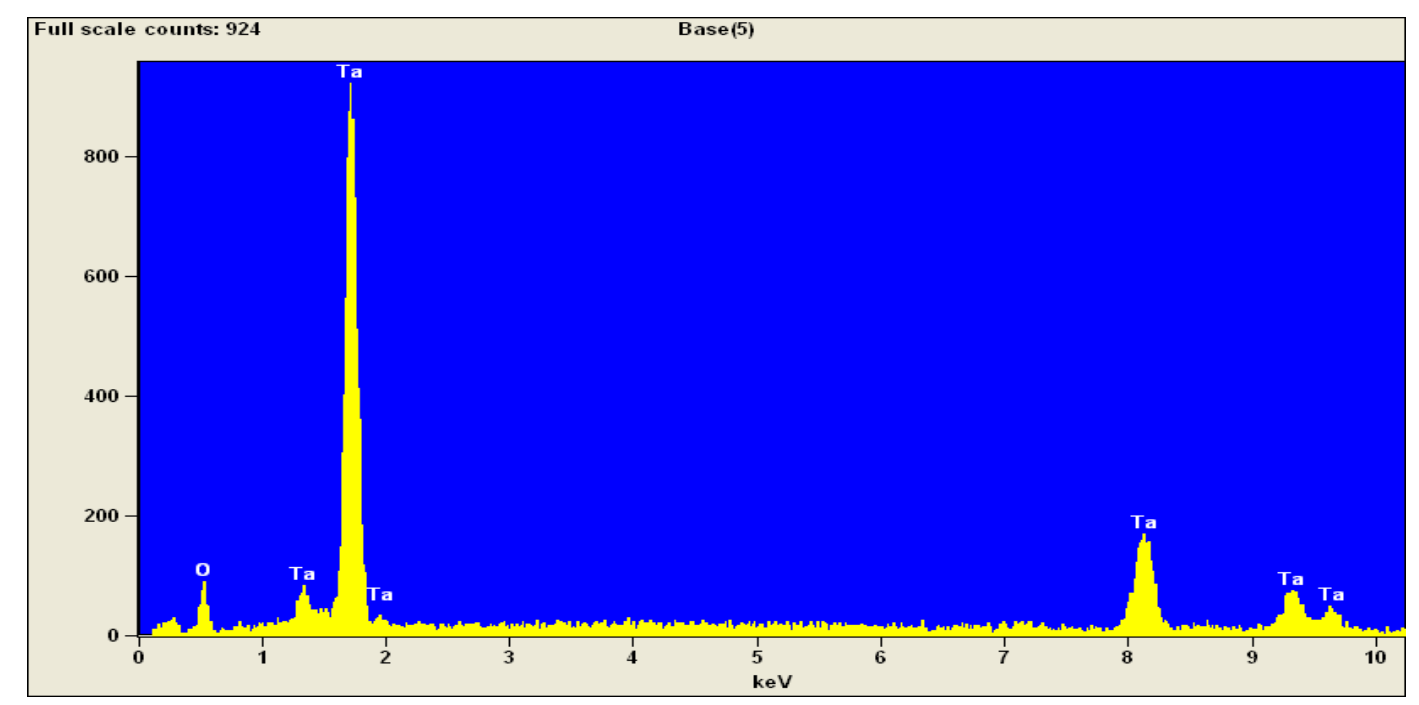

Figura 33. Espectro de EDS da amostra de $\mathrm{Ta}_{2} \mathrm{O}_{5}$ após a cloração com $\mathrm{C}_{2} \mathrm{Cl}_{4}$ a $800^{\circ} \mathrm{C}$. 
Tabela 8. Resultado da análise de EDS da amostra de $\mathrm{Ta}_{2} \mathrm{O}_{5}$ após a cloração com $\mathrm{C}_{2} \mathrm{Cl}_{4}$ a $800^{\circ} \mathrm{C}$.

\begin{tabular}{ccccc}
$\begin{array}{c}\text { Element } \\
\text { Line }\end{array}$ & Weight \% & $\begin{array}{c}\text { Weight \% } \\
\text { Error }\end{array}$ & Atom \% & $\begin{array}{c}\text { Atom \% } \\
\text { Error }\end{array}$ \\
\hline O K & 13.04 & $+/-0.71$ & 62.92 & $+/-3.43$ \\
Ta $L$ & 86.96 & $+/-3.61$ & 37.08 & $+/-1.54$ \\
Total & 100.00 & & 100.00 & \\
\hline
\end{tabular}
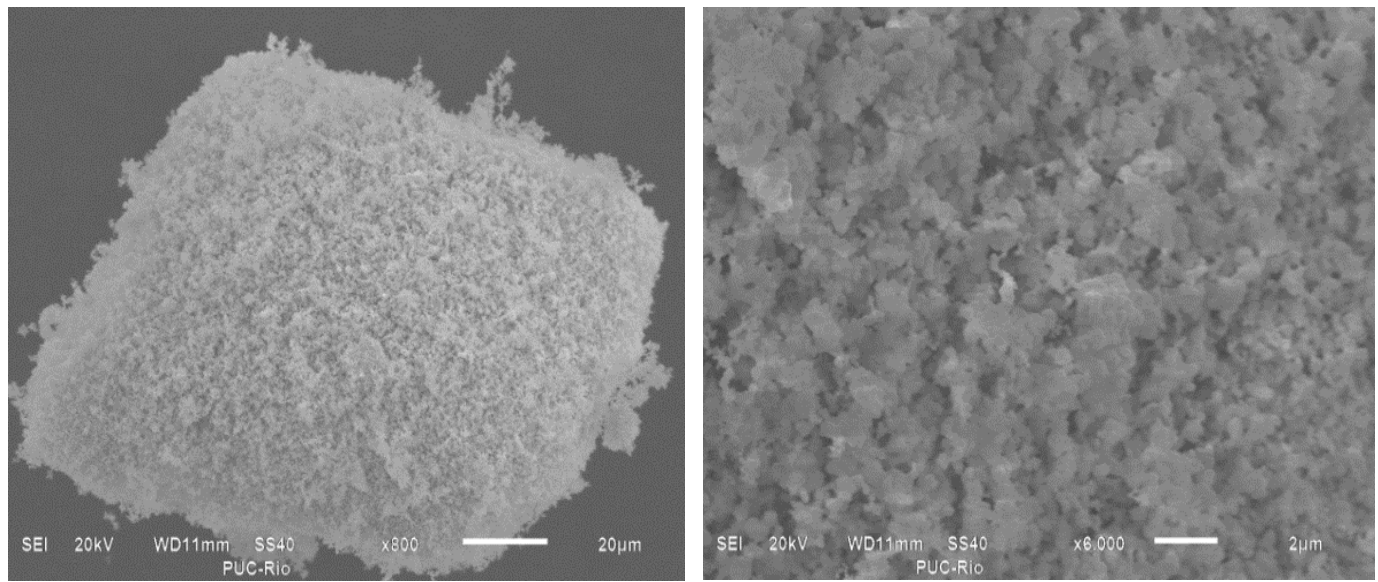

Figura 34. Imagens (MEV) da amostra de $\mathrm{Ta}_{2} \mathrm{O}_{5}$ após a cloração com $\mathrm{C}_{2} \mathrm{Cl}_{4}$ a $800^{\circ} \mathrm{C}$.
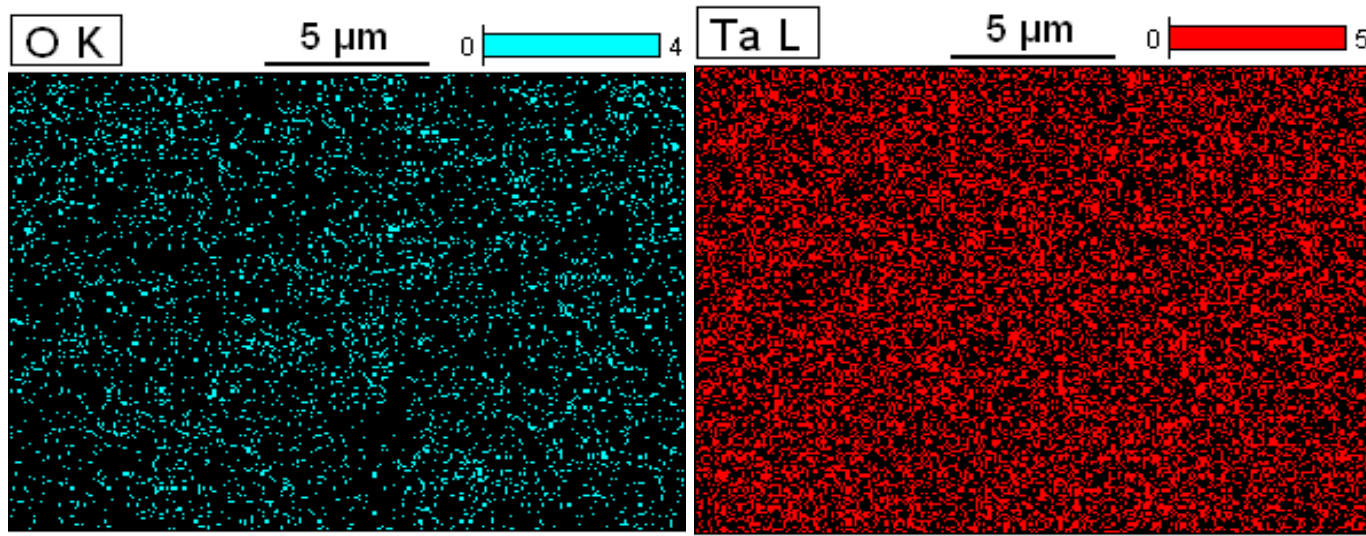

Figura 35. Mapa de EDS da amostra de $\mathrm{Ta}_{2} \mathrm{O}_{5}$ após a cloração $\operatorname{com~}_{2} \mathrm{Cl}_{4}$ a $800^{\circ} \mathrm{C}$.

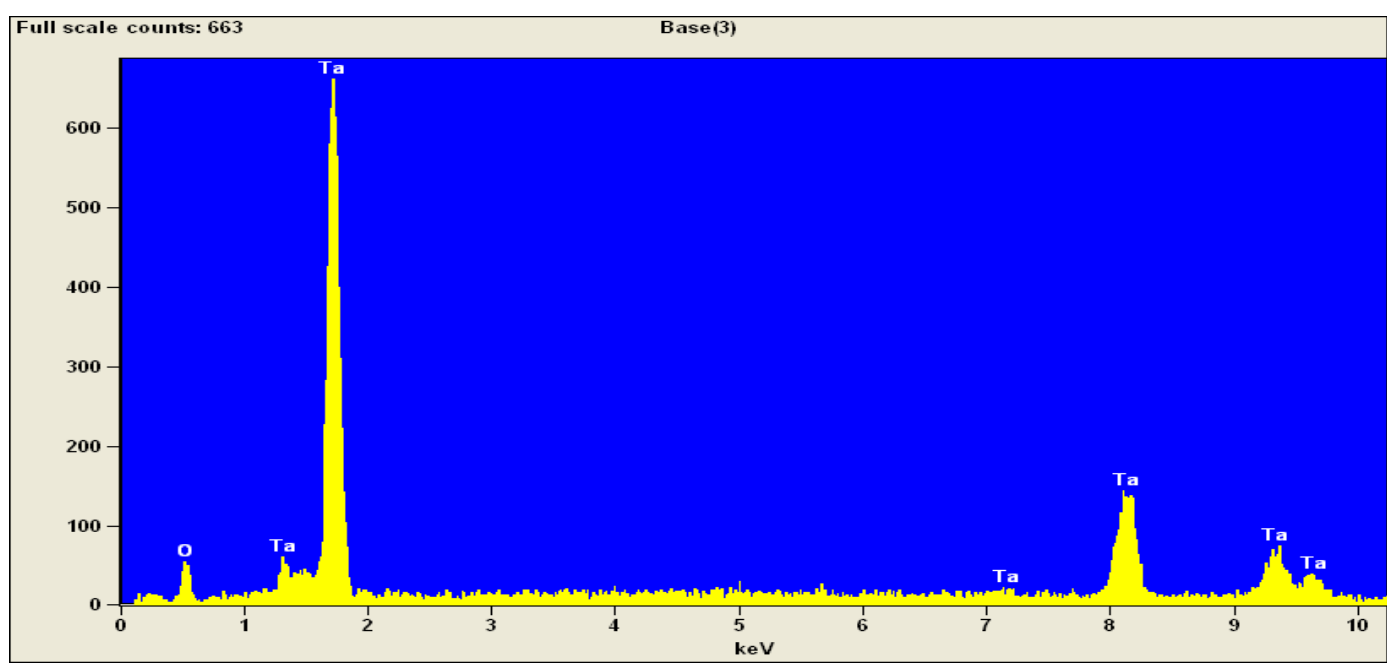

Figura 36. Espectro de EDS da amostra de $\mathrm{Ta}_{2} \mathrm{O}_{5}$ após a cloração com $\mathrm{C}_{2} \mathrm{Cl}_{4}$ a $950^{\circ} \mathrm{C}$. 
Tabela 9. Resultado da análise de EDS da amostra de $\mathrm{Ta}_{2} \mathrm{O}_{5}$ após a cloração $\operatorname{com} \mathrm{C}_{2} \mathrm{Cl}_{4}$ a $950^{\circ} \mathrm{C}$.

\begin{tabular}{ccccc}
$\begin{array}{c}\text { Element } \\
\text { Line }\end{array}$ & Weight \% & $\begin{array}{c}\text { Weight \% } \\
\text { Error }\end{array}$ & Atom \% & $\begin{array}{c}\text { Atom \% } \\
\text { Error }\end{array}$ \\
\hline O K & 11.52 & $+/-0.73$ & 59.55 & $+/-3.76$ \\
Ta L & 88.48 & $+/-4.13$ & 40.45 & $+/-1.89$ \\
Total & 100.00 & & 100.00 & \\
\hline
\end{tabular}

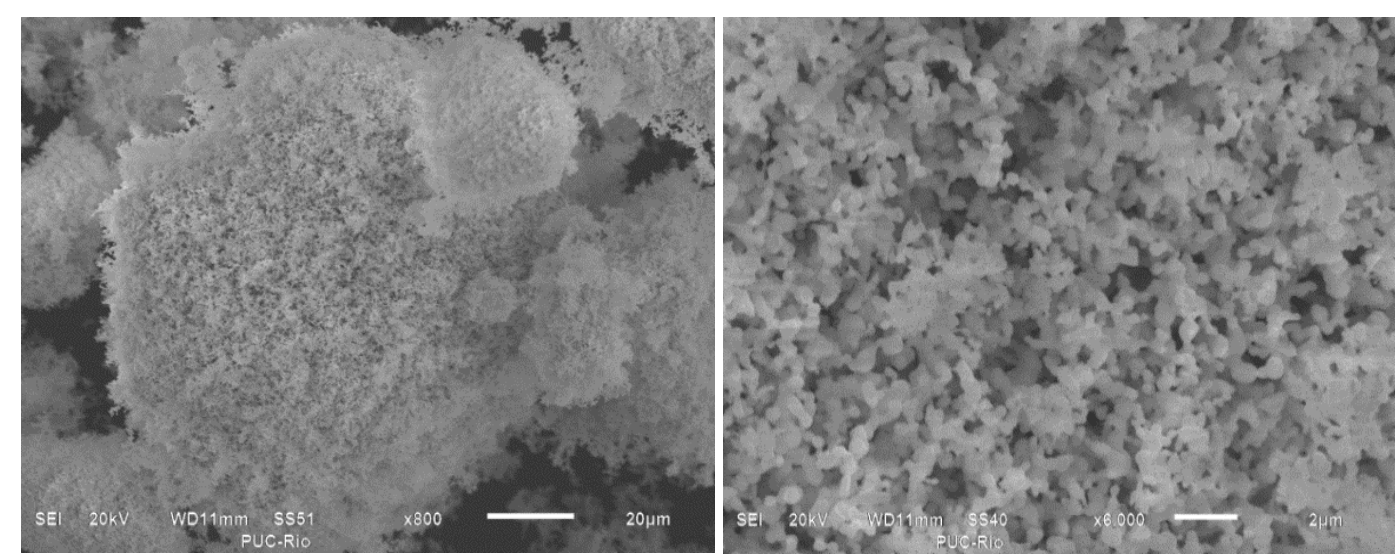

Figura 37. Imagens (MEV) da amostra de $\mathrm{Ta}_{2} \mathrm{O}_{5}$ após a cloração com $\mathrm{C}_{2} \mathrm{Cl}_{4}$ a $950^{\circ} \mathrm{C}$.

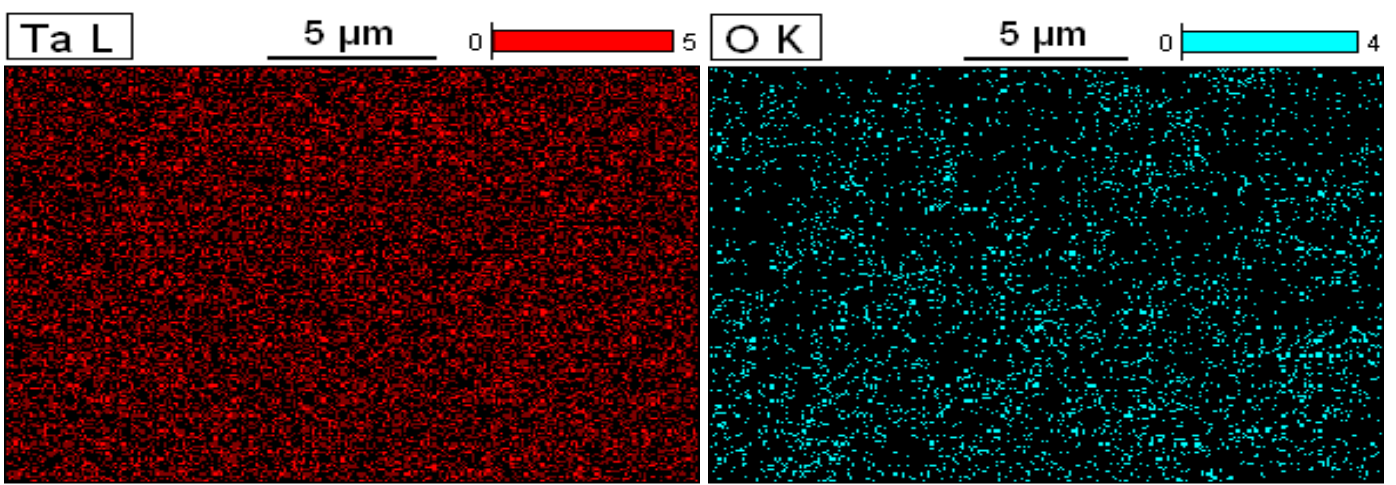

Figura 38. Mapa de EDS da amostra de $\mathrm{Ta}_{2} \mathrm{O}_{5}$ após a cloração com $\mathrm{C}_{2} \mathrm{Cl}_{4}$ a $950^{\circ} \mathrm{C}$.

No que diz respeito ao precipitado depositado na saída do tubo do reator, observou-se a presença de cloro, tântalo, carbono e oxigênio (Figura 39). A presença de $\mathrm{Cl}$ e $\mathrm{O}$ é condizente com a formação de $\mathrm{TaOCl}_{3}$, um dos possíveis produtos da reação, quando esta é conduzida com $0 \mathrm{C}_{2} \mathrm{Cl}_{4}$ diluído, de acordo com a avaliação termodinâmica apresentada no Tópico (4.1.3). A presença de carbono no mesmo material serve de comprovação para a decomposição térmica (total ou parcial) do $\mathrm{C}_{2} \mathrm{Cl}_{4}$ no trajeto entre a entrada do tubo do reator e a amostra, já apontada anteriormente como uma reação possível durante a apreciação termodinâmica do sistema reacional em questão. 


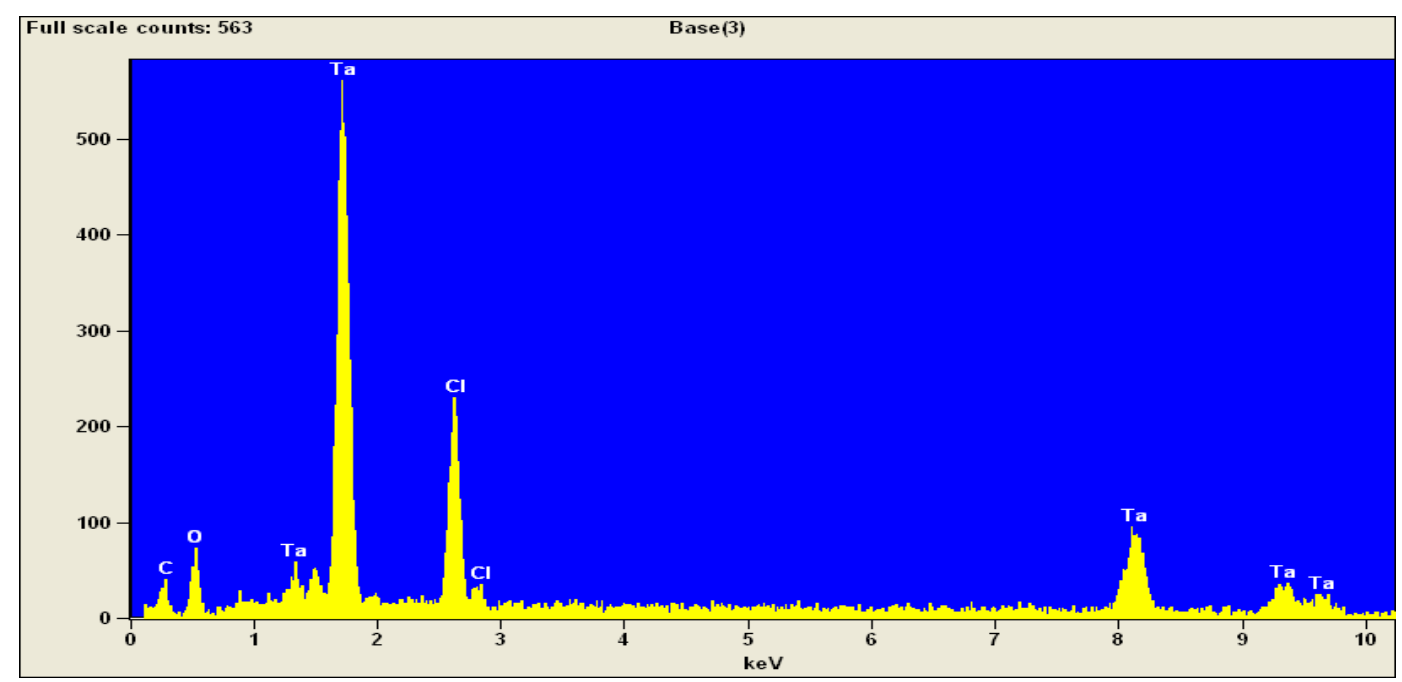

Figura 39. Espectro de EDS amostra do precipitado coletado da parede do tubo após os experimentos de cloração.

Tabela 10. Resultado da análise de EDS da amostra de precipitado coletado da parede do tubo após os experimentos de cloração.

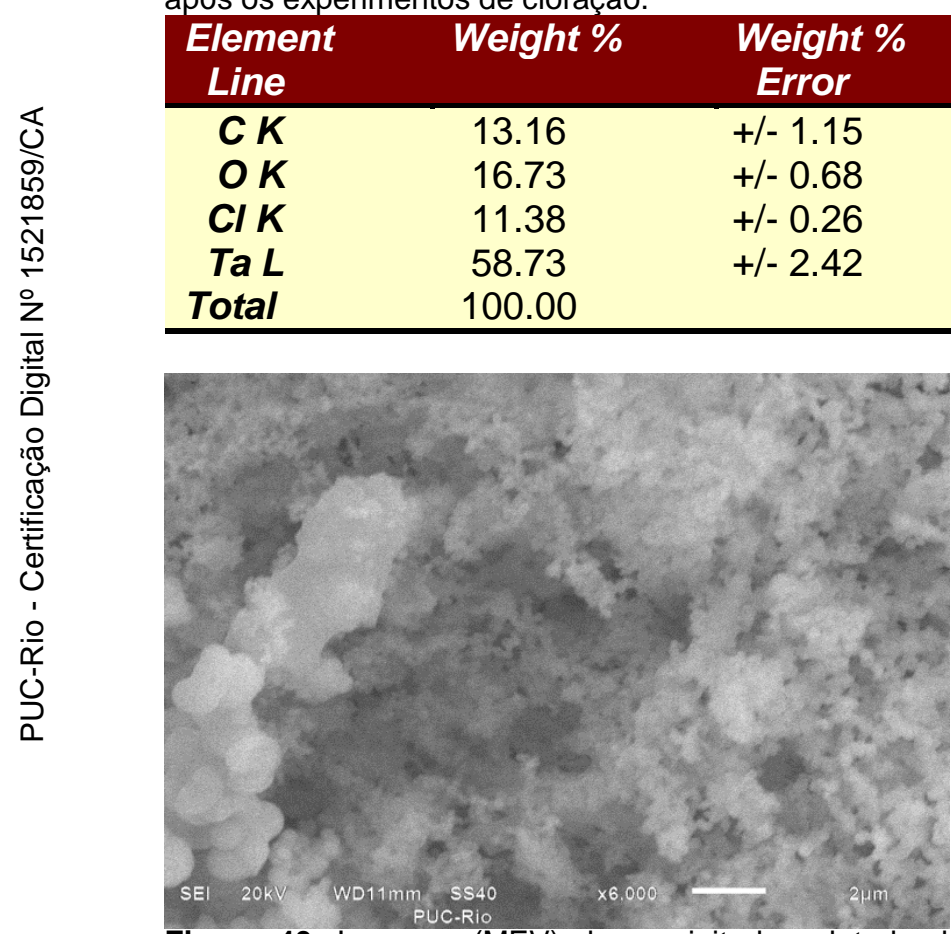

Figura 40. Imagens (MEV) do precipitado coletado da parede do tubo após experimentos de cloração. 

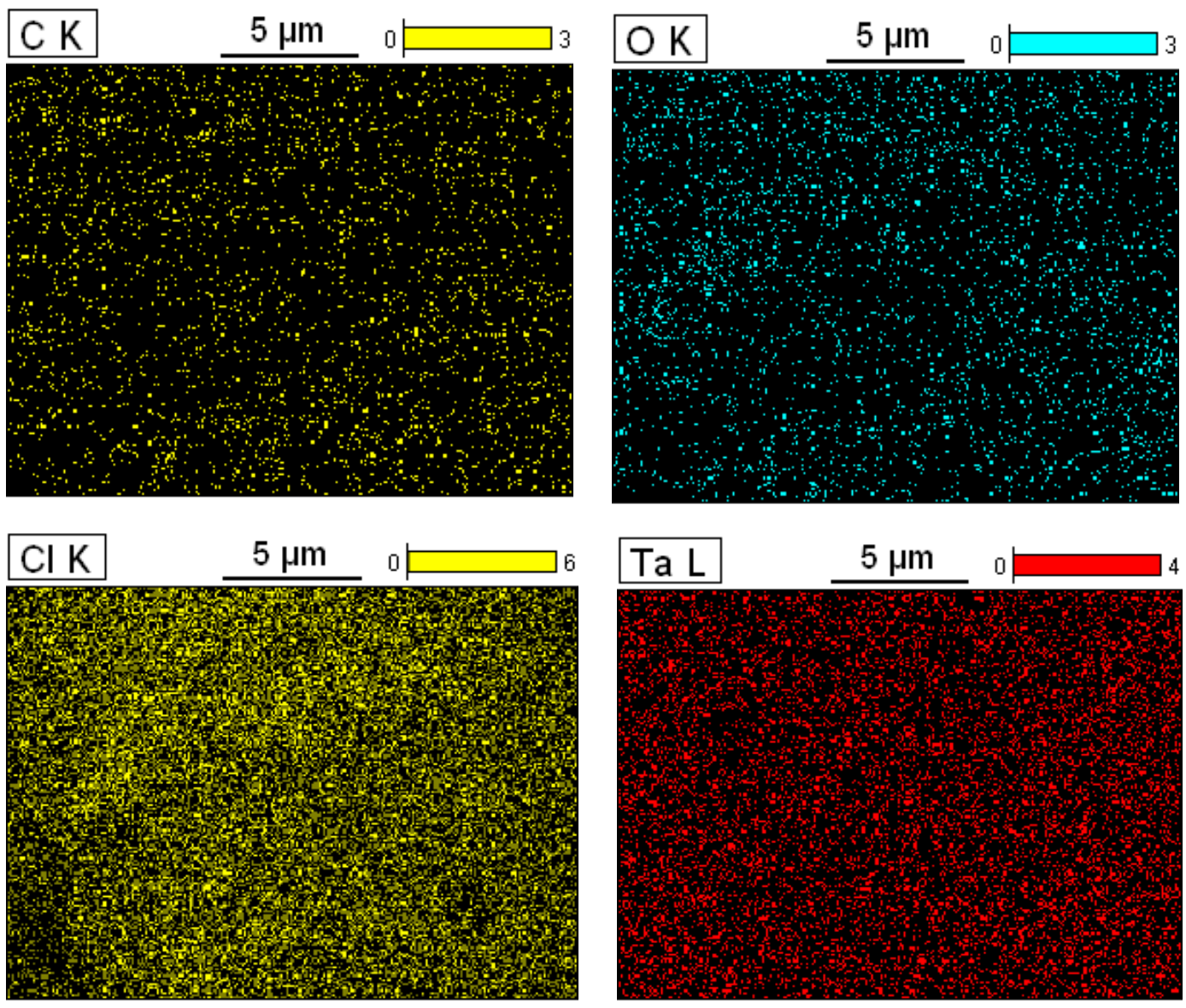

Figura 41. Mapa de EDS da amostra de precipitado coletado da parede do tubo após os experimentos de cloração.

\subsection{3}

\section{Avaliação da concentração de tântalo nas soluções de $\mathrm{KOH}$}

A Tabela 10 apresenta os resultados oriundos das análises da concentração de tântalo dissolvido nas soluções de $\mathrm{KOH}$ via ICP-AES, onde a solução 1 representa o primeiro vaso que foi o responsável pelo recebimento dos gases gerados durante o processo, e a solução 2 a solução contida no vaso acoplado ao primeiro, responsável pela captação do excedente de cloretos voláteis presentes na corrente de saída. Conforme esperado, a concentração de Ta no primeiro vaso é significativamente superior à concentração do mesmo elemento no segundo, sugerindo que a solução empregada, de fato, permitiu uma absorção eficiente dos cloretos gasosos produzidos durante o processo. A detecção de tântalo em ambas as soluções serve de forte indício para a formação de cloretos voláteis, prevista durante a avaliação termodinâmica do sistema. 
Tabela 11. Concentração de tântalo (ICP-AES) nas soluções de KOH.

Solução Concentração de Ta $(\mathrm{mg} / \mathrm{L})$

1

70

2

6,2

\section{2}

\section{Perda de massa do $\mathrm{C}_{2} \mathrm{Cl}_{4}$}

Antes dos testes de cloração, foram realizados estudos da perda de massa do $\mathrm{C}_{2} \mathrm{Cl}_{4}$ de acordo com os procedimentos descritos no Tópico (5.4.1). Os resultados foram obtidos para uma temperatura de banho de $25 \stackrel{\circ}{ } \mathrm{C}$, considerando-se três ensaios independentes (Figura 42).

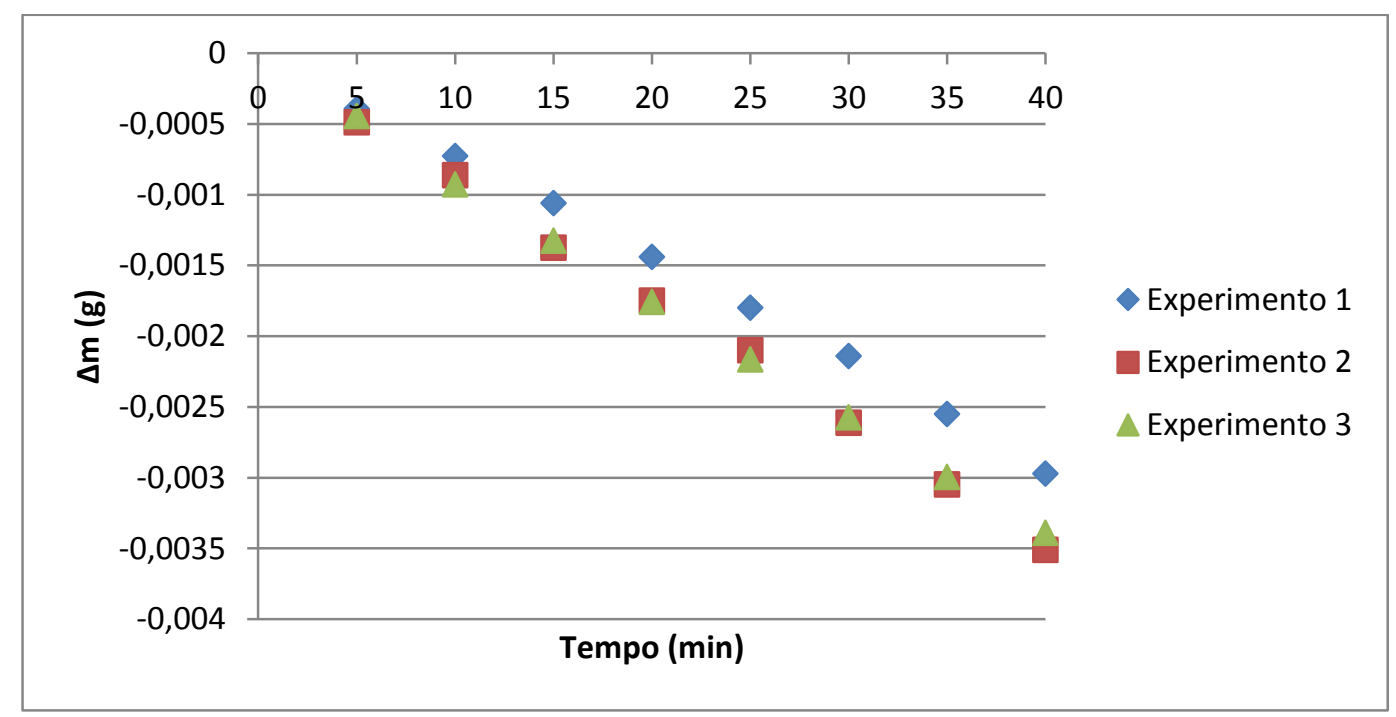

Figura 42. Perda de massa de $\mathrm{C}_{2} \mathrm{Cl}_{4}$ em função do tempo (3 experimentos).

Pode-se observar que 0 teste apresentou uma excelente reprodutibilidade. A massa total (vaso $+\mathrm{C}_{2} \mathrm{Cl}_{4}$ líquido) como função do tempo foi plotada na Figura (43), ajustando-se os dados via regressão linear. Com base na Eq. (42), no tempo total e na vazão total na saída do vaso $\left(\mathrm{N}_{2}+\mathrm{C}_{2} \mathrm{Cl}_{4}\right)$ foi possível calcular a pressão parcial de $\mathrm{C}_{2} \mathrm{Cl}_{4}$ na entrada do reator, obtendo-se um valor igual a 0,0239 atm, comprovando que o agente cloretante de fato esta sendo ofertado em condição diluída, o que, de acordo com o estudo termodinâmico prévio (Tópico 4.1.3) reduz a probabilidade de formação de grafite, que poderia se depositar sobre a amostra, interferindo com isso nos resultados do estudo cinético, parte central do presente trabalho. 


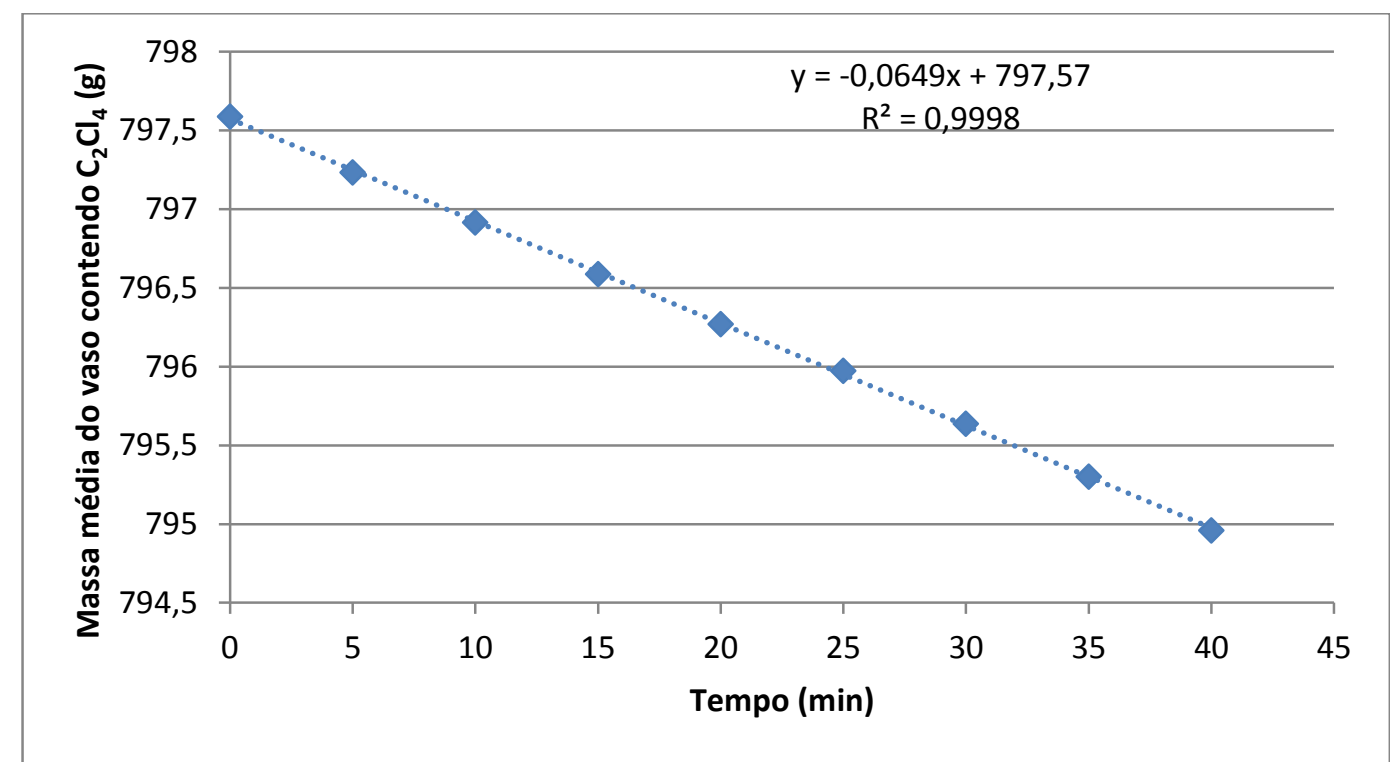

Figura 43. Perda de massa média do vaso contendo $\mathrm{C}_{2} \mathrm{Cl}_{4}$ em função do tempo.

\section{3}

\section{Cinética de cloração}

No presente tópico serão apresentados os testes realizados entre $800^{\circ} \mathrm{e}$ $950^{\circ} \mathrm{C}$ para determinar as conversões de $\mathrm{Ta}_{2} \mathrm{O}_{5}$ como função do tempo e, a partir da média destas conversões, os dados foram linearizados e ajustados de acordo com os modelos do núcleo não reagido e o auto catalítico.

\subsection{1}

\section{Testes realizados a $800^{\circ} \mathrm{C}$}

As conversões de $\mathrm{Ta}_{2} \mathrm{O}_{5}$ medidas como função no tempo podem ser observadas a $800^{\circ} \mathrm{C}$ no gráfico da Figura 44. 


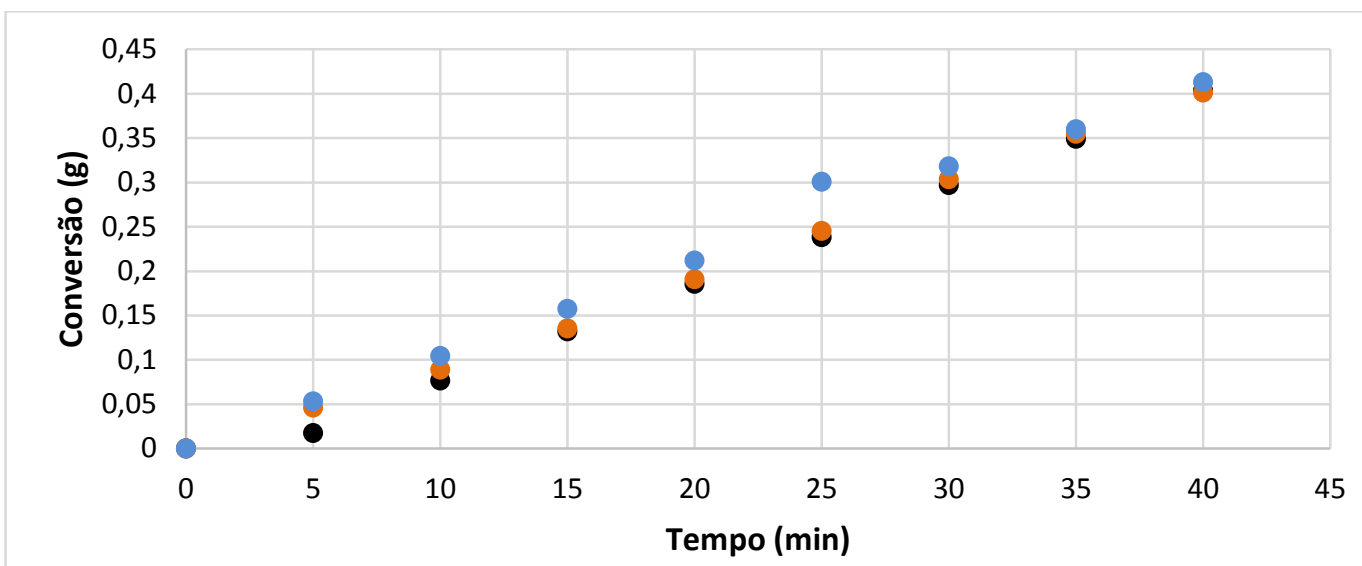

- Experimento 1 Experimento 2 Experimento 3

Figura 44. Conversão de $\mathrm{Ta}_{2} \mathrm{O}_{5}$ vs. tempo para três experimentos de cloração independentes realizados a $800^{\circ} \mathrm{C}$.

Com base nos dados de conversão acima, foi calculada a média dos três experimentos e a partir dessa média, os dados foram linearizados e ajustados de acordo com os modelos do núcleo não reagido (Fig. 45) e o auto catalítico (Fig. 46).

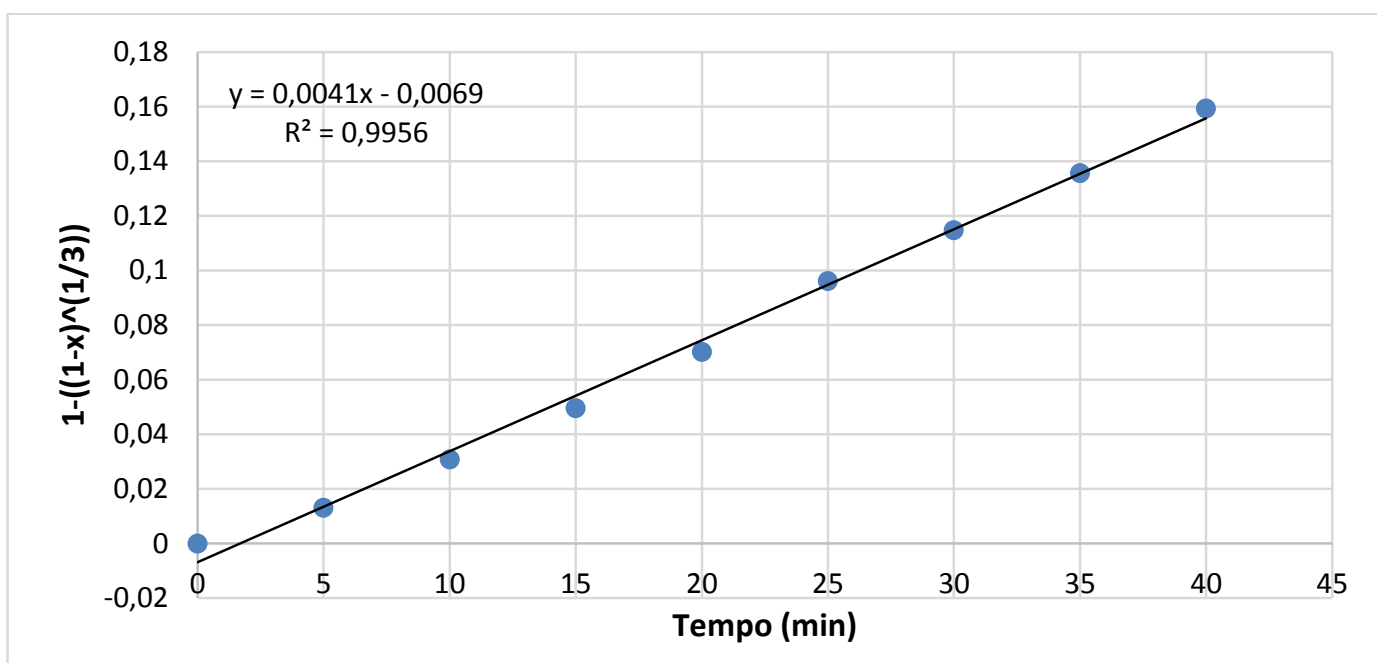

Figura 45. Ajuste linearizado do modelo do núcleo não reagido com fator de forma igual a três. 


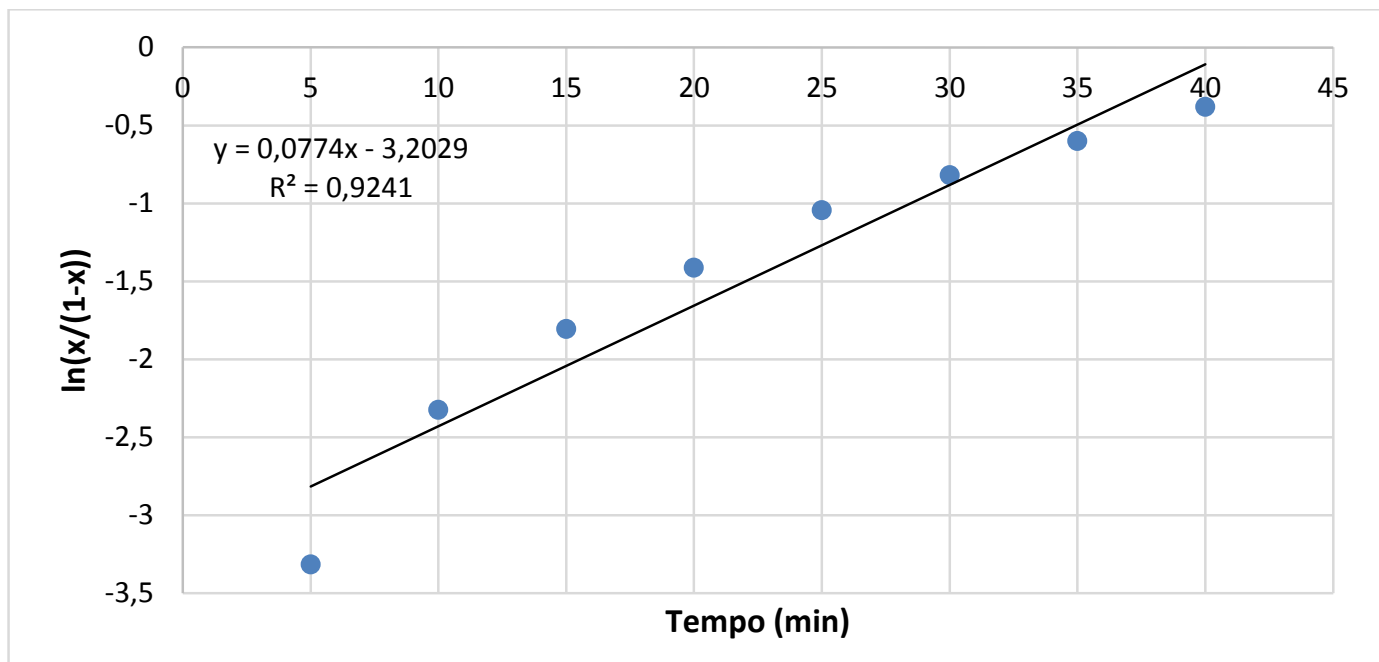

Figura 46. Ajuste linearizado do modelo auto catalítico.

Pode-se observar que o modelo do núcleo não reagido com fator de forma igual a três se ajustou melhor na temperatura considerada, uma vez que o $\mathrm{R}^{2}$ tem um valor mais próximo de um, se aproximando melhor dos dados experimentais.

\subsection{2}

\section{Testes realizados a $850^{\circ} \mathrm{C}$}

As conversões de $\mathrm{Ta}_{2} \mathrm{O}_{5}$ medidas como função no tempo a $850^{\circ} \mathrm{C}$ podem ser observadas no gráfico da Figura 47.

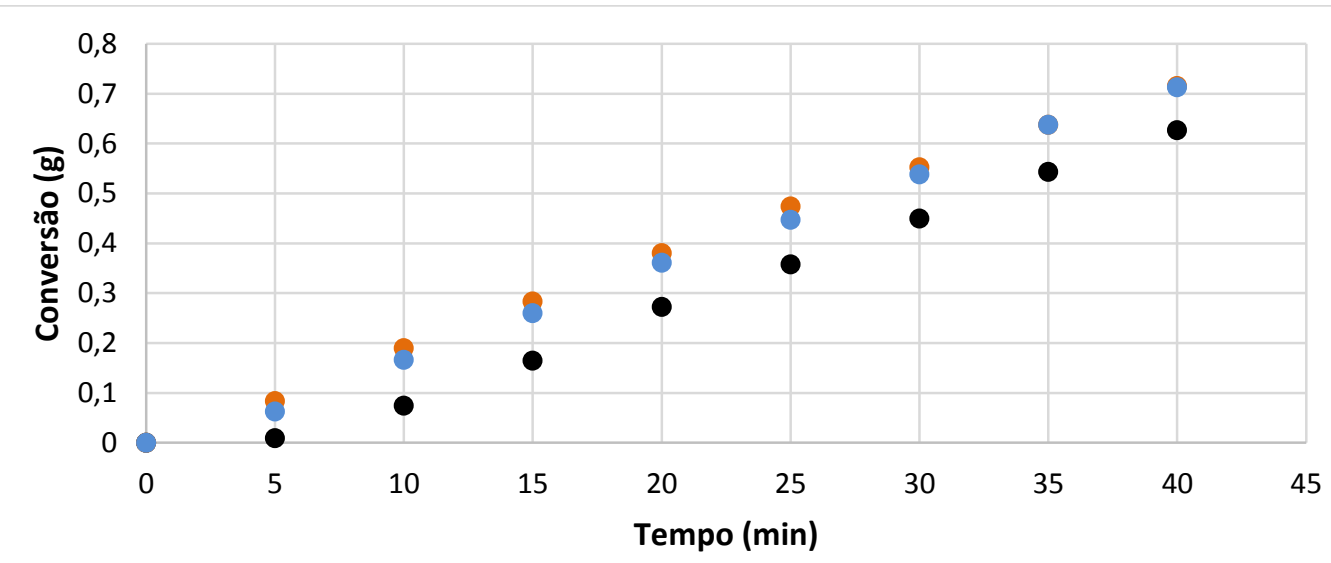

- Experimento 1 Experimento 2 Experimento 3

Figura 47. Conversão de $\mathrm{Ta}_{2} \mathrm{O}_{5}$ vs. tempo para três experimentos de cloração independentes realizados a $850^{\circ} \mathrm{C}$. 
Pode-se observar que as conversões de $\mathrm{Ta}_{2} \mathrm{O}_{5}$ medidas no primeiro experimento apresentaram valores sistematicamente inferiores aos demais para todos os instantes considerados. Isso poderia ser explicado pelo tempo de pesagem. Tempos maiores resultam na possível incorporação de umidade à amostra, resultando em uma massa final superior à real, reduzindo, portanto, o valor de conversão calculado.

De acordo com dados de conversão acima, também foi calculada a média dos três experimentos e a partir dessa média, os dados foram linearizados e ajustados de acordo com os modelos do núcleo não reagido (Fig. 48) e o auto catalítico (Fig. 49).

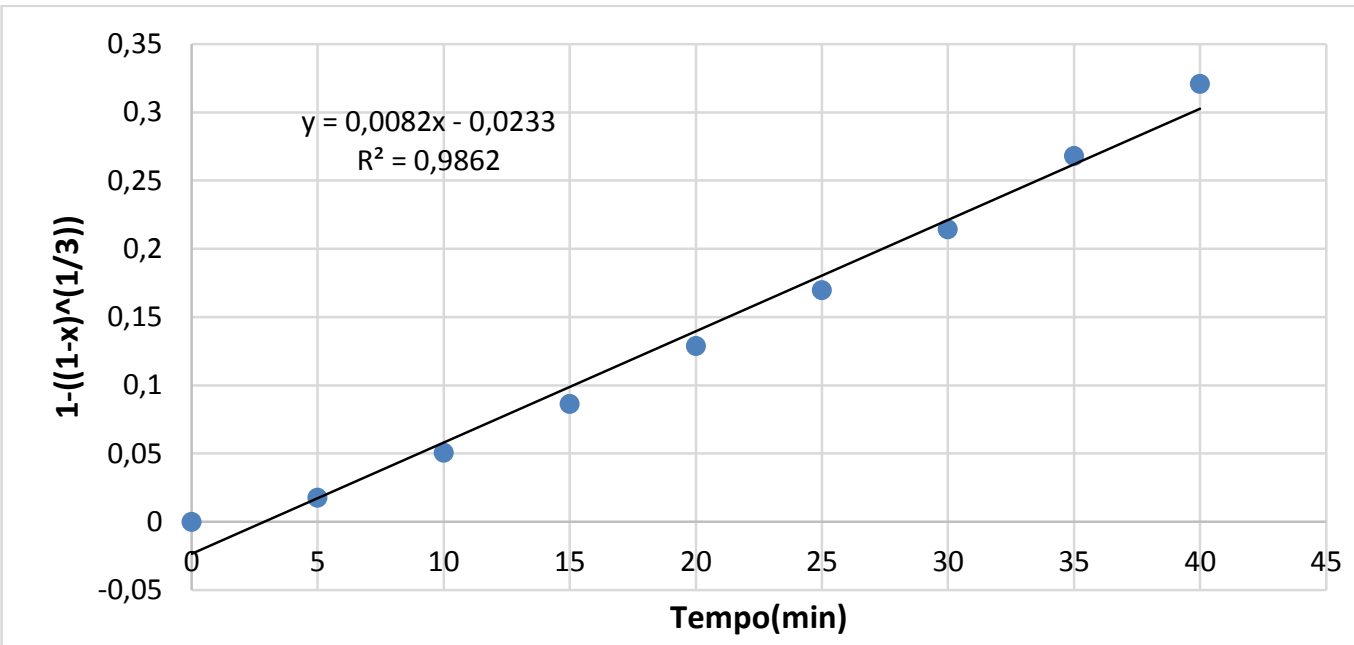

Figura 48. Ajuste linearizado do modelo do núcleo não reagido com fator de forma igual a três.

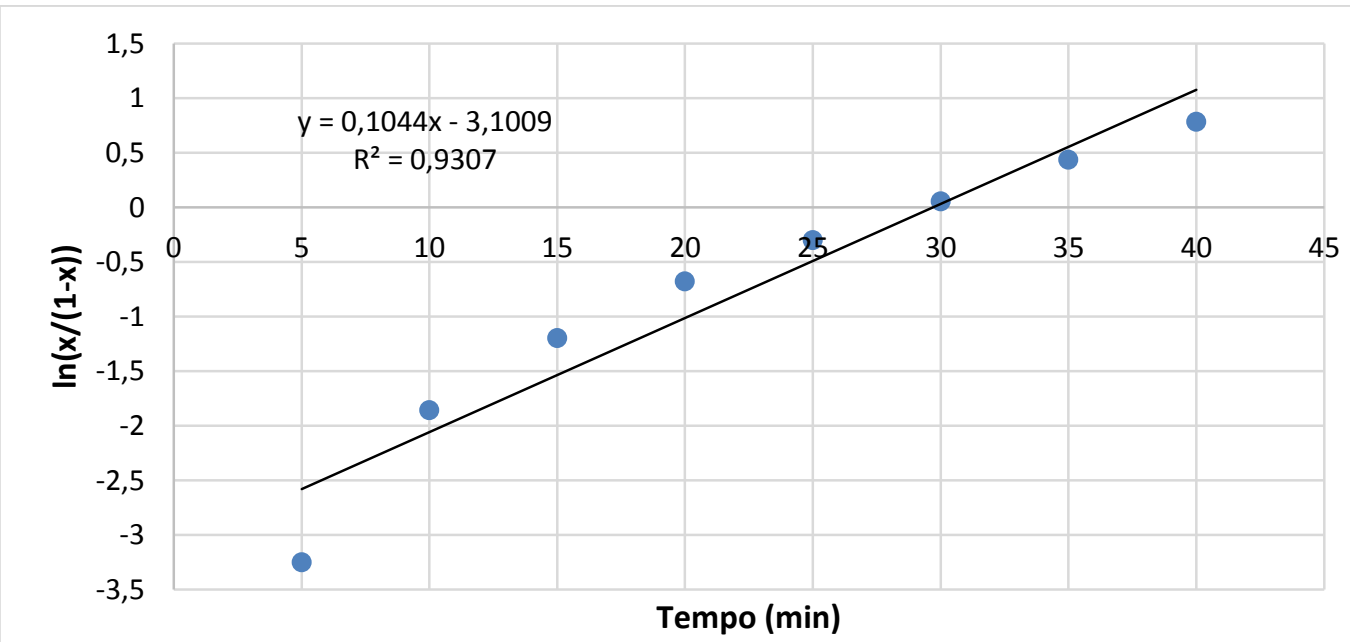

Figura 49. Ajuste linearizado do modelo auto catalítico.

Pode-se observar que o modelo do núcleo não reagido de fator de forma igual a três se ajustou melhor na temperatura considerada, uma vez que o $\mathrm{R}^{2}$ 
tem um valor mais próximo de um, se aproximando melhor dos dados experimentais.

\subsection{3}

\section{Testes realizados a $900^{\circ} \mathrm{C}$}

As conversões de $\mathrm{Ta}_{2} \mathrm{O}_{5}$ medidas como função no tempo a $900^{\circ} \mathrm{C}$ podem ser observadas no gráfico da Figura 50.

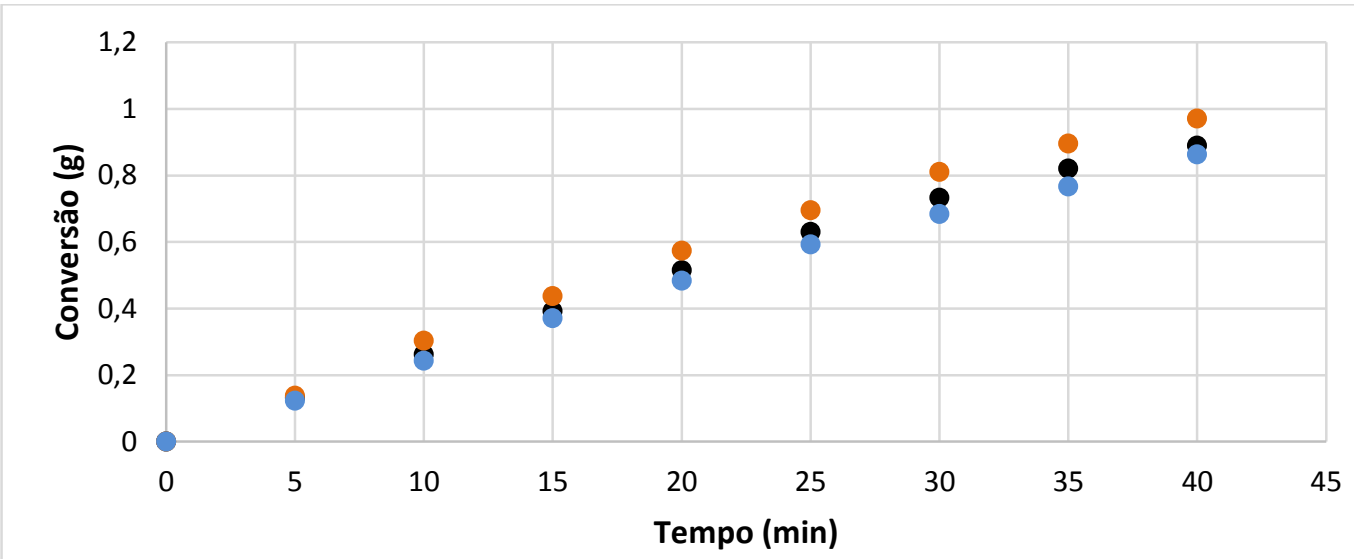

- Experimento 1 Experimento 2 Experimento 3

Figura 50. Conversão de $\mathrm{Ta}_{2} \mathrm{O}_{5}$ vs. tempo para três experimentos de cloração independentes realizados a $900^{\circ} \mathrm{C}$.

Com base nos dados de conversão acima, também foi calculada a média dos três experimentos e a partir dessa média, os dados foram linearizados e ajustados de acordo com os modelos do núcleo não reagido (Fig. 51) e o auto catalítico (Fig. 52).

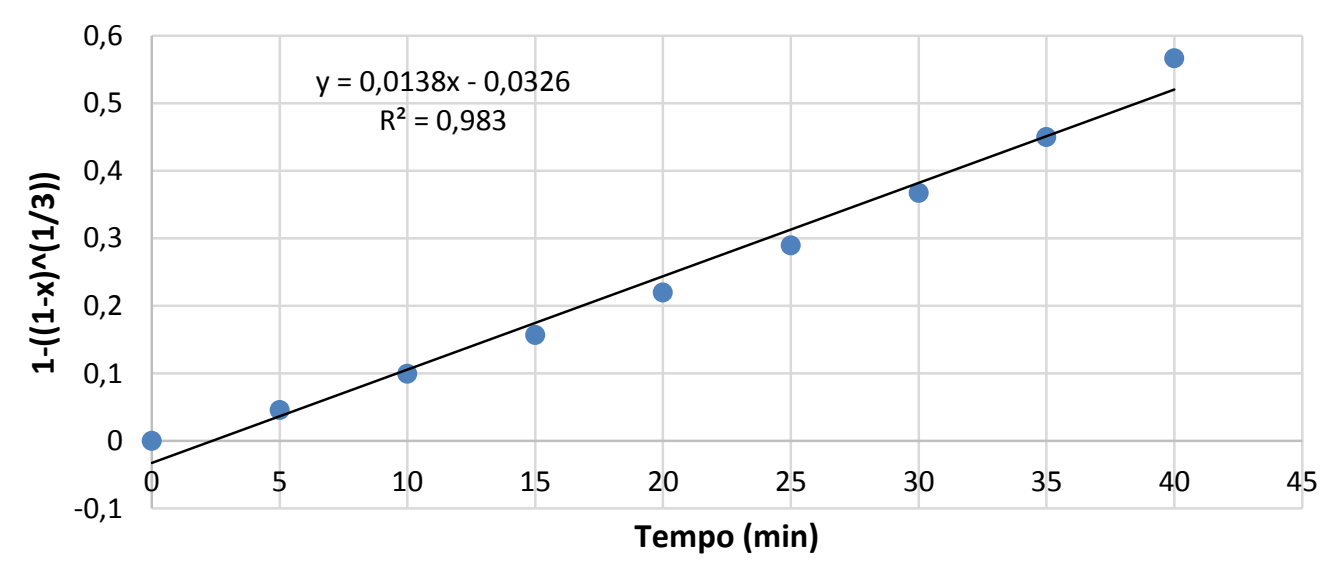

Figura 51. Ajuste linearizado do modelo do núcleo não reagido com fator de forma igual a três. 


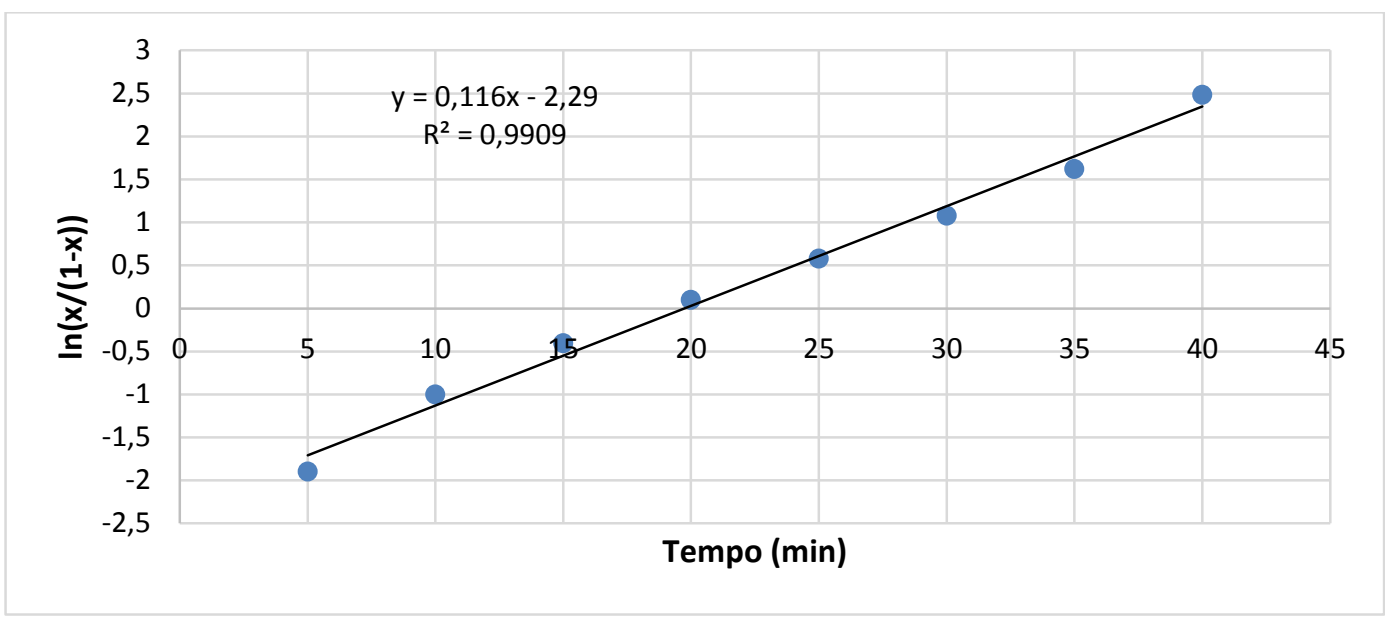

Figura 52. Ajuste linearizado do modelo auto catalítico.

Observa-se que a partir da temperatura de $900^{\circ} \mathrm{C}$, ambos os modelos se ajustam bem, uma vez que o $\mathrm{R}^{2}$ destes modelos possuem um valor muito próximo de um, sugerindo a possibilidade do $\mathrm{Ta}_{2} \mathrm{O}_{5}$ atuar como catalizador, em concordância com evidências recentes da literatura para outros processos ${ }^{(36,37 \mathrm{e}}$ 38).

\subsection{4}

\section{Testes realizados a $950 \circ \mathrm{C}$}

As conversões de $\mathrm{Ta}_{2} \mathrm{O}_{5}$ medidas como função no tempo a $950^{\circ} \mathrm{C}$ podem ser observadas no gráfico da Figura 53.

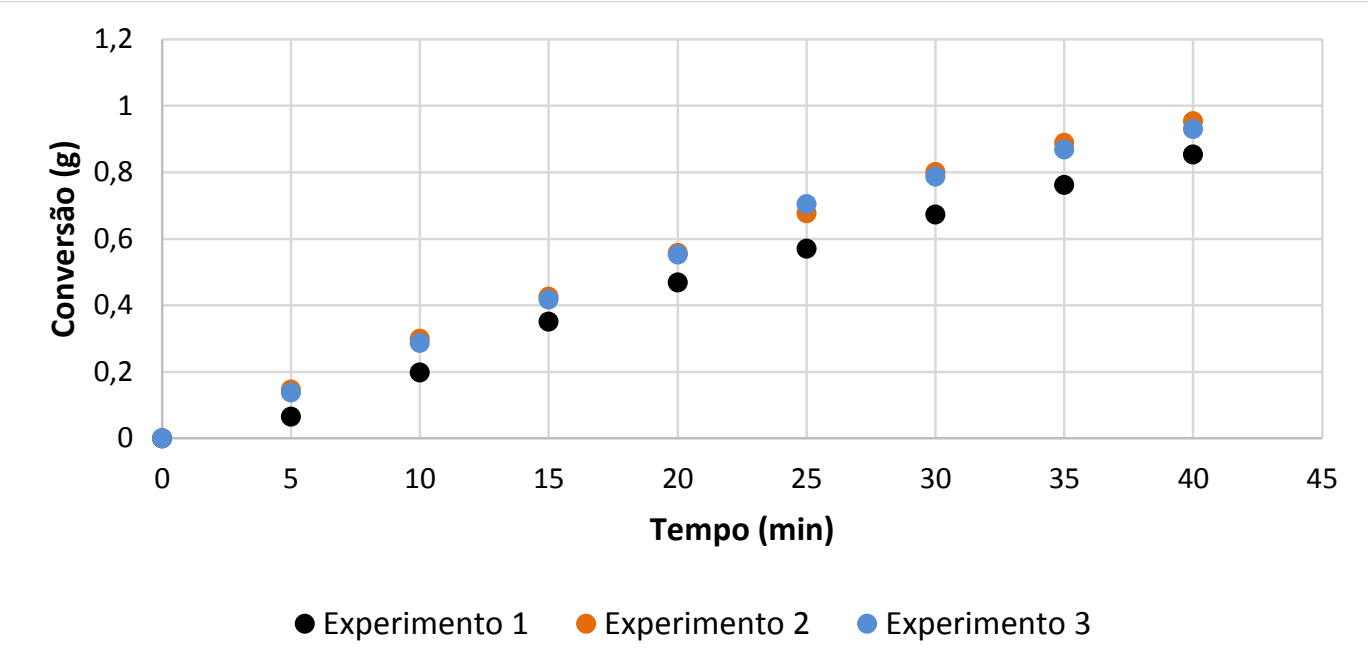

Figura 53. Conversão de $\mathrm{Ta}_{2} \mathrm{O}_{5}$ vs. tempo para três experimentos de cloração independentes realizados a $950^{\circ} \mathrm{C}$.

De acordo com os dados de conversão acima, também foi calculada a média dos três experimentos e a partir dessa média, os dados foram linearizados 
e ajustados de acordo com os modelos do núcleo não reagido (Fig. 54) e o auto catalítico (Fig. 55).

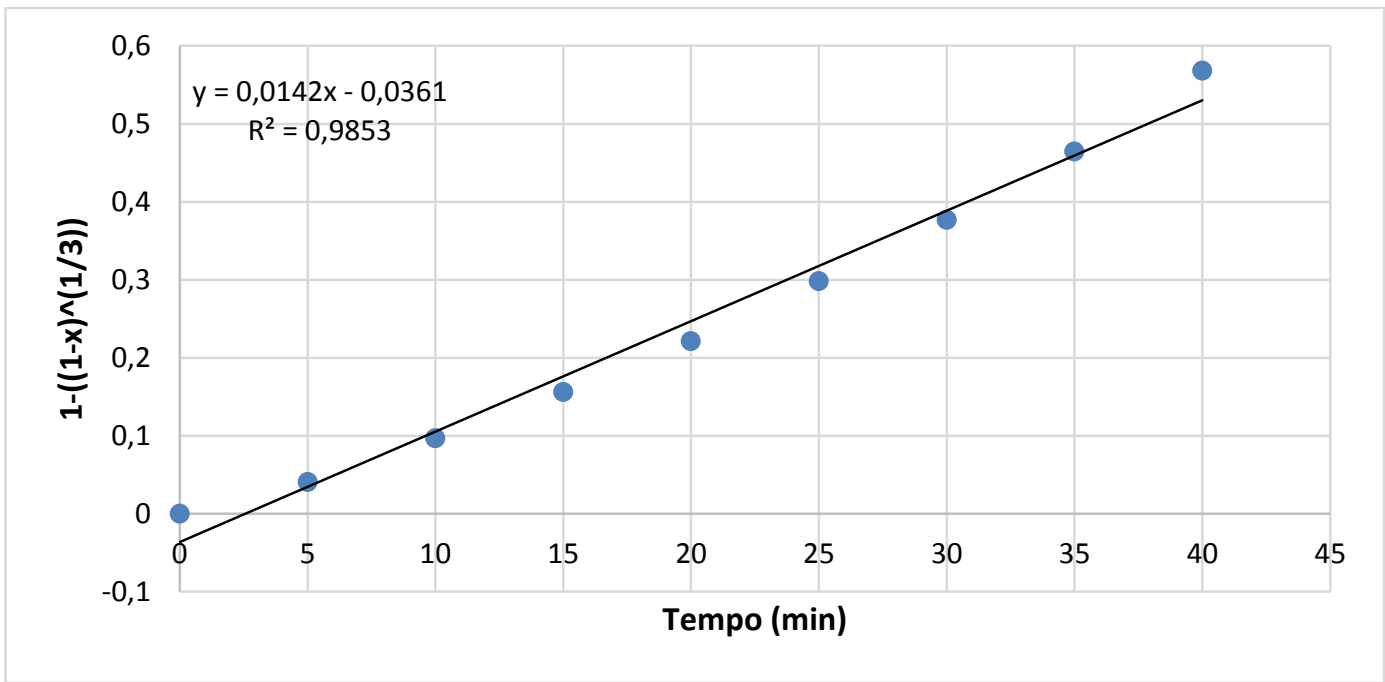

Figura 54. Ajuste linearizado do modelo do núcleo não reagido com fator de forma igual a três a $950^{\circ} \mathrm{C}$.

\section{Modelo Auto Catalítico}

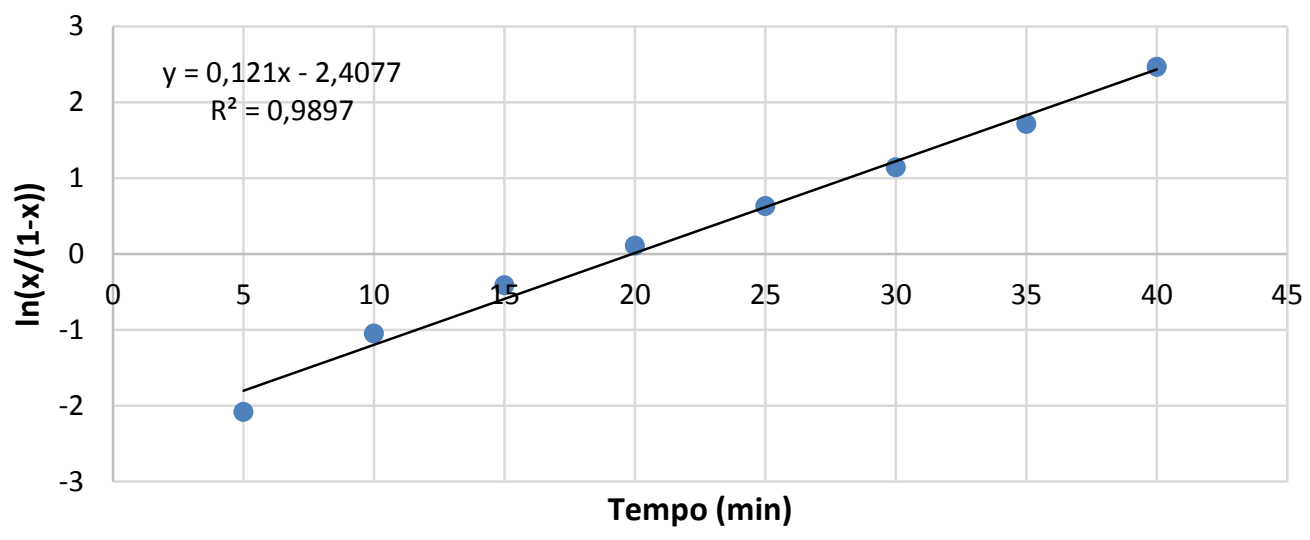

Figura 55. Ajuste linearizado do modelo auto catalítico a $950^{\circ} \mathrm{C}$.

Observa-se que ambos os modelos (auto catalítico e núcleo não reagido) se ajustam bem aos dados, com um desempenho ligeiramente superior para o modelo auto catalítico, dado que o $\mathrm{R}^{2}$ se mostra superior. Tal resultado reforça a ideia de que $0 \mathrm{Ta}_{2} \mathrm{O}_{5}$ pode atuar como um catalisador para o processo em questão em temperaturas superiores a $900^{\circ} \mathrm{C}$. 


\subsection{5}

\section{Energia de ativação global}

A energia de ativação global foi determinada para cada modelo cinético considerado (núcleo não reagido e auto catalítico) conforme os gráficos contidos nas Figuras 56 e 57 e Tabela 12.

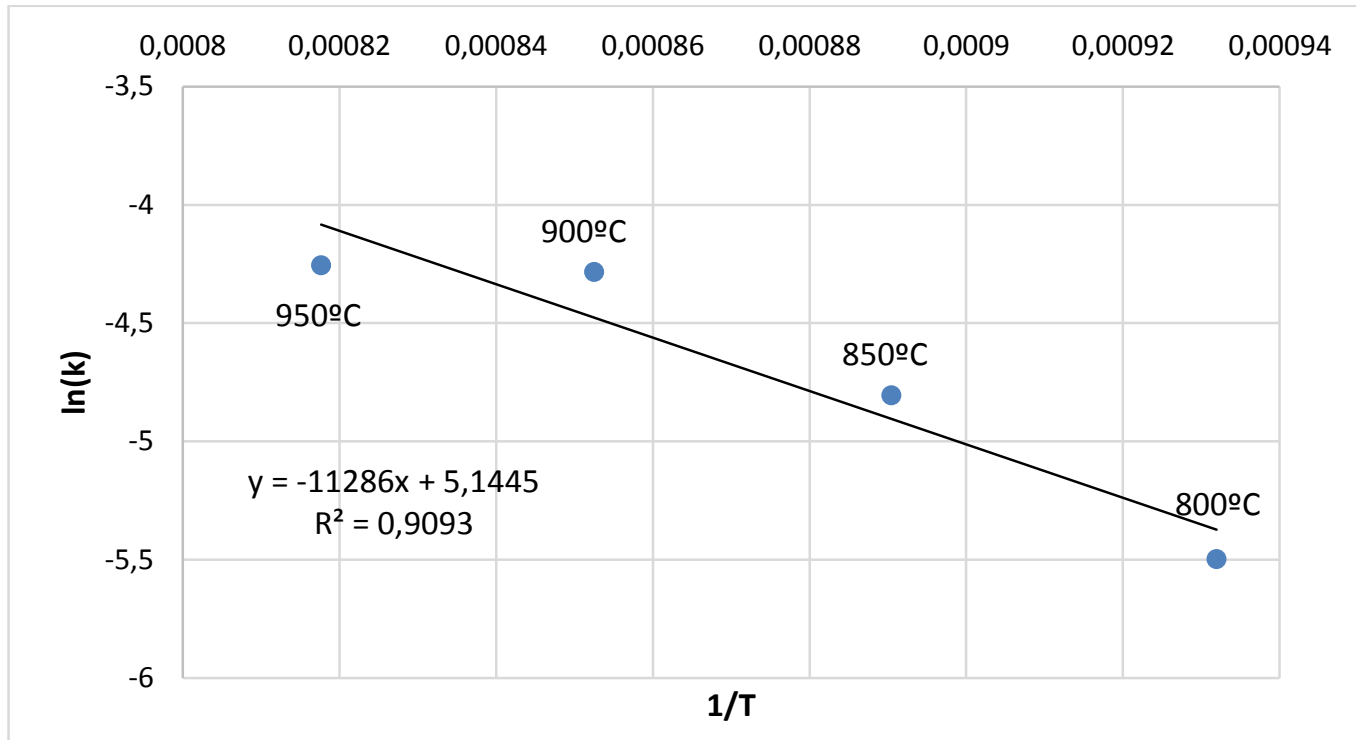

Figura 56. Ink vs. 1/T para os experimentos de cloração realizados entre 800 a $950^{\circ} \mathrm{C}$ (modelo do núcleo não reagido com $\mathrm{f}=3$ ).

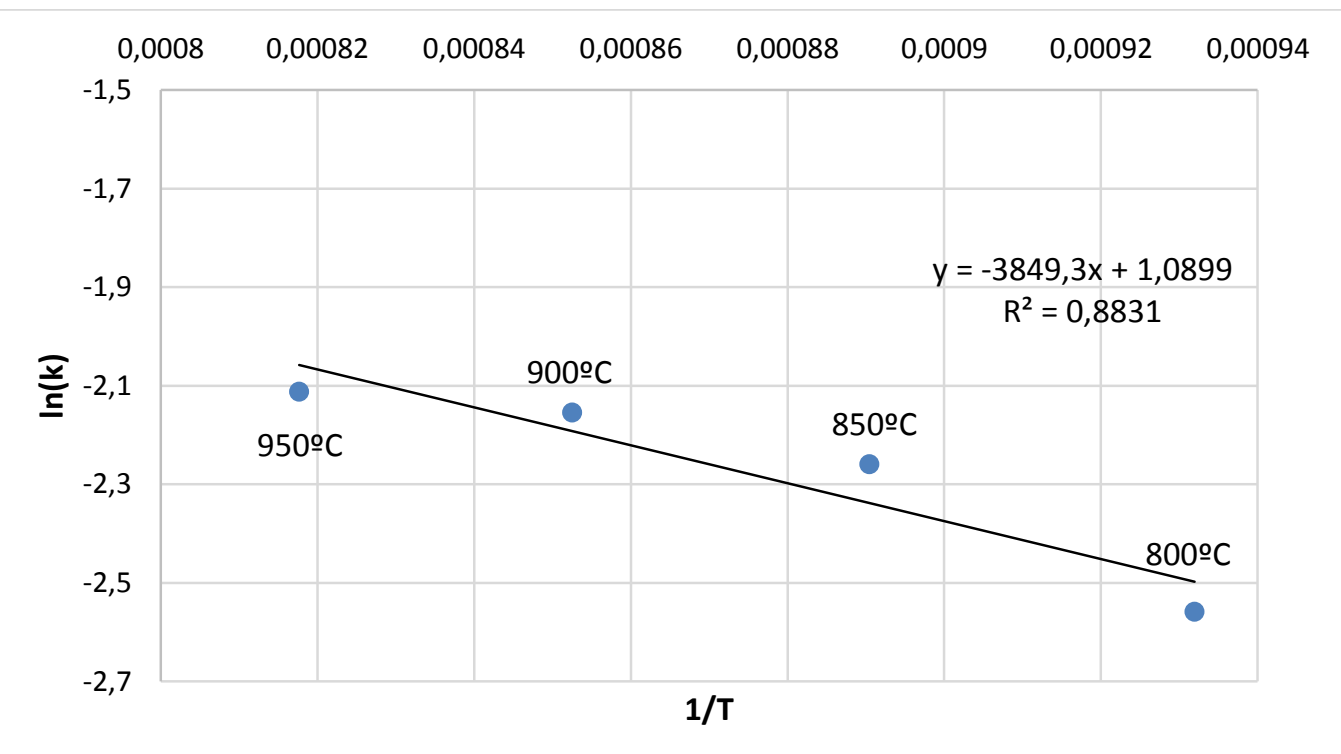

Figura 57. Ink vs. $1 / \mathrm{T}$ para os experimentos de cloração realizados entre 800 a $950^{\circ} \mathrm{C}$ (modelo auto catalítico).

Através dos resultados obtidos com os gráficos das Figuras (58 e 59), foi possível montar a Tabela 12 a partir da equação de Ahrenius (Eq. 27). 
Tabela 12. Energia de ativação global calculada para cada modelo cinético considerado.

\begin{tabular}{ll}
\hline Modelo & $\mathbf{E}(\mathbf{k J} / \mathbf{m o l})$ \\
\hline Núcleo não reagido & 93,837 \\
Auto Catalítico & 32,005 \\
\hline
\end{tabular}

Mediante o emprego do modelo auto catalítico tem-se uma energia de ativação consideravelmente inferior ao valor associado ao modelo do núcleo não reagido, fato este consistente com o esperado para a ação de um catalizador.

Em ambos os casos, embora um ajuste com $R^{2}$ elevado pôde ser realizado considerando os dados obtidos em todas as temperaturas, os valores do referido parâmetro numérico se mostram inferiores a $90 \%$, sugerindo que os ajustes podem ainda ser melhorados, por exemplo, considerando que cada modelo funciona em uma faixa de temperatura específica. Tal análise não foi, por uma questão de tempo, incluída no corpo do presente trabalho, porém é sugerida na sessão de trabalhos futuros (Tópico 8).

A partir dos dados extraídos da literatura (Tópicos 3.6 e 3.7) podem-se realizar comparações com os valores de energia de ativação globais calculados na presente dissertação. Jena et. $\mathrm{al}^{(16)}$ e Carvalho ${ }^{(12)}$ utilizaram a mesma linha de cloração utilizada nos experimentos do presente trabalho e também reagentes similares: $\mathrm{CCl}_{4}, \mathrm{Nb}_{2} \mathrm{O}_{5}{ }^{(16)}$ e $\mathrm{Ta}_{2} \mathrm{O}_{5}{ }^{(12)}$. Já Bertóti et. al( ${ }^{(8)}$ investigaram a cloração da alumina $\left(\mathrm{Al}_{2} \mathrm{O}_{3}\right)$ com $\mathrm{C}_{2} \mathrm{Cl}_{4}$ via termogravimetria.

No estudo de Jena et al. ${ }^{(16)}$, a energia de ativação encontrada foi entre 57 e $115 \mathrm{~kJ} / \mathrm{mol}$ para temperaturas entre 425 e $580^{\circ} \mathrm{C}$. No segundo caso(12), a energia de ativação foi entre 31 e $142 \mathrm{~kJ} / \mathrm{mol}$. Já no terceiro caso(8), a energia de ativação calculada foi de $141 \mathrm{~kJ} / \mathrm{mol}$ para cinética de instantes iniciais e 133 $\mathrm{kJ} / \mathrm{mol}$ para temperaturas entre 660 e $777^{\circ} \mathrm{C}$. Nota-se que as energias de ativação encontradas na literatura estão na mesma ordem de grandeza das encontradas no presente trabalho, onde os autores ${ }^{(16,12)}$ utilizaram os modelos do núcleo não reagido, que tem por premissa o controle químico.

No que se refere ao trabalho de Bertóti et. al $^{(8)}$, foi utilizado o modelo de Langmuir-Hinshelwood que tem como uma das suas premissas a decomposição térmica do $\mathrm{C}_{2} \mathrm{Cl}_{4}$ adsorvido sobre as partículas de óxido, como uma etapa prévia à reação de cloração em si. De acordo com Bertóti et. $\mathrm{al}^{(8)}$, a etapa lenta do processo é a decomposição do agente cloretante na superfície do óxido e não a quebra da ligação entre o metal e o oxigênio. $O$ fato da energia de ativação calculada na presente dissertação com o modelo do núcleo não reagido para o $\mathrm{Ta}_{2} \mathrm{O}_{5}$ ser próximo dos valores obtidos por Bertóti et al. ${ }^{(8)}$ para $\circ \mathrm{Al}_{2} \mathrm{O}_{3}$ sugere 
que a mesma etapa de decomposição seja a controladora do processo de interesse para o presente trabalho. Em temperaturas elevadas $\left(T>900^{\circ} \mathrm{C}\right), 0$ $\mathrm{Ta}_{2} \mathrm{O}_{5}$ passaria a atuar como catalisador (modelo auto catalítico), contribuindo para uma expressiva redução na energia de ativação do mencionado processo de decomposição (93 para $32 \mathrm{~kJ} / \mathrm{mol}$ ). Convém relembrar do estudo termodinâmico do presente processo, que a referida decomposição deve estar associada a uma expressiva força motriz.

Finalmente, o fato dos referidos autores terem utilizado uma balança termogravimétrica, implica na minimização de efeitos difusionais, ou seja, que possam limitar o contato do óxido com o $\mathrm{C}_{2} \mathrm{Cl}_{4}$ admitido favorecendo, em última instância, o controle químico. Isso também sugere que no presente trabalho tais efeitos seriam desprezíveis, como, por exemplo, aqueles associados a uma possível sinterização da amostra, com redução da área superficial de contato entre o $\mathrm{Ta}_{2} \mathrm{O}_{5}$ e a atmosfera reacional, cuja tendência se encontra evidente nos resultados obtidos via DRX (aumento do tamanho médio de cristalito) e MEV (tamanho de partícula) do óxido remanescente após o processo. 


\section{7 \\ CONCLUSÃO}

No presente tópico são apresentadas as principais conclusões referentes à avaliação termodinâmica, análise cinética e caracterização das amostras geradas no presente trabalho.

\section{1}

\section{Análise termodinâmica}

a) A cloração do $\mathrm{Ta}_{2} \mathrm{O}_{5}$ com $\mathrm{C}_{2} \mathrm{Cl}_{4}$ diluído é um processo termodinamicamente viável, porém de força motriz inferior ao processo similar utilizando-se $\mathrm{Cl}_{2}$ como agente cloretante.

b) A reatividade do pentóxido de tântalo é dependente da temperatura do forno, tornando-se mais expressiva à medida que a temperatura reacional se eleva.

c) Existe a possibilidade da decomposição térmica do agente cloretante no caminho entre a entrada do reator e a amostra, sendo recomendável um reator de leito fluidizado.

d) Os principais cloretos formados são o $\mathrm{TaCl}_{5}(\mathrm{~g})$ e o $\mathrm{TaOCl}_{3}$. Á medida que a atmosfera fica mais concentrada em $\mathrm{C}_{2} \mathrm{Cl}_{4}$ e a temperatura aumenta, todo $\mathrm{TaOCl}_{3}$ formado é convertido em $\mathrm{TaCl}_{5}$.

\section{2}

\section{Estudo cinético}

a) Os dados experimentais foram quantitativamente descritos por ambos os modelos testados, porém com um desempenho superior do modelo do núcleo não reagido para temperaturas inferiores a $850^{\circ} \mathrm{C}$ e do modelo auto catalítico para temperaturas acima deste valor.

b) Tanto para o modelo auto catalítico quanto para o modelo do núcleo não reagido, somente uma energia de ativação foi observada em toda faixa de temperatura, sugerindo que a etapa lenta do mecanismo não deve mudar.

c) Como esperado, a energia de ativação do modelo auto catalítico (32 $\mathrm{kJ} / \mathrm{mol}$ ) é significativamente inferior ao modelo do núcleo não reagido 
(93.8 kJ/mol). Ambos os valores estão de acordo com dados da literatura ${ }^{(8,16,12)}$, que sugerem um controle químico.

d) Os valores calculados no presente trabalho estão na mesma ordem de grandeza dos autores Bertóti et al. ${ }^{(8)}$ para cloração do $\mathrm{Al}_{2} \mathrm{O}_{3} \operatorname{com~} \mathrm{C}_{2} \mathrm{Cl}_{4}$, onde encontraram energias de ativação de $141 \mathrm{~kJ} / \mathrm{mol}$ para cinética de instantes iniciais e $133 \mathrm{~kJ} / \mathrm{mol}$ para temperaturas entre $660^{\circ}$ e $777^{\circ} \mathrm{C}$, uma vez que foi utilizado o modelo de Langmuir-Hinshelwood, que tem como uma das suas premissas a decomposição térmica do $\mathrm{C}_{2} \mathrm{Cl}_{4}$ adsorvido sobre as partículas de óxido, sendo esta a etapa lenta do processo.

\section{3 \\ Caracterização}

a) $\mathrm{O} \mathrm{Ta}_{2} \mathrm{O}_{5}$ clorado apresenta pureza superior a $99 \%$ e natureza nanoestruturada.

b) O óxido remanescente não apresenta nenhuma evidência de contaminação por grafite, bem como a presença de cloretos condensados.

c) A caracterização do precipitado coletado nas paredes do tubo na saída do reator via MEV/EDS sugerem a presença exclusiva de tântalo, cloro e carbono. A presença de tântalo e cloro pode ser explicada pela formação de um cloreto volátil $\left(\mathrm{TaOCl}_{3}\right)$ que precipita na região mais fria do tubo. Já a presença de carbono pode ser explicada pela decomposição térmica parcial do $\mathrm{C}_{2} \mathrm{Cl}_{4}$ admitido, no caminho entre a entrada do reator e a amostra. A condução do processo de um leito fluidizado ao invés de leito fixo permitiria inibir a decomposição do agente em temperaturas acima de $800^{\circ} \mathrm{C}$, uma vez que o contato entre os cristais de $\mathrm{Ta}_{2} \mathrm{O}_{5}$ e as moléculas de $\mathrm{C}_{2} \mathrm{Cl}_{4}$ seria facilitado.

d) A caracterização nas soluções de $\mathrm{KOH}$ via ICPAES comprovaram a presença de tântalo, sendo a primeira solução com $70 \mathrm{mg} / \mathrm{L}$ e a segunda, com 6,2mg/L, sugerindo a formação de cloretos voláteis, em concordância com os dados oriundos das simulações termodinâmicas. 


\section{8 \\ TRABALHOS FUTUROS}

\section{1}

\section{Investigação de mudança no mecanismo}

Obtenção de mais dados cinéticos nas faixas entre 700 e $850^{\circ} \mathrm{C}$ e entre 900 e $1000^{\circ} \mathrm{C}$ de maneira a confirmar uma possível mudança no mecanismo, passando de núcleo - não reagido para auto catalítico, mantendo-se todos os demais parâmetros operacionais constantes (vazão de $\mathrm{N}_{2}$ e temperatura do banho termoestatizado).

\section{2}

\section{Determinação da ordem da reação}

Para avaliar a ordem global da reação, os processos de cloração serão realizados com metodologia oposta ao estudo feito para determinar a energia de ativação, fixando-se a temperatura do reator e variando-se a temperatura do banho termoestatizado.

Os dados obtidos a $800^{\circ} \mathrm{C}$ serão ajustados com o modelo do núcleo não reagido e a $950^{\circ} \mathrm{C}$ com o modelo auto catalítico variando-se a temperatura do banho na faixa entre 20 e $30^{\circ} \mathrm{C}$. A inexistência de uma diferença na ordem nessas duas temperaturas poderia servir de comprovação do fato já comentado anteriormente, de que a etapa controladora da cinética da cloração do $\mathrm{Ta}_{2} \mathrm{O}_{5}$ com $\mathrm{C}_{2} \mathrm{Cl}_{4}$ pode ser definida pela decomposição térmica do agente cloretante na superfície das partículas de óxido presentes.

\section{3}

\section{Caracterização do precipitado e filtrado}

Realização de análises de DRX (método de Rietveld) para a comprovação da natureza do cloreto formado $\left(\mathrm{TaOCl}_{3}\right)$ presente no precipitado coletado na parede do forno, bem como dos sólidos em suspensão filtrados das soluções de $\mathrm{KOH}$. 


\section{4}

Otimização da absorção e recuperação do tântalo

Tendo em vista um possível aumento de escala do processo estudado no presente trabalho, convém entender de forma aprofundada os mecanismos que norteiam a absorção dos cloretos $\mathrm{TaCl}_{5}$ e $\mathrm{TaOCl}_{3}$ em soluções aquosas com pH controlado. Tal estudo poderia resultar na maximização da absorção do tântalo extraído visando uma futura recuperação deste. 
9

\section{REFERÊNCIAS BIBLIOGRÁFICAS}

1. TANTALUM (TANTALITA). U. S. Geological Survey, Mineral Commodity Summaries, 2014. Disponível em: http://pubs.usgs.gov/fs/2014/3054/pdf/fs2014-3054.pdf.

2. Costa, F.E.V.T.B. Perfil Analítico da Columbita/Tantalita. Departamento Nacional de Produção Mineral. Ministério de Minas e Energia. Boletim no 9. 1973.

3. TÂNTALO. Departamento Nacional de Produção Mineral - DNPM/AM. Sumário $\quad$ Mineral, 2015.2 Disponível em: http://www.dnpm.gov.br/dnpm/sumarios/sumario-mineral-2015/view.

4. Lacombe, M., Navarro, R.C.S, Brocchi, E. A. Estudo Cinético da Carbocloração do $\mathrm{Ta}_{2} \mathrm{O}_{5} 2011$.

5. Vasconcelos, E. T., Navarro, R.C.S, Brocchi, E. A. Estudo da Cloração de Óxidos de Cobre e Níquel em Altas Temperaturas com $\mathrm{C}_{2} \mathrm{Cl}_{4}$. p. 19. 2015.

6. Ferreira, B.V., Brocchi, E.A., de Souza, R.F.M. Emprego de Reagentes Alternativos em Reações de Cloração Envolvendo Óxidos Metálicos. 2012.

7. Bertóti, I., Pap, I.S., Tóth, A., Székelu, T. Kinects of y-alumina Chlorination by Carbon Tetrachloride. Thermochimica Acta, 41. p. 2732. Hungary. 1980.

8. Bertóti, I., Pap, I.S., Tóth, A., Székelu, T. Kinects of y-alumina Chlorination by Tetrachloroethylene. Thermochimica Acta, 44. p. 333336. Hungary. 1981.

9. Barbosa, L.I., González, J.A., Ruiz, M.C. Extraction of Lithium from $\beta$ spodumene using chlorination roasting with calcium chloride. Thermochimica Acta 605. p. 63-67. 2015.

10. Santos, F. S., Brocchi, E.A. Caracterização e Processamento Químico por Meio de Reagentes Cloretantes de um Resíduo Industrial. Departamento de Engenharia de Materiais, Pontifícia Universidade Católica do Rio de Janeiro. Dissertação de Mestrado. Rio de Janeiro: 2008. 
11. Allain, E., Djona, M., Gaballah, I. Kinects of Chlorination and Carbochlorination of Pure Tantalum and Niobium Pentoxides. p.1 11. Vol. 28B. 233. 1997.

12. Carvalho, M. P. A., Brocchi, E.A., Jena, P.K. Cinética da Cloração do Pentóxido de Tântalo com Tetracloreto de Carbono. Departamento de Engenharia de Materiais, Pontifícia Universidade Católica do Rio de Janeiro. Dissertação de Mestrado. Rio de Janeiro: 2000.

13. Villela, T.F., Brocchi, E.A. Cinética da Cloração de Óxido de Zircônio Utilizando Tetracloreto de Carbono. Departamento de Engenharia de Materiais, Pontifícia Universidade Católica do Rio de Janeiro. Dissertação de Mestrado. Rio de Janeiro: 1993.

14. Jena, P.K., Brocchi, E.A., J. Gonzaléz. Kinetics of Low-Temperature Chlorination of Vanadium Pentoxide by Carbon Tetrachloride Vapor. vol. 36B, p. 1-2. 2005.

15. Jena, P.K., Brocchi, E.A. Metal Extraction Through Chlorine Metallurgy. Min. Ext. Met. Review, vol 16, PP. 211-237, 1995.

16. Jena, P.K, Brocchi, E.A, Garcia, R.I. Kinetics of Chlorination of Niobium Pentoxide by Carbon Tetrachloride. Metallurgical and Materials Transactions B. Vol. 28B. 1997.

17. Leprevost, A. Minerais para Indústria. Universidade Federal do Pará UFP, Curitiba. 1978.

18. Balaj, T., Govindaiah, R., Sharma, M. K., Purushotham, Y., Arbind K., Prakash, T. L. Sintering and Electrical Properties of Tantalum Anodes for Capacitor Applications. Materials Letters. p.560-563. 2002.

19. Turner, L. W. Circuitos e Dispositivos eletrônicos. Copyright do Electronics Engineer's Reference Books. São Paulo, Brasil. Editora Hemus, 4ª ed. Capítulo 8. 2005.

20. TANTALUM-NIOBIUM. Internacional Study Center. Disponível em: http://tanb.org/tantalum. Acesso em 22 de janeiro de 2016.

21. Greenwood, N. N. Vanadium to Dubnium: From Confusion Through Clarity to Complexity. Catalysis Today. p. 5-11. 2003.

22. Sultanov, R. M., Dzhemilev, U. M., Samoilova, E. V., Ismagilov, R. R., Khalilov, L. M. Two Routes of Tantalum-Catalyzed Alkene Carbomagnesiation with Ethyl Grignard Reagents. Journal of Organometallic Chemistry, p. 5-8. 2012. 
23. Habashi, Fathi. Handbook of Extractive Metallurgy. Volume III: Precious Metals, Refractory Metals, Scattered Metals, Radioactive Metals, Rare Earth Metals. Université Laval. Département de Mines et de Méttallurgie. Canadá. p. 1417 - 1429. 1997.

24. Moura, F.J. Estudo Cinético da Cloração Redutora dos Óxidos de Nióbio, Tântalo e Titânio Contidos em Uma Escória Proveniente da Metalurgia Extrativa do Estanho. Dissertação de Mestrado. Pontifícia Universidade Católica - PUC. Rio de Janeiro - RJ. 1986.

25. Brocchi, E.A. Moura, F. J. Chlorination methods applied to recover refractory metals from tin slags. Minerals Engineering 21. p. 150-156. 2008.

26. De Micco, G. Carignan, M. Canavesio, C.A. Bohé, A.E. Determination of intrinsic parameters for $\mathrm{MoO}_{3}$ chlorination with $\mathrm{Cl}_{2}$ gas between 798 and $873 \mathrm{~K}$. Thermochimica Acta 543. p. 211-217. 2012.

27. Pap, I.S. Mink, G. Auroux, A. Karmazsin, E. A kinectic study of the chlorination of $\mathbf{M O}_{3}$ by $\mathbf{C C l}_{4}$. Thermochimica Acta 241. p. 247-258. 1994.

28. Spencer P, Ansara I. SGTE Casebook - Thermodynamics at Work: Materials modeling series. London: Klaus Hack; 1996.

29. Roine, A. Outokumpu HSC-Chemistry for Windows, 06120-ORC-T, Versão 6.0, Outokumpu Research Oy, Information Service, Pori, Finlândia, 2006.

30. Levenspiel, O. Ingeniería de las Reacciones Químicas, Tradução Dr. Gabriel Tojo Barreiro, Espanha, Editorial Reverté S.A.; p. 638-642. 1995.

31. Coudurier, L., Wilkomirsky, I. Fundamentos dos Processos Metalúrgicos. Escuela de Ingeniería, Universidad de Concepción, Chile, 1971.

32. Reis, M. L., Brocchi, E.A. Cinética da Cloração de Óxido de Zircônio. Dissertação de Mestrado. Pontifícia Universidade Católica - PUC. Rio de Janeiro - RJ. 1991.

33. Antropov, L. Electrochemie Théorique. Ed. MIR. Moscow, p. 459. 1979.

34. Fogler, H.S. Gürmen. M.N. Elements of Chemical Reaction Engineering. Fourth Edition. 2005. 
35. Yang, V. e Hlavacek, V. Kinetic study of chlorination of niobium (V) oxide with chlorine and carbon monoxide. Powder Tecnology, p. 177183, 1999.

36. Y. Takahara, J.N. Kondo, T. Takata, D. Lu, K. Domen. Chem. Mater. 13. 2001.

37. J.N. Kondo, M. Uchida, K. Nakajima, L. Daling, M. Hara, K. Domen. Chem. Mater. 16. 2004.

38. R. Nakajima, D. Lu, M. Hara, K. Domen, J.N. Kondo. Stud. Surf. Sci. Catal. 158. 2005. 